\title{
A review of the traditional use of southern African medicinal plants for the treatment of fungal skin infections
}

I. E. Cock, ${ }^{\text {abb, }}{ }^{*}$ S. F. Van Vuuren ${ }^{\mathrm{c}}$

${ }^{a}$ School of Environment and Science, Nathan Campus, Griffith University, 170 Kessels Rd, Nathan, Queensland 4111, Australia.

${ }^{b}$ Environmental Futures Research Institute, Nathan Campus, Griffith University, 170 Kessels Rd, Nathan, Queensland 4111, Australia.

'Department of Pharmacy and Pharmacology, Faculty of Health Sciences, University of the Witwatersrand, Parktown, Gauteng 2193, South Africa

*Corresponding author. Tel.: +61 0737357637 


\begin{abstract}
Ethnopharmacological relevance: Human dermatophyte infections are one of the most common classes of infection globally, with an estimated 1.7 billion people contracting at least one infection annually. Southern African ethnic groups used multiple plants to treat dermatophytosis and to alleviate the symptoms, yet the anti-dermatophyte properties of most species remain poorly explored.
\end{abstract}

Aim of the study: Our study aimed to critically review the literature to document southern African plant species used to treat one or more dermatophytic infections, and to summarise scientific evaluations of these and other plant species. Our study aims to stimulate and focus future studies in this field.

Materials and methods: A thorough review of the ethnobotanical books, reviews and primary scientific studies were undertaken to identify southern African plants used traditionally to treat dermatophytosis, thereby identifying gaps in the research requiring further study.

Results: Eighty-nine southern African plant species are recorded as traditional therapies for dermatophytosis. Scientific evaluations of 140 plant species were identified, although most of the species in those studies were selected for reasons apart from their traditional uses. None of those studies examined the mechanism of action of the plant species, and only a single study screened the extracts for toxicity.

Conclusions: Despite southern Africa having some of the longest continuous human civilisations globally, as well as unique and diverse flora, and good ethnobotanical records, the anti-dermatophyte properties of southern African medicinal plants remains relatively poorly explored. The efficacy of the majority of plants used traditionally to treat fungal skin disease are yet to be verified and substantial further research is required in this field. 


\section{Keywords}

Ringworm, tinea pedis, onychomycosis, dermatophytosis, Candida albicans, traditional medicine, South African medicinal plants

\section{Contents}

1. Introduction

1.1. Human dermatophytosis

1.2. Zoonotic nature of dermatophytosis: animals as sources of fungal pathogens

2. Current treatment options for fungal skin infections and antibiotic drug resistance

3. An overview of fungal skin disease in South Africa

4. Materials and methods

5. South African medicinal plants used traditionally to treat fungal skin disease

6. Scientific studies into the growth inhibitory activity of fungal skin pathogens by South African plants

6.1. Antifungal activity of plant monotherapies

6.2. Synergistic antifungal activity of plant combinations

7. Discussion and conclusions

Abbreviations: CDC, Centre for Disease Control; MIC, minimum inhibitory concentration; TCM, traditional Chinese medicine; SI, selectivity index; WHO, World Health Organisation

\section{Introduction}

Superficial fungal skin infections in humans are common globally, although there is a substantially higher incidence in developing countries, rural communities, and amongst socio- 
economically disadvantaged groups. Whilst fungal pathogens may affect all people, they are opportunistic and are especially common as secondary infections and in immunocompromised individuals (Köhler et al., 2015). It has been estimated that more than 1.7 billion people globally ( $25 \%$ of the world's population) contract at least one fungal skin infection each year (Havlickova et al., 2008). Whilst approximately 40 fungal pathogens can infect human skin, nearly all fungal skin infections in humans are caused by closely related dermatophytes of three genre, namely the Epidermophyton, Microsporum and Trichophyton spp.

Most of the dermatophytes are similar and induce similar symptoms. For this reason, dermatophytic infections in humans are generally classified with regard to the part of the body that they affect, rather than on the basis of the fungal species causing the infection. Whilst dermatophytes may infect almost any exterior body surface, they thrive in warm, moist environments and are most frequent in areas with high perspiration, and in skin folds. Individual dermatophytic infections can be caused by multiple fungal pathogens. For example, tinea capitis (ringworm of the scalp) may be caused by multiple fungal pathogens, although it is primarily caused by several Microsporum and Trichophyton spp. The severity of each individual dermatophytic infection depends on several factors, including the infecting dermatophyte species, the site of infection, if the affected individual has co-infections, the host's general health and the extent of their immune response.

\subsection{Human dermaphytosis}

Of the human dermatophytic infections, tinea pedis (athlete's foot) is particularly common. Indeed, it has been estimated that it affects approximately $15 \%$ of the world's population at any time (Brown et al., 2012). Tinea pedis infections induce itching and cause scaling, cracking, redness and inflammation of the feet. Any part of the foot may be affected, 
although the warm, moist environment between the toes and on the soles of the foot are best suited to fungal growth and are most commonly affected. Tinea pedis may be caused by numerous Epidermophyton, Microsporum and Trichophyton species via contact with the skin of other infected individuals, or via contact with environmental fungal sources (e.g. soil, infected clothing and bedding, household surfaces etc).

Tinea cruris (often referred to as jock itch) is also common and often occurs concurrently with tinea pedis. This infection occurs most frequently in males and may be caused by transfer of dermatophytes from the feet to the groin region whilst dressing. Tinea cruris is most commonly caused by Trichophyton rubrum, although it may also be caused by Trichophyton mentagrophytes and Epidermophyton floccosum.

Notably, Candida albicans infections also frequently cause tinea cruris. C. albicans is not generally classified as a dermatophytic disease and instead is better known to for oral, throat, infant nappy rash and vulvovaginal infections. However, in humid tropical environments, it can also cause fungal skin infections, with identical symptoms to dermatophytosis. Therefore, despite it not generally being regarded as a dermatophyte, we have included C. albicans in this study.

Tinea corpis (ringworm of the body) is also common and may affect the arms, legs and trunk/body regions. It manifests as a scaly, red, itchy circular rash. This dermatophytosis is particularly versatile and can be caused by nearly 40 fungal pathogens, with Epidermophyton, Microsporum and Trichophyton species accounting for most infections. When these dermatophytes infect other regions of the body, similar symptoms may occur. Ring-shaped dermatophytic infections caused by the same fungal pathogens may also occur on the hands (tinea manuum), face (tinea faciei), or scalp (tinea capitis). As well as causing superficial skin infections, the same fungal pathogens may also infect the nails. 
Onychomyosis (tinea unguium) are fungal infections which may affect either the fingernails or toenails. However, onychomyosis of the toenails are far more frequent, perhaps because the feet provide a warmer, moister environment conducive to fungal growth. Multiple fungal pathogens can cause onychomyosis, although Epidermophyton, Microsporum and Trichophyton and Fusarium spp., are the main causative dermatophytes in temperate regions. In contrast, in humid tropical regions, Candida spp. (particularly $C$. albicans) are the most common causes of onychomyosis.

Whilst generally not classified as dermatophytosis (and are therefore not the focus of this study), fungal infections of mucosal tissues, especially of the oral and urogenitial tracts, are also common. Oral and vulvovaginal candidiasis (commonly known as thrush) are caused by Candida spp., particularly, C. albicans. Vaginal thrush is particularly prevalent and it has been estimated that approximately $75 \%$ of adult women will suffer from at least one vaginal thrush infection annually (Sobel, 2007).

\subsection{Zoonotic dermatophytosis: animals as sources of fungal pathogens}

Many of the same fungal pathogens that affect humans also affect other mammals, where wild and domestic animals constitute a major reservoir of dermatophytes. Of the three main genre responsible for human dermatophytosis, Trichophyton and Microsporum are also widespread in animals. Indeed, a study examined ten domestic and farm animals for the presence of humaninfective dermatophytes and reported the presence of at least one dermatophyte species in all of the animal species tested (Nweze, 2011). Domestic dogs and cats were both main reservoirs of dermatophytes, with four and six dermatophyte species isolated from each respectively. Furthermore, $52 \%$ of dogs and $47 \%$ of cats tested were infected with at least one dermatophyte in that study. Farm animals also provided a substantial reservoir for dermatophytes, with $27 \%$ 
of cows, $15 \%$ of sheep, $17 \%$ of goats, $22 \%$ of pigs, $11 \%$ of horses and $6 \%$ of rabbits tested also infected with at least one dermatophyte species. Notably cows, pigs and horses each harboured six different dermatophyte species. Whilst less prevalent in domestic fowl, ducks and chickens tested in that study also harboured at least one dermatophyte species. Microsporum canis and T. mentagrophytes were generally the most common dermatophyte across species, being present in approximately $37 \%$ and $23 \%$ of all dermatophyte positive samples respectively (Nweze, 2011) .

While that study tested domestic animals in Nigeria, very little could be found on similar studies screening South African domestic animals for dermatophytes so the prevalence may differ between these regions Interestingly, there has been a South African study on an animal vector (cat) and the not so common Chromoblastomycosis (an emerging fungal tropical disease transmitted to humans in mostly farming communities) (Zambelli and Griffiths, 2015). These studies demonstrate the importance of domestic animals as dermatophyte reservoirs. Interestingly, whilst those studies did not detect Epidermophyton spp. in the animals that they tested, other studies have reported Epidermophyton spp. dermatophytes in domestic animals (Efuntoye and Fashanu, 2002). The dermatophytes in domestic animals may cross species and ultimately infect humans. Thus, prevention of human dermatophytosis should also consider animal reservoirs to inhibit reinfection. As this review focuses specifically on the treatment of dermatophytosis in humans we have excluded any studies that exclusively discuss the use of southern African plants to treat these infections in domestic animals and livestock, rather than in humans.

\section{Current treatment options for fungal skin infections and antibiotic drug resistance}


Several effective therapeutic options are available for the treatment of dermatophytic infections in humans, with the treatment regimen dependent on the region of the body affected and the severity of the infection. Generally, for most superficial skin infections, over the counter antifungal creams, lotions or powders are effective against most fungal strains (Brown et al., 2012). Some of the most common therapies include:

- Clotrimazole may be used as a monotherapy to treat oral, vulvovaginal and skin Candida spp. infections. It functions by altering the permeability of the fungal cell membrane by inhibiting fungal ergosterol synthesis (Crowley and Gallagher, 2014) Clotrimazole may also be combined with glucocorticoids (e.g. betamethasone) to produce creams to treat tinea pedis, tinea cruris and tinea corporis. Whilst these treatments are generally effective, they are not preferred treatments for longer-term antifungal therapy due to the side-effects associated with the glucocorticoid component. Furthermore, fungal resistance to clotrimazole is increasingly being reported and the expression of clotrimazole efflux pumps is now relatively common, especially in Candida spp. (Crowley and Gallagher, 2014). Further resistance mechanisms, including modification of the lanosterol-14- $\alpha$-demethylase target have also been reported (Mishra et al., 2007). The development of resistance to clotrimazole by fungal skin pathogens is worrisome due to our previous reliance on this drug due to its safety and efficacy. Effective new therapies are urgently needed.

- Miconazole is also effective for the treatment of tinea pedis, tinea cruris, tinea corporis and vulvovaginal Candida spp. infections. It functions via the same mechanism as clotrimazole and causes many of the same side effects and drug interactions. Furthermore, miconazole resistant fungal strains have recently been reported (Krishnasamy et al., 2018).

- Ketokonazole is another azole antifungal drug that functions via similar mechanisms as clotrimazole and miconazole, as well as inducing similar side effects and having similar 
resistance patterns (Ghannoum et al., 2016). It is expected that it will also have reduced efficacy against many dermatophytic strains in the future.

- Terbinafine is a different class of drug to the previous three azole drugs. However, it also works by blocking fungal sterol synthesis, thereby decreasing the permeability of the fungal cell membrane. The drug is quite safe when used topically. However, when ingested, numerous side effects and adverse reactions have been reported (George et al., 2015). Furthermore, resistance to terbinafine is now relatively common in Trichophyton spp. via alterations in fungal squalene epoxidase (Yamada et al., 2017) and salicylate 1-monooxygenase genes (Santos et al., 2017). Recently, terbinafine resistant Microsporum canis (Hsiao et al., 2018) and C. albicans strains have also been reported ( $\mathrm{Hu}$ et al., 2017) and it is expected that the prevalence of terbinafine resistant dermatophytic strains will increase further in the future.

For more severe infections, the oral medications fluconazole, griseofulvin and itraconazole may be used and are generally effective. However, as for the topical therapies, antibiotic failures are increasingly being reported due to the development of fungal resistance mechanisms. Indeed, the overuse of fluconazole has resulted in rapid increases in fluconazoleresistant fungal strains in recent years (Berkhow and Lockhart, 2017). Thus, medical science is faced with a diminishing arsenal of effective treatments to treat human fungal skin diseases and new therapies are urgently needed. However, the development of new dermatophytosis therapies tends to be a relatively neglected field compared to the development of new therapies targeting other infectious diseases. Whilst dermatophytosis induces discomfort, it is limited to superficial skin infections and generally does not cause mortality or morbidity. Furthermore, dermatophytic infections are usually transient and are often self-resolved by the host's immune system (Brown et al., 2012). However, timely treatment of these infections is recommended as there is a risk of re-infection or transfer to other individuals if untreated. 
Plant-based and traditional medicines are also used to treat and control fungal skin infections, especially in developing countries. Consultation with traditional healers for fungal skin infections is particularly prevalent among rural patients (Dlova and Ollengo, 2018). Furthermore, allopathic drugs are relatively expensive compared to traditional medicines and are not affordable to some low-income groups in rural areas. Inhabitants in isolated rural regions may also not have regular access to Westernised medical practitioners and conventional medicines may not always be readily available. An examination of the antifungal properties of traditional medicines against dermatophytes may detect new and effective therapies and may highlight future leads for antifungal drug discovery.

\section{An overview of fungal skin disease in South Africa}

Dermatophytosis is common worldwide and nearly all 40 fungal dermatophytes that cause these infections in humans are present and cause skin infections in southern Africa. However, the causative species and infection severity may vary widely across regions. Several dermatophyte species are common globally (T. rubrum, T. mentagrophytes, M. canis and E. floccosum). These species are also prevalent in southern Africa and account for a substantial amount of the fungal skin infections across the region. Indeed, T. rubrum is a major cause of tinea cruris and tinea unguium in developed urban regions of South Africa (Ameen, 2010). However, the major causative species for dermatophyte infections are variable in southern Africa, with strong geographic and cultural correlations.

Tinea capitis accounts for the highest number of reported cases of dermatophytosis in southern Africa and is particularly high amongst children (Coulibaly et al., 2018). Unlike other regions of the world, Microsporum audouinii and Trichophyton violaceum are the most prevalent dermatophytes responsible for tinea capitis in much of southern Africa. Indeed, one study in KwaZulu-Natal province tested individuals with tinea capitis and identified $T$. 
violaceum in $90 \%$ of cases (Morar et al., 2004). An earlier study in the Cape Peninsula and Western Cape coast regions of South Africa reported similar results, with T. violaceum reported in $91 \%$ of cases of tinea capitis (Neil et al., 1987). Those studies concluded that $T$. violaceum is the major cause of tinea capitis in South Africa. However, in the neighbouring country of Mozambique, M. audouinii has been reported to be responsible for $88 \%$ of the cases of tinea capitis (Sidat et al., 2006). It is interesting that the causative dermatophytes of tinea capitis in southern Africa are different to the other regions of the developed world, where $M$. canis, $T$. rubrum, T. mentagrophytes and Trichophyton tonsurans are the main causative species (Ameen, 2010). Thus, screening southern African plants against those fungal species may not be the most relevant model in a southern African context and studies should also test against the most prevalent southern Africa dermatophyte species.

The classes of dermaphytosis also vary widely in South Africa and often correlated with specific cultural groupings. Interestingly, tinea pedis and tinea unguium (particularly of the toenails) are relatively rare in rural regions of southern Africa, but are common in urban environments (Havlickova et al., 2008). This may be because much of the population in rural areas do not wear shoes and thus do not provide an environment conducive to feet and toenail dermatophytosis. Globally, T. rubrum, T. mentagrophytes and E. floccosum are the main species responsible for tinea pedis and tinea unguium (Ameen, 2010). As tinea pedis dermatophytes may be readily transferred from the feet to the groin region whilst dressing, these are also the main causes of tinea cruris. These dermatophyte species are also major causes of tinea pedis, tinea unguium and tinea cruris in southern Africa. However, T. violaceum and M. audouinii (to a lesser extent) also cause a large proportion of these infections in southern Africa (Coulibaly et al., 2018; Ameen, 2010). In tropical regions of southern Africa, $C$. albicans also has a greater contribution to these infections. Similar trends have also been reported for tinea corpis (Coulibaly et al., 2018). 
Rural areas and lower socio-economic communities often have higher incidences of dermatophytic infections than other regions. Dermatophytes are zoonotic, and may infect domestic animals and livestock, as well as humans. People living in rural areas often have close contact with animals, providing an extra avenue for infection. Similarly, high density living in some urban areas also increases the likelihood of person to person dermatophyte transfer. Rural and the lower socio-economic urban communities also share attributes that increase the spread of dermatophytes:

- Residents of these communities may have limited access to clinical care due to their isolation, and availability of medical personnel.

- Even where medical care is available, individuals may not be able to afford those services. Instead, residents of these communities may rely on traditional healers. Alternatively, given the lower concern regarding dermatophytes compared to other infectious diseases, they may forgo medical treatment and instead allow dermatophyte infections to clear up on their own. Indeed, it has been proposed that the relatively low reported levels of tinea pedis in southern Africa (compared to other regions of the world) may be partly due to individuals with this condition not seeking medical assistance (Ameen, 2010; Coulibaly et al., 2018;).

- Socioeconomically disadvantaged individuals and rural residents may also have less access to education than people in urban areas and therefore have less understanding of preventative methods to limit the spread of dermatophytes.

Notably, the incidences of dermatophytic infections and most notably, the fungi that cause them, are changing in southern Africa. Whilst T. violaceum and M. audouinii and are still the most prevalent dermatophytes in most regions of southern Africa, in recent years there has seen a substantial increase in dermatophytes that are more frequently found in infections from Europe and the United States. In particular, substantial increases in the prevalence of $T$. rubrum, T. mentagrophytes and E. floccosum have been noted in recent years (Zhan and Liu, 
2017; Coulibaly et al., 2018; Nweze and Eke, 2018). Increased globalisation and more frequent travel have introduced fungal species to regions that they were previously not prevalent. Furthermore, increasing resistance to clinical antifungal agents have allowed resistance strains to out-compete non-resistant dermatophyte species, thereby changing the epidemiology of dermatophytosis in southern Africa.

\section{Materials and methods}

The aim of this was to identify southern African plants traditionally used for the treatment of fungal skin diseases in humans. The information presented herein was sourced from several ethnobotanical books (Smith, 1888; Watt and Breyer-Brandwijk, 1962; Hutchings et al., 1996; Von Koenen, 2001; Moffett, 2010; Ngwenya et al., 2003; Van Wyk et al., 2009) and variety of ethnobotanical reviews (Thring and Weitz, 2006; Van Wyk, 2008; de Beer and Van Wyk, 2011; Nortje and Van Wyk, 2011; Philander, 2011; De Wet et al., 2013; Afolayan et al., 2014; Hulley and Van Wyk 2017; Asong et al., 2019). Google-Scholar, PubMed, Scopus and Science-Direct electronic databases were also used to identify original scientific research papers. The following terms were used as filters and were searched both alone and as combinations: "South African", "medicinal plant", "traditional medicine", “ethnobotany", "fungal skin infection" "dermatophyte", "dermatophytosis", "ringworm", "tinea", "Epidermophyton”, “Microsporum", "Trichophyton", "Candida", "antifungal”. Our study was non-biased and was without taxonomic preference. We did not only include plants native to southern Africa, but also included other introduced plant species if they were extensively documented in traditional southern African healing systems. The initial aim was to document the usage of all plant species used therapeutically for fungal skin diseases in southern Africa. A thorough literature search identified eighty-nine plant species as traditional remedies in 
southern Africa for fungal skin infections. The majority of these species are native southern African plants. However, several introduced species that have either been naturalised or are widely cultivated were included where they have been incorporated into the pharmacopoea of at least one southern African ethnic group. Subsequently, a further literature review was then undertaken on each of the plant species identified as therapies for fungal skin disease to identify the extent of scientific research previously reported on each of the identified species.

Specific criteria to filter studies for inclusion in review included ethnomedicine, South African medicinal plants and other key words related to dermatophytic infections. We did not prioritise the need for scientific evidence to support the traditional use of plants in our initial ethnobotanical literature search. However, further searches were undertaken on all plants identified as being used to treat fungal skin diseases to determine whether the traditional usage had been validated via rigorous scientific studies. Despite domestic animals forming readily available reservoirs of fungal skin pathogens, ethnobotanical veterinary studies were excluded from this review and only the use of plants to treat human fungal infections have been included. Our study aimed to summarise the published traditional South African ethnopharmacological knowledge and discuss the plant species traditionally used to treat fungal skin infections, with the hopes of highlighting plant species for future testing and to foster future research in this field.

\section{South African medicinal plants used traditionally to treat fungal skin disease}

An extensive search of ethnobotanical books and reviews, and from primary research studies, was used to identify the plant species used to treat fungal skin diseases presented herein. Traditional medicines are often used to target multiple diseases and infections presenting with similar symptoms. Medicinal plant species are often described as being used for skin complaints, or for skin infections. However, skin complaints may include rashes, sores, 
boils, cuts and abrasions, as well as skin infections (Mabona and Van Vuuren, 2013). Even if skin infections are specified, they may be due to pathogen classes other than fungi such as bacterial pathogens, including Streptococcus pyogenes (which causes impetigo), Cutibacterium acnes (which causes acne) or Trepanoma palladium (which causes syphilis and its associated sores). Similarly, several viral pathogens including measles virus cause skin rashes, as do some protozoal pathogens including Leishmania spp. (which can cause cutaneous leishmaniasis). Many of these other diseases produce rashes and flaking inflamed skin, similar to some dermatophytic fungal infections which can lead to an ambiguous diagnosis.

Herein we list eighty-nine South African plants which are used in at least one southern African traditional healing system to treat fungal skin infections (Table 1). Given the prevalence of these infections, this number may seem relatively low. However, where ambiguity exists as to the nature of the infection that the southern African plants were used to treat, the plant species were excluded from this record. It is therefore likely that this review has underestimated the number of species used for this purpose. For example, Hutchings (1996) lists multiple plant species including Crinum bulbispermum (Burm.f) Milne-Redh. \& Schweick, Crinum moorei (Hook.f.) Stapf, Haemanthus coccineus L., Stylochiton natalensis Schott, Gloriosa superba L. and numerous other species as being used to treat various skin complaints. However, that text does not specify the type of complaint(s) treated by these species. Due to the constraints we have applied to this study, plant species were only included where their usage to treat fungal skin diseases is specific. It is therefore likely that future studies may identify substantially more plants used for this purpose. Indeed, a number of plant species have been identified in recent botanical studies that have not previously been reported to treat fungal skin disease. For example, a recent report by Hulley and Van Wyk (2017) was the first to thoroughly examine the ethnobotany of the Kannaland region of western Little Karoo. The study identified a number of plant species as being used to treat ringworm. Even though a 
number of these species had already been identified for the treatment of ringworm (and other fungal skin diseases), 12 plant species (Ascelpias crispa P.J.Bergius, Elytropappus rhinocerotis (L.f) Less., Euphorbia mauritanica L., Galium tomentosum Thunb., Hermannia cuneifolia Jacq., Oesteospermum calendulaceum L.f., Ricinus communis L., Rosmarinus officianalis L., Salvia microphylla Kunth., Salvia runcinata L.f., Solanum tomentosum L., Urtica urens L.) were identified as new reports for the treatment of ringworm. It is likely that future ethnobotanical studies will identify substantially more species for this purpose, especially if specific questions to address dermatophytic diseases are targeted. Ethnobotanical studies such as these are valuable for evaluating the therapeutic potential of a medicinal plant preparation. Application of traditional plant preparation that produce notable effects on skin infections are relatively trustworthy indication of efficacy. 
Table 1: South African plants used traditionally to treat fungal skin conditions

\begin{tabular}{|c|c|c|c|c|c|}
\hline Plant species & Family & Common name(s) & $\begin{array}{l}\text { Plant part } \\
\text { used }\end{array}$ & Used for & References \\
\hline $\begin{array}{l}\text { Acacia burkei } \\
\text { Benth }\end{array}$ & Fabaceae & $\begin{array}{l}\text { Black monkey thorn (English), } \\
\text { swartapiesdoring (Afrikaans), } \\
\text { umkhaya wehlatalathi, } \\
\text { umbabampala (Zulu). Mokgwa, } \\
\text { mokoba (Tswana), }\end{array}$ & Bark & $\begin{array}{l}\text { A decoction is } \\
\text { applied topically to } \\
\text { treat ringworm } \\
\text { infections }\end{array}$ & $\begin{array}{l}\text { De Wet et al., } \\
\text { 2013; Dlova } \\
\text { and Ollengo, } \\
\text { 2018; et al. }\end{array}$ \\
\hline $\begin{array}{l}\text { Acacia karoo } \\
\text { Hayne }\end{array}$ & Fabaceae & $\begin{array}{l}\text { Sweet thorn (English), } \\
\text { soetdoring (Afrikaans), mooka } \\
\text { (Tswana), umuNga (Zulu, } \\
\text { Xhosa) }\end{array}$ & Bark & $\begin{array}{l}\text { A decoction is } \\
\text { applied topically to } \\
\text { treat ringworm } \\
\text { infections }\end{array}$ & $\begin{array}{l}\text { Afolayan et al., } \\
\text { 2014; Maroyi, } \\
\text { 2017; et al. }\end{array}$ \\
\hline Aloe ferox Miller & Asphodelaceae & $\begin{array}{l}\text { Cape aloe (English), } \\
\text { Bitteraalwyn, Winkelaalwyn } \\
\text { (Afrikaans), iKhala (Xhosa), } \\
\text { iNhlaba (Zulu) }\end{array}$ & Leaves & $\begin{array}{l}\text { Applied topically to } \\
\text { treat ringworm }\end{array}$ & $\begin{array}{l}\text { De Wet et al., } \\
\text { 2013; Dlova } \\
\text { and Ollengo, } \\
\text { 2018; et al. }\end{array}$ \\
\hline Aloe maculata All. & Asphodelaceae & $\begin{array}{l}\text { Soap aloe (English), bontaalwyn } \\
\text { (Afrikaans), lekhala (southern } \\
\text { Sotho) }\end{array}$ & Leaves & $\begin{array}{l}\text { Applied topically to } \\
\text { treat ringworm }\end{array}$ & $\begin{array}{l}\text { Smith, } \\
\text { 1888; Watt and } \\
\text { Breyer- } \\
\text { Brandwijk, } \\
\text { 1962; } \\
\text { Hutchings, } \\
1996\end{array}$ \\
\hline $\begin{array}{l}\text { Aloe microstigma } \\
\text { Salm-Dyck subsp. } \\
\text { microstigma }\end{array}$ & Asphodelaceae & $\begin{array}{l}\text { Bitteraalwyn, } \\
\text { veldaalwyn, } \\
\text { (Afrikaans) }\end{array}$ & Leaves & $\begin{array}{l}\text { Applied topically to } \\
\text { treat ringworm }\end{array}$ & $\begin{array}{l}\text { Nortje and Van } \\
\text { Wyk, } 2015\end{array}$ \\
\hline $\begin{array}{l}\text { Aloe vera (L.) } \\
\text { Burm.f }\end{array}$ & Asphodelaceae & $\begin{array}{l}\text { Burn aloe, True aloe, Indian aloe, } \\
\text { Barbados aloe (English) }\end{array}$ & Leaves & $\begin{array}{l}\text { Applied topically to } \\
\text { treat ringworm }\end{array}$ & $\begin{array}{l}\text { Asong et al., } \\
2019\end{array}$ \\
\hline
\end{tabular}




\begin{tabular}{|c|c|c|c|c|c|}
\hline $\begin{array}{l}\text { Aptosimum } \\
\text { procumbens } \\
\text { (Lehm.) Steud. }\end{array}$ & Scrophulariaceae & $\begin{array}{l}\text { Veld violet, violet of the karoo, } \\
\text { wild violet, karoo carpet flower } \\
\text { (English),brandblare, } \\
\text { brandbossie, karooviooltjie } \\
\text { (Afrikaans) }\end{array}$ & Not specified & $\begin{array}{l}\text { A decoction is } \\
\text { applied topically to } \\
\text { treat ringworm } \\
\text { infections }\end{array}$ & $\begin{array}{l}\text { Watt and } \\
\text { Breyer- } \\
\text { Brandwijk, } \\
\text { 1962; } \\
\text { Hutchings, } \\
\text { 1996; }\end{array}$ \\
\hline $\begin{array}{l}\text { Arctotis arctoides } \\
\text { (L.F.) O.Hoffm. }\end{array}$ & Asteraceae & $\begin{array}{l}\text { Botterblom (Afrikaans), } \\
\text { ubushwa (Xhosa) }\end{array}$ & Leaves, juice & $\begin{array}{l}\text { A decoction is } \\
\text { applied topically to } \\
\text { treat ringworm } \\
\text { infections }\end{array}$ & $\begin{array}{l}\text { De Wet et al., } \\
\text { 2013; Dlova } \\
\text { and Ollengo, } \\
\text { 2018; et al. }\end{array}$ \\
\hline $\begin{array}{l}\text { Ascelpias crispa } \\
\text { P.J.Bergius }\end{array}$ & Apocynaceae & $\begin{array}{l}\text { Bitterwortel, witvergeet, } \\
\text { kattedoring (Afrikaans) }\end{array}$ & Leaves & $\begin{array}{l}\text { An infusion is } \\
\text { applied topically to } \\
\text { treat ringworm } \\
\text { infections }\end{array}$ & $\begin{array}{l}\text { Hulley and } \\
\text { Van Wyk, } \\
2017\end{array}$ \\
\hline $\begin{array}{l}\text { Blumea lacera } \\
\text { (Burm.f.) DC. }\end{array}$ & Asteraceae & Unknown & Unspecified & $\begin{array}{l}\text { Useful in the } \\
\text { treatment of tinea. } \\
\text { Preparation and } \\
\text { application are not } \\
\text { specified }\end{array}$ & $\begin{array}{l}\text { Watt and } \\
\text { Breyer- } \\
\text { Brandwijk, } \\
\text { 1962; } \\
\text { Hutchings, } \\
\text { 1996; }\end{array}$ \\
\hline $\begin{array}{l}\text { Bulbine } \\
\text { asphodeloides R. \& } \\
\text { S. }\end{array}$ & Asphodelaceae & $\begin{array}{l}\text { Snake flower, copaiva (English), } \\
\text { balsamkopieva, geelkatstert } \\
\text { (Afrikaans), ibhucu, inthethe } \\
\text { elimpofu (Zulu), intelezi, } \\
\text { itswelemyoka (Xhosa), pekane, } \\
\text { moetsa-mollo Sotho) }\end{array}$ & Leaves & $\begin{array}{l}\text { The leaf juice is } \\
\text { applied directly to } \\
\text { ringworm infections }\end{array}$ & $\begin{array}{l}\text { Watt and } \\
\text { Breyer- } \\
\text { Brandwijk, } \\
\text { 1962; } \\
\text { Hutchings, } \\
1996\end{array}$ \\
\hline $\begin{array}{l}\text { Bulbine frutescens } \\
\text { (L.) Willd }\end{array}$ & Asphodelaceae & $\begin{array}{l}\text { Burn jelly plant, cat's tail, snake } \\
\text { flower (English), balsem } \\
\text { kopieva, geelkatstert (Afrikaans) }\end{array}$ & Leaves & $\begin{array}{l}\text { Applied topically to } \\
\text { treat ringworm }\end{array}$ & $\begin{array}{l}\text { Mabona and } \\
\text { Van Vuuren, } \\
2013\end{array}$ \\
\hline
\end{tabular}


Strap-leaved bulbine, snake

\begin{tabular}{|c|c|c|c|c|c|}
\hline $\begin{array}{l}\text { Bulbine } \\
\text { narcissifolia Salm } \\
\text { Dyck. }\end{array}$ & Asphodelaceae & $\begin{array}{l}\text { flower (English), lintblaar } \\
\text { bulbine, geelslangkop, } \\
\text { wildekopieva (Afrikaans), } \\
\text { khomo-ea-balisa, serelelile }\end{array}$ & Leaves & $\begin{array}{l}\text { The leaf juice is } \\
\text { applied directly to } \\
\text { ringworm infections }\end{array}$ & $\begin{array}{l}\text { Watt and } \\
\text { Breyer- } \\
\text { Brandwijk, } \\
1962\end{array}$ \\
\hline
\end{tabular}

(Sotho)

\begin{tabular}{|c|c|c|c|c|c|}
\hline $\begin{array}{l}\text { Buxus natalensis } \\
\text { (Oliv.) Hitch. }\end{array}$ & Buxaceae & $\begin{array}{l}\text { Large leaved box, Natal box, } \\
\text { box wattle (English), } \\
\text { grootblaarbuksboom, } \\
\text { Natalsebuksboom (Afrikaans), } \\
\text { umgalagala, isixesa, umngquzu, } \\
\text { isixhaza (Xhosa), igudlangulubi, } \\
\text { umgalagala, umhlulambazo } \\
\text { (Zulu) }\end{array}$ & Leaves, juice & $\begin{array}{l}\text { A decoction is } \\
\text { applied topically to } \\
\text { treat ringworm } \\
\text { infections }\end{array}$ & $\begin{array}{l}\text { Afolayan et al., } \\
2014\end{array}$ \\
\hline $\begin{array}{l}\text { Canthium inerme } \\
\text { (L.f.) Kuntze }\end{array}$ & Rubiaceae & $\begin{array}{l}\text { Turkey berry, Cape date } \\
\text { (English). Gewone bokdrol, } \\
\text { doringels (Afrikaans), } \\
\text { umvuthwamini (Xhosa, Zulu), } \\
\text { isipintigo (Xhosa), isotobe } \\
\text { (Zulu), muvhibvela-shadani } \\
\text { (Venda) }\end{array}$ & Leaves & $\begin{array}{l}\text { A decoction is } \\
\text { applied topically to } \\
\text { treat ringworm } \\
\text { infections }\end{array}$ & $\begin{array}{l}\text { Afolayan et al., } \\
2014\end{array}$ \\
\hline $\begin{array}{l}\text { Carpobrotus edulis } \\
\text { (L.) L. Bolus }\end{array}$ & Aisoaceae & $\begin{array}{l}\text { Sour fig, Cape fig, Hottentot's fig } \\
\text { (English), vyerank, } \\
\text { ghaukum,ghoenavy, hotnotsvye, } \\
\text { Kaapvy, perdevy, rankvy } \\
\text { (Afrikaans), ikhambi- } \\
\text { lamabulawo, umgongozi (Zulu) }\end{array}$ & Leaves & $\begin{array}{l}\text { Juice from squeezed } \\
\text { leaves is applied } \\
\text { topically to treat } \\
\text { ringworm }\end{array}$ & $\begin{array}{l}\text { Watt and } \\
\text { Breyer- } \\
\text { Brandwijk, } \\
\text { 1962; } \\
\text { Hutchings, } \\
\text { 1996; Thring } \\
\text { and Weitz, } \\
2006\end{array}$ \\
\hline
\end{tabular}


Carpobrotus

acinaciformis

acinacifor
L. Bolus

Hottentot fig

Leaves

Juice from squeezed

leaves is applied

topically to treat

Thring and

ringworm

Weitz, 2006

Juice from squeezed

Carpobrotus murii

(L.) L. Bolus

Aisoaceae

Dwarf sour fig (English), Dwerg

Suurvy (Afrikaans)

leaves is applied

Thring and

topically to treat

Weitz, 2006 ringworm.

\begin{tabular}{|c|c|c|c|c|c|}
\hline $\begin{array}{l}\text { Cassytha ciliolate } \\
\text { Nees }\end{array}$ & Lauriaceae & $\begin{array}{l}\text { False Dodder, devils tresses } \\
\text { (English), bobbejaantou, } \\
\text { nooienshar (Afrikaans) }\end{array}$ & Leaves & $\begin{array}{l}\text { A decoction is } \\
\text { applied topically to } \\
\text { treat ringworm } \\
\text { infections }\end{array}$ & $\begin{array}{l}\text { Nortje and Van } \\
\text { Wyk, } 2015\end{array}$ \\
\hline Citrus limon L. & Rutaceae & Lemon (English) & $\begin{array}{l}\text { Fruit peel, } \\
\text { juice }\end{array}$ & $\begin{array}{l}\text { Diluted fruit juice is } \\
\text { applied directly to } \\
\text { ringworm infections. } \\
\text { A fruit peel } \\
\text { decoction was } \\
\text { applied topically to } \\
\text { treat skin Candida } \\
\text { infections }\end{array}$ & $\begin{array}{l}\text { Watt and } \\
\text { Breyer- } \\
\text { Brandwijk, } \\
\text { 1962; Otang } \\
\text { and Afolayan, } \\
2016\end{array}$ \\
\hline $\begin{array}{l}\text { Conyza bonariensis } \\
\text { (L.) Cronquist }\end{array}$ & Asteraceae & $\begin{array}{l}\text { Horseweed, asthmaweed, } \\
\text { Candian fleabane, coltstail, } \\
\text { marestail, butterweed (English) }\end{array}$ & Unspecified & $\begin{array}{l}\text { Used to treat } \\
\text { ringworm. } \\
\text { Preparation and } \\
\text { usage not specified. }\end{array}$ & Moffett, 2010 \\
\hline Cordia myxa L. & Boraginaceae & Assyrian plum & Bark & $\begin{array}{l}\text { Powdered bark is } \\
\text { applied directly to } \\
\text { ringworm infections. }\end{array}$ & $\begin{array}{l}\text { Watt and } \\
\text { Breyer- } \\
\text { Brandwijk, } \\
1962\end{array}$ \\
\hline
\end{tabular}




\begin{tabular}{|c|c|c|c|c|c|}
\hline $\begin{array}{l}\text { Cirsium vulgare } \\
\text { Airy-Shaw }\end{array}$ & Asteraceae & $\begin{array}{l}\text { Scottish thistle, spear thistle } \\
\text { (English), skotse dissel } \\
\text { (Afrikaans), hlaba (Sotho) }\end{array}$ & Unspecified & $\begin{array}{l}\text { A brandy tincture is } \\
\text { applied directly to } \\
\text { ringworm infections. }\end{array}$ & $\begin{array}{l}\text { Watt and } \\
\text { Breyer- } \\
\text { Brandwijk, } \\
1962\end{array}$ \\
\hline $\begin{array}{l}\text { Cissampelos } \\
\text { capensis L.f. }\end{array}$ & Menispermaceae & $\begin{array}{l}\text { Dawidjies, fynblaarklimop } \\
\text { (Afrikaans) }\end{array}$ & Leaves & $\begin{array}{l}\text { The leaf juice is } \\
\text { applied directly to } \\
\text { ringworm infections }\end{array}$ & $\begin{array}{l}\text { De Wet and } \\
\text { Van Wyk, } \\
2008\end{array}$ \\
\hline $\begin{array}{l}\text { Dichapetalum } \\
\text { cymosum (Hook.) } \\
\text { Engl. \& Prantl. }\end{array}$ & Dichapetalaceae & $\begin{array}{l}\text { Poison leaf (English), gifblaar } \\
\text { (Afrikaans) }\end{array}$ & Leaves & $\begin{array}{l}\text { A leaf decoction is } \\
\text { applied directly to } \\
\text { ringworm infections }\end{array}$ & $\begin{array}{l}\text { Von Koenen, } \\
2001\end{array}$ \\
\hline $\begin{array}{l}\text { Dicoma anomala } \\
\text { Sond. }\end{array}$ & Asteraceae & $\begin{array}{l}\text { Fever bush, stomach bush } \\
\text { (English), maagbitterwortel, } \\
\text { kalwerbossie, koorsbossie, } \\
\text { gryshout, maagbossie } \\
\text { (Afrikaans), inyongana (Xhosa), } \\
\text { isihlabamakhondlwane, umuna } \\
\text { (Zulu) }\end{array}$ & $\begin{array}{l}\text { Charred roots, } \\
\text { stems, leaves }\end{array}$ & $\begin{array}{l}\text { A paste is prepared } \\
\text { and appiled topically } \\
\text { to ringworm } \\
\text { infections }\end{array}$ & $\begin{array}{l}\text { Watt and } \\
\text { Breyer- } \\
\text { Brandwijk, } \\
\text { 1962; } \\
\text { Hutchings, } \\
\text { 1996; Mabona } \\
\text { and Van } \\
\text { Vuuren, } 2013\end{array}$ \\
\hline $\begin{array}{l}\text { Diospyros austro- } \\
\text { africana De Winter }\end{array}$ & Ebenaceae & $\begin{array}{l}\text { Fire sticks, star-apple (English), } \\
\text { kritikom, jakkalsbos, } \\
\text { vuurmaakbossie (Afrikaans), } \\
\text { umbhongisa (Xhosa) }\end{array}$ & Leaves & $\begin{array}{l}\text { An infusion is } \\
\text { applied topically to } \\
\text { treat ringworm } \\
\text { infections }\end{array}$ & $\begin{array}{l}\text { Van Wyk et } \\
\text { al., } 2008\end{array}$ \\
\hline
\end{tabular}


Watt and

Breyer-

Diospyros

mespiliformis

Hochst. Ex A.D.C.
African ebony, jackal berry

(English), jakkalbessie

(Afrikaans), mgula (Tsonga)
A decoction is applied topically to

treat ringworm

infections
Brandwijk,

1962; Von

Koenen, 2001;

Mabona and

Van Vuuren,

2013

\begin{tabular}{|c|c|c|c|c|c|}
\hline $\begin{array}{l}\text { Dodonaea viscosa } \\
\text { Jacq var. } \\
\text { agustifolia } \text { L.f. } \\
\text { benth }\end{array}$ & Sapindaceae & $\begin{array}{l}\text { Sand olive (English), sandolien, } \\
\text { ysterbos (Afrikaans), mutata- } \\
\text { vhana (Venda) }\end{array}$ & Leaves, twigs & $\begin{array}{l}\text { A decoction is } \\
\text { applied topically to } \\
\text { treat ringworm } \\
\text { infections }\end{array}$ & $\begin{array}{l}\text { Mabona and } \\
\text { Van Vuuren, } \\
2013\end{array}$ \\
\hline $\begin{array}{l}\text { Drimea sanguinea } \\
\text { (Schinz) Jessop }\end{array}$ & Asparagaceae & $\begin{array}{l}\text { rooislangkop (Afrikaans), } \\
\text { sekaname (Tswana) }\end{array}$ & Bulb & $\begin{array}{l}\text { A decoction is } \\
\text { applied topically to } \\
\text { treat skin Candida } \\
\text { infections }\end{array}$ & $\begin{array}{l}\text { Asong et al., } \\
2019\end{array}$ \\
\hline $\begin{array}{l}\text { Elytropappus } \\
\text { rhinocerotis (L.f) } \\
\text { Less. }\end{array}$ & Asteraceae & Rhinoceros bush (English) & Unspecified & $\begin{array}{l}\text { Preparation and } \\
\text { application methods } \\
\text { are not specified. }\end{array}$ & $\begin{array}{l}\text { Hulley and } \\
\text { VanWyk, } 2017\end{array}$ \\
\hline $\begin{array}{l}\text { Erigeron } \\
\text { canadense L. }\end{array}$ & Asteraceae & $\begin{array}{l}\text { Horseweed, coltstail, marestail, } \\
\text { butterweed (English) }\end{array}$ & Leaf & $\begin{array}{l}\text { Ringworm infected } \\
\text { areas are washed } \\
\text { with a leaf } \\
\text { decoction. }\end{array}$ & $\begin{array}{l}\text { Watt and } \\
\text { Breyer- } \\
\text { Brandwijk, } \\
1962\end{array}$ \\
\hline $\begin{array}{l}\text { Eriocephalus } \\
\text { punctalatis DC }\end{array}$ & Asteraceae & $\begin{array}{l}\text { Wild rosemary, Cape snowbush } \\
\text { (English), kapokbos (Afrikaans) }\end{array}$ & Leaf & $\begin{array}{l}\text { A leaf decoction is } \\
\text { applied directly to } \\
\text { treat ringworm on } \\
\text { the scalp. }\end{array}$ & $\begin{array}{l}\text { Nortje and Van } \\
\text { Wyk, } 2015\end{array}$ \\
\hline
\end{tabular}




\begin{tabular}{|c|c|c|c|c|c|}
\hline $\begin{array}{l}\text { Eucalyptus } \\
\text { gummifera Hochr. }\end{array}$ & Myrtaceae & Red bloodwood (English) & Sap/gum & $\begin{array}{l}\text { A devoction of the } \\
\text { gum is applied } \\
\text { directly to ringworm } \\
\text { infections. }\end{array}$ & $\begin{array}{l}\text { Watt and } \\
\text { Breyer- } \\
\text { Brandwijk, } \\
1962\end{array}$ \\
\hline $\begin{array}{l}\text { Euphorbia } \\
\text { mauritanica L. }\end{array}$ & Euphorbiaceae & $\begin{array}{l}\text { Yellow milk bush, golden spurge } \\
\text { (English), geelmelkbos, } \\
\text { beesmelkbos, gifmelkbos, } \\
\text { kleinmelkbos (Afrikaans) }\end{array}$ & Stem latex & $\begin{array}{l}\text { Milky latex is } \\
\text { applied directly to } \\
\text { ringworm infections. }\end{array}$ & $\begin{array}{l}\text { Hulley and } \\
\text { VanWyk, } 2017\end{array}$ \\
\hline $\begin{array}{l}\text { Euphorbia } \\
\text { prostrata Aiton }\end{array}$ & Asparagaceae & $\begin{array}{l}\text { Prostrate spurge, prostrate } \\
\text { sandmat (English), letsletwane } \\
\text { (Tswana) }\end{array}$ & Roots & $\begin{array}{l}\text { A decoction is } \\
\text { applied topically to } \\
\text { treat skin Candida } \\
\text { infections }\end{array}$ & $\begin{array}{l}\text { Asong et al., } \\
2019\end{array}$ \\
\hline $\begin{array}{l}\text { Euphorbia serpens } \\
\text { Kunths }\end{array}$ & Asparagaceae & $\begin{array}{l}\text { Matted sandmat (English), } \\
\text { lwetsane (Tswana) }\end{array}$ & Roots, leaves & $\begin{array}{l}\text { Decocotions used to } \\
\text { treat tinea pedis and } \\
\text { ringworm. }\end{array}$ & $\begin{array}{l}\text { Asong et al., } \\
2019\end{array}$ \\
\hline $\begin{array}{l}\text { Ficus exasperata } \\
\text { Vahl. }\end{array}$ & Moraceae & $\begin{array}{l}\text { White fig, sandpaper tree } \\
\text { (English) }\end{array}$ & Leaf & $\begin{array}{l}\text { Fresh leaves are } \\
\text { applied as plasters to } \\
\text { ringworm infections. }\end{array}$ & $\begin{array}{l}\text { Watt and } \\
\text { Breyer- } \\
\text { Brandwijk, } \\
1962\end{array}$ \\
\hline Galenia africana $\mathrm{L}$. & Aisoaceae & $\begin{array}{l}\text { Yellow bush (English), } \\
\text { brakkraalbossie, geelbos, } \\
\text { kraalbos, muisbos, } \\
\text { muisgeelbossie, perdebos } \\
\text { (Afrikaans), iqina (Xhosa) }\end{array}$ & $\begin{array}{l}\text { Leaves and } \\
\text { twigs }\end{array}$ & $\begin{array}{l}\text { An infusion is } \\
\text { applied topically to } \\
\text { treat ringworm. }\end{array}$ & $\begin{array}{l}\text { Nortje and Van } \\
\text { Wyk, 2015; } \\
\text { Hulley and } \\
\text { Van Wyk, } \\
2017 \text { Van }\end{array}$ \\
\hline $\begin{array}{l}\text { Galium } \\
\text { tomentosum Thunb. }\end{array}$ & Rubiaceae & $\begin{array}{l}\text { Old man's beard (English), } \\
\text { kleefgras, rooivergeet } \\
\text { (Afrikaans) }\end{array}$ & Roots & $\begin{array}{l}\text { Root infusions are } \\
\text { applied topically to } \\
\text { ringworm infections. }\end{array}$ & $\begin{array}{l}\text { Hulley and } \\
\text { Van Wyk, } \\
2017\end{array}$ \\
\hline
\end{tabular}


Forest gasteria forest ox-tongue,

\begin{tabular}{|c|c|c|c|c|c|}
\hline $\begin{array}{l}\text { Gasteria croucheri } \\
\text { (Hook.f.) Baker }\end{array}$ & Asphodelaceae & $\begin{array}{l}\text { Natal gasteria (English), } \\
\text { bosaalwee, oukossies } \\
\text { (Afrikaans), impundu, }\end{array}$ & Whole plant & $\begin{array}{l}\text { Decocotions used to } \\
\text { treat ringworm } \\
\text { infections. }\end{array}$ & $\begin{array}{l}\text { Philander, } \\
2011\end{array}$ \\
\hline
\end{tabular}

\begin{tabular}{|c|c|c|c|c|c|}
\hline $\begin{array}{l}\text { Hawthoria fasciata } \\
\text { (Willd.) Haw. }\end{array}$ & Asphodelaceae & Zebra plant (English) & Whole plant & $\begin{array}{l}\text { Decocotions used to } \\
\text { treat ringworm } \\
\text { infections. }\end{array}$ & $\begin{array}{l}\text { Philander, } \\
2011\end{array}$ \\
\hline $\begin{array}{l}\text { Helichrysum } \\
\text { paronychiodies DC } \\
\text { Humbert }\end{array}$ & Asteraceae & Phate-ya-ngaka (Tswana) & Whole plant & $\begin{array}{l}\text { Decocotions used to } \\
\text { treat ringworm and } \\
\text { Candida skin } \\
\text { infections. }\end{array}$ & $\begin{array}{l}\text { Asong et al., } \\
2019\end{array}$ \\
\hline $\begin{array}{l}\text { Hermannia } \\
\text { cuneifolia Jacq. }\end{array}$ & Malvaceae & $\begin{array}{l}\text { Agtdaegeneesbos, broodbos, } \\
\text { geneesbossie, pleisterbos } \\
\text { (Afrikaans) }\end{array}$ & Unspecified & $\begin{array}{l}\text { Used as an ointment } \\
\text { to treat ringworm. }\end{array}$ & $\begin{array}{l}\text { Hulley and } \\
\text { Van Wyk, } \\
2017\end{array}$ \\
\hline $\begin{array}{l}\text { Heteromorpha } \\
\text { arborescens Cham. } \\
\text { \& Schlect. }\end{array}$ & Apiaceae & $\begin{array}{l}\text { Parsley tree (English), } \\
\text { wildepietersielie (Afrikaans) }\end{array}$ & Leaves & $\begin{array}{l}\text { Leaf decoctions are } \\
\text { applied directly to } \\
\text { ringworm infections. }\end{array}$ & $\begin{array}{l}\text { Watt and } \\
\text { Breyer- } \\
\text { Brandwijk, } \\
1962\end{array}$ \\
\hline $\begin{array}{l}\text { Hypoxis argentea } \\
\text { Harv.ex Baker }\end{array}$ & Malvaceae & $\begin{array}{l}\text { Small silver star-flower } \\
\text { (English), inongwe (Xhosa and } \\
\text { Zulu), isinana (Zulu), ixalanxa } \\
\text { (Xhosa) }\end{array}$ & Corms & $\begin{array}{l}\text { A decoction is } \\
\text { applied topically to } \\
\text { treat ringworm } \\
\text { infections }\end{array}$ & $\begin{array}{l}\text { Afolayan et al., } \\
2014\end{array}$ \\
\hline
\end{tabular}


Yellow star, star lily, star flower (English), sterblom,

Hypoxis

hemerocallidea

Fisch. C.A. Mey \& Malvaceae

Ave geelsterretjie, gifbol (Afrikaans),

moli kharatsa, lotsane (southern

Sotho); inkomfe, inkomfe enkulu

(Zulu), inongwe, ilabatheka,

ixhalanxa, ikhubalo lezithunzela

(Xhosa), tshuka (Tswana)

$\begin{array}{lll} & \text { A decoction is } & \text { De Wet et al., } \\ \text { applied topically to } & \text { 2013; Dlova } \\ \text { treat ringworm } & \text { and Ollengo, } \\ \text { infections } & \text { 2018 et al. }\end{array}$

A decoction is

treat ringworm

2018 et al.

De Wet et al.

and Ollengo

\begin{tabular}{|c|c|c|c|c|c|}
\hline $\begin{array}{l}\text { Jatropha zeyheri } \\
\text { Sond. }\end{array}$ & Euphorbiaceae & $\begin{array}{l}\text { Verfbol (Afrikaans), sefapabadia } \\
\text { (Sotho), ugodide (Zulu) }\end{array}$ & Unspecified & $\begin{array}{l}\text { A decoction is } \\
\text { applied topically to } \\
\text { treat ringworm } \\
\text { infections }\end{array}$ & $\begin{array}{l}\text { Watt and } \\
\text { Breyer- } \\
\text { Brandwijk, } \\
1962\end{array}$ \\
\hline $\begin{array}{l}\text { Kigellia africana } \\
\text { (Lam.) Benth. }\end{array}$ & Bignoniaceae & $\begin{array}{l}\text { Sausage tree (English), } \\
\text { worsboom (Afrikaans), } \\
\text { umVunguta, umFongothi (Zulu), } \\
\text { muvevha (Venda) }\end{array}$ & Bark, fruit & $\begin{array}{l}\text { A decoction is } \\
\text { applied topically to } \\
\text { treat ringworm } \\
\text { infections }\end{array}$ & $\begin{array}{l}\text { De Wet et al., } \\
\text { 2013; Dlova } \\
\text { and Ollengo, } \\
\text { 2018; et al. }\end{array}$ \\
\hline $\begin{array}{l}\text { Lantana angolensis } \\
\text { Moldenke }\end{array}$ & Verbenaceae & Selaole (Tswana) & Roots & $\begin{array}{l}\text { A decoction is } \\
\text { applied topically to } \\
\text { treat ringworm } \\
\text { infections }\end{array}$ & $\begin{array}{l}\text { Asong et al., } \\
2019\end{array}$ \\
\hline $\begin{array}{l}\text { Lobostemon } \\
\text { fruticosus } \\
\text { (Linné)Buek }\end{array}$ & Boraginaceae & $\begin{array}{l}\text { Agdaegeneesbos, douwurmbos } \\
\text { (Afrikaans) }\end{array}$ & Leaves & $\begin{array}{l}\text { Leaves were ground } \\
\text { into a paste and } \\
\text { applied directly to } \\
\text { ringworm infections. }\end{array}$ & $\begin{array}{l}\text { Watt and } \\
\text { Breyer- } \\
\text { Brandwijk, } \\
\text { 1962; } \\
\text { Hutchings, } \\
\text { 1996; VanVan } \\
\text { Wyk et al., }\end{array}$ \\
\hline
\end{tabular}


2009; Hulley and Van Wyk,

\begin{tabular}{|c|c|c|c|c|c|}
\hline $\begin{array}{l}\text { Macea lanceolata } \\
\text { Forssk. }\end{array}$ & Primulaceae & $\begin{array}{l}\text { False assegai (English), } \\
\text { isidenda, umaguqu (Zulu) }\end{array}$ & Fruit & $\begin{array}{l}\text { Fruit are ground into } \\
\text { milk and consumed } \\
\text { to treat ringworm. }\end{array}$ & $\begin{array}{l}\text { Ngwenya et } \\
\text { al., } 2003\end{array}$ \\
\hline $\begin{array}{l}\text { Maerua edulis } \\
\text { (Gilg. \& Gilg-Ben.) } \\
\text { DeWolf }\end{array}$ & Capparaceae & Blue bush cherry (English) & Roots & $\begin{array}{l}\text { A decoction is } \\
\text { applied topically to } \\
\text { treat unspecified } \\
\text { fungal skin } \\
\text { infections }\end{array}$ & $\begin{array}{l}\text { Samie et al., } \\
2010\end{array}$ \\
\hline $\begin{array}{l}\text { Melianthus } \\
\text { comosus Vahl. }\end{array}$ & Francoaceae & $\begin{array}{l}\text { Honey flower (Eng); kruidjie- } \\
\text { roer-my-nie (Afr.) }\end{array}$ & Leaves & $\begin{array}{l}\text { An infusion is } \\
\text { applied topically to } \\
\text { treat ringworm. }\end{array}$ & $\begin{array}{l}\text { Thring and } \\
\text { Weitz, 2006; } \\
\text { Van Wyk et } \\
\text { al., 2009; } \\
\text { Mabona, 2013; } \\
\text { Vanet al. }\end{array}$ \\
\hline $\begin{array}{l}\text { Melianthus major } \\
\text { L. }\end{array}$ & Francoaceae & $\begin{array}{l}\text { Giant honey flower, kruidjie- } \\
\text { roer-my-nie (Afrikaans) }\end{array}$ & Leaves & $\begin{array}{l}\text { An infusion is } \\
\text { applied topically to } \\
\text { treat ringworm. Also } \\
\text { useful for the } \\
\text { treatment of tinea }\end{array}$ & $\begin{array}{l}\text { Watt and } \\
\text { Breyer- } \\
\text { Brandwijk, } \\
1962\end{array}$ \\
\hline $\begin{array}{l}\text { Myrsine africana } \\
\text { L. }\end{array}$ & Primulaceae & $\begin{array}{l}\text { Cape myrtle, African boxwood } \\
\text { (English), vlieebos, mirting } \\
\text { (Afrikaans), moroko-pheleu, } \\
\text { samapo, thakisa (Sotho) }\end{array}$ & Fruit & $\begin{array}{l}\text { Preparation and } \\
\text { application methods } \\
\text { are not specified. }\end{array}$ & $\begin{array}{l}\text { Watt and } \\
\text { Breyer- } \\
\text { Brandwijk, } \\
1962\end{array}$ \\
\hline
\end{tabular}




\begin{tabular}{|c|c|c|c|c|c|}
\hline $\begin{array}{l}\text { Nicotiana tabacum } \\
\text { L. }\end{array}$ & Solonaceae & Tobacco (English) & Leaves & $\begin{array}{l}\text { A decoction is } \\
\text { applied topically to } \\
\text { treat ringworm. }\end{array}$ & $\begin{array}{l}\text { Watt and } \\
\text { Breyer- } \\
\text { Brandwijk, } \\
1962\end{array}$ \\
\hline $\begin{array}{l}\text { Oesteospermum } \\
\text { calendulaceum L.f. }\end{array}$ & Asteraceae & Geneesbos, bietou (Afrikaans) & Not specified & $\begin{array}{l}\text { Infusions are applied } \\
\text { topically to treat } \\
\text { ringworm. }\end{array}$ & $\begin{array}{l}\text { Hulley and } \\
\text { Van Wyk, } \\
2017\end{array}$ \\
\hline $\begin{array}{l}\text { Pappea capensis E. } \\
\text { \& Z. var. radlkoferi } \\
\text { Schinz. }\end{array}$ & Sapindaceae & $\begin{array}{l}\text { Jacket plum, indaba tree, } \\
\text { bushveld cherry (English), } \\
\text { doppruim (Afrikaans), } \\
\text { umqhokwane, umvuna, indaba } \\
\text { (Zulu), ilitye, umgqalutye } \\
\text { (Xhosa) }\end{array}$ & $\begin{array}{l}\text { Seed kernal } \\
\text { oil }\end{array}$ & $\begin{array}{l}\text { Applied topically to } \\
\text { treat ringworm. Also } \\
\text { useful in the } \\
\text { treatment of tinea } \\
\text { capitis }\end{array}$ & $\begin{array}{l}\text { Watt and } \\
\text { Breyer- } \\
\text { Brandwijk, } \\
\text { 1962; } \\
\text { Hutchings, } \\
\text { 1996; Von } \\
\text { Koenen, 2001; }\end{array}$ \\
\hline $\begin{array}{l}\text { Phyllanthus } \\
\text { maderaspatensis L. }\end{array}$ & Phyllanthaceae & Leestane (Tswana) & Leaves & $\begin{array}{l}\text { A decoction is } \\
\text { applied topically to } \\
\text { treat ringworm } \\
\text { infections and } \\
\text { exzema. }\end{array}$ & $\begin{array}{l}\text { Asong et al., } \\
2019\end{array}$ \\
\hline $\begin{array}{l}\text { Pterocarpus } \\
\text { angolensis DC. }\end{array}$ & Fabaceae & $\begin{array}{l}\text { kiaat, bloodwood, paddle-wood, } \\
\text { sealing-wax tree, wild teak, } \\
\text { Transvaal teak (English), } \\
\text { bloedhout, dolfhout, greinhout, } \\
\text { kajatenhout, wilde-kiaat } \\
\text { (Afrikaans), moroto (Northern } \\
\text { Sotho), umvangazi, umbilo } \\
\text { (Zulu) }\end{array}$ & Sap & $\begin{array}{l}\text { The red sap from } \\
\text { under the bark is } \\
\text { applied directly to } \\
\text { ringworm infections. }\end{array}$ & $\begin{array}{l}\text { Watt and } \\
\text { Breyer- } \\
\text { Brandwijk, } \\
\text { 1962; Von } \\
\text { Koenen, 2001; }\end{array}$ \\
\hline
\end{tabular}




\begin{tabular}{|c|c|c|c|c|c|}
\hline $\begin{array}{l}\text { Rawsonia lucida } \\
\text { Harv. \& Sond. }\end{array}$ & Archariaceae & $\begin{array}{l}\text { Forest peach(English), bosperske } \\
\text { (Afrikaans), iThambo (Zulu), } \\
\text { umLongo (Xhosa) }\end{array}$ & Leaves & $\begin{array}{l}\text { A decoction is } \\
\text { applied topically to } \\
\text { treat ringworm } \\
\text { infections }\end{array}$ & $\begin{array}{l}\text { Amoo et al., } \\
\text { 2014Dlova and } \\
\text { Ollengo, 2018; } \\
\text { et al. }\end{array}$ \\
\hline $\begin{array}{l}\text { Ricinus communis } \\
\text { L. }\end{array}$ & Euphorbiaceae & $\begin{array}{l}\text { Castor bean, castor oil plant } \\
\text { (English) }\end{array}$ & Leaves & $\begin{array}{l}\text { Fresh leaves are used } \\
\text { as a compress to } \\
\text { treat ringworm } \\
\text { infections on the } \\
\text { head. }\end{array}$ & $\begin{array}{l}\text { Hulley and } \\
\text { Van Wyk, } \\
2017\end{array}$ \\
\hline $\begin{array}{l}\text { Rosmarinus } \\
\text { officianalis L. }\end{array}$ & Lamiaceae & $\begin{array}{l}\text { Rosemary (English), } \\
\text { makroosmaryn (Afrikaans) }\end{array}$ & Leaves & $\begin{array}{l}\text { Used as an ointment } \\
\text { to treat ringworm. }\end{array}$ & $\begin{array}{l}\text { Hulley and } \\
\text { Van Wyk, } \\
2017 \\
\end{array}$ \\
\hline Rumex crispus L. & Polygonaceae & Yellow dock (English) & $\begin{array}{l}\text { Used to treat } \\
\text { ringworm. } \\
\text { Preparation } \\
\text { and } \\
\text { application } \\
\text { methods are } \\
\text { not specified. }\end{array}$ & $\begin{array}{l}\text { Preparation and } \\
\text { application methods } \\
\text { are not specified. }\end{array}$ & $\begin{array}{l}\text { Watt and } \\
\text { Breyer- } \\
\text { Brandwijk, } \\
1962\end{array}$ \\
\hline $\begin{array}{l}\text { Salvia microphylla } \\
\text { Kunth. }\end{array}$ & Lamiaceae & $\begin{array}{l}\text { Rooiblomsalie, rooisalie } \\
\text { (Afrikaans) }\end{array}$ & Not specified & $\begin{array}{l}\text { Used to treat } \\
\text { ringworm. } \\
\text { Preparation and } \\
\text { application methods } \\
\text { are not specified. }\end{array}$ & $\begin{array}{l}\text { Hulley and } \\
\text { Van Wyk, } \\
2017\end{array}$ \\
\hline $\begin{array}{l}\text { Salvia runcinata } \\
\text { L.f. }\end{array}$ & Lamiaceae & $\begin{array}{l}\text { Sage (English), hardie salie } \\
\text { (Afrikaans) }\end{array}$ & Not specified & $\begin{array}{l}\text { A compress is } \\
\text { applied to treat } \\
\text { ringworm on the } \\
\text { head. }\end{array}$ & $\begin{array}{l}\text { Hulley and } \\
\text { Van Wyk, } \\
2017\end{array}$ \\
\hline
\end{tabular}




\begin{tabular}{|c|c|c|c|c|c|}
\hline $\begin{array}{l}\text { Samolus valerandi } \\
\text { L. }\end{array}$ & Primulaceae & $\begin{array}{l}\text { Brookweed, seaside brookweed, } \\
\text { water cabbage, water rose } \\
\text { (English) }\end{array}$ & Not specified & $\begin{array}{l}\text { Used to treat } \\
\text { ringworm. } \\
\text { Preparation and } \\
\text { application methods } \\
\text { are not specified. }\end{array}$ & $\begin{array}{l}\text { Watt and } \\
\text { Breyer- } \\
\text { Brandwijk, } \\
\text { 1962; Von } \\
\text { Koenen, 2001 }\end{array}$ \\
\hline $\begin{array}{l}\text { Scilla nervosa } \\
\text { (Burch) Jessop }\end{array}$ & Asparagaceae & Isiphingo (Xhosa) & Leaves & $\begin{array}{l}\text { A paste is prepared } \\
\text { and appiled topically } \\
\text { to ringworm } \\
\text { infections. }\end{array}$ & $\begin{array}{l}\text { Afolayan et al., } \\
2014\end{array}$ \\
\hline $\begin{array}{l}\text { Senecio longifolia } \\
\text { (DC) Sch.Bip }\end{array}$ & Asteraceae & Mosiama (Tswana) & Whole plant & $\begin{array}{l}\text { A decoction is } \\
\text { applied topically to } \\
\text { treat tinea pedis }\end{array}$ & $\begin{array}{l}\text { Asong et al., } \\
2019\end{array}$ \\
\hline $\begin{array}{l}\text { Senicio scapiflorus } \\
\text { (L'Hér.) C.A.Sm. }\end{array}$ & Asteraceae & Unknown & Leaves & $\begin{array}{l}\text { An infusion is } \\
\text { applied topically to } \\
\text { treat ringworm. }\end{array}$ & $\begin{array}{l}\text { Nortje and Van } \\
\text { Wyk, } 2015\end{array}$ \\
\hline $\begin{array}{l}\text { Senna alata (L.) } \\
\text { Roxb. }\end{array}$ & Fabaceae & $\begin{array}{l}\text { Candle bush, emperor's } \\
\text { candlesticks, candelabra bush, } \\
\text { ringworm shrub (English) }\end{array}$ & $\begin{array}{l}\text { Bark, leaves } \\
\text { and flowers }\end{array}$ & $\begin{array}{l}\text { Ringworm infected } \\
\text { areas are bathed in a } \\
\text { decoction prepared } \\
\text { from bark, leaves } \\
\text { and flowers. }\end{array}$ & $\begin{array}{l}\text { Watt and } \\
\text { Breyer- } \\
\text { Brandwijk, } \\
1962\end{array}$ \\
\hline $\begin{array}{l}\text { Solanum } \\
\text { acanthoideum } \\
\text { Drége ex Dun. }\end{array}$ & Solonaceae & Unknown & Fruit & $\begin{array}{l}\text { Juice from the fruit } \\
\text { is applied directly to } \\
\text { ringworm infections. }\end{array}$ & $\begin{array}{l}\text { Watt and } \\
\text { Breyer- } \\
\text { Brandwijk, } \\
1962\end{array}$ \\
\hline
\end{tabular}


Goat bitter apple, bitter apple,

goat apple, poison apple

Solanum Solonaceae (English), bok-bitterappel,

aculeastrum Dun. Solonaceae

bitterappel, gifappel (Afrikaans), Fruit

murulwa (Venda), umthuma,

itunga (Xhosa), mtuma (Zulu)
Juice from the fruit Watt and

is applied directly to Breyer-

ringworm infections Brandwijk,

1962

\begin{tabular}{|c|c|c|c|c|c|}
\hline $\begin{array}{l}\text { Solanum capense } \\
\text { L. }\end{array}$ & Solonaceae & Nightshade (English) & Berries & $\begin{array}{l}\text { Berries are squashed } \\
\text { and applied directly } \\
\text { to ringworm } \\
\text { infections }\end{array}$ & $\begin{array}{l}\text { Watt and } \\
\text { Breyer- } \\
\text { Brandwijk, } \\
\text { 1962; Von } \\
\text { Koenen, 2001; } \\
\text { Mabona and } \\
\text { Van Vuuren, } \\
\text { 2013; Von }\end{array}$ \\
\hline $\begin{array}{l}\text { Solanun incanum } \\
\text { L. }\end{array}$ & Solonaceae & $\begin{array}{l}\text { Bark weed, bitter apple, thorn } \\
\text { apple (English) }\end{array}$ & $\begin{array}{l}\text { Roots and } \\
\text { leaves }\end{array}$ & $\begin{array}{l}\text { A decoction is } \\
\text { applied topically to } \\
\text { treat ringworm } \\
\text { infections }\end{array}$ & $\begin{array}{l}\text { Watt and } \\
\text { Breyer- } \\
\text { Brandwijk, } \\
\text { 1962;Van; } \\
\text { Von Koenen, } \\
\text { 2001; Mabona } \\
\text { and Van } \\
\text { Vuuren, } 2013\end{array}$ \\
\hline $\begin{array}{l}\text { Solanum indicum } \\
\text { L. }\end{array}$ & Solonaceae & Indian nightshade (English) & Roots & $\begin{array}{l}\text { Preparation and } \\
\text { application methods } \\
\text { are not specified. }\end{array}$ & $\begin{array}{l}\text { Watt and } \\
\text { Breyer- } \\
\text { Brandwijk, } \\
1962\end{array}$ \\
\hline
\end{tabular}




\begin{tabular}{|c|c|c|c|c|c|}
\hline $\begin{array}{l}\text { Solanum } \\
\text { lichensteinii Willd. }\end{array}$ & Solonaceae & Kgaba (Tswana) & Roots & $\begin{array}{l}\text { A decoction is } \\
\text { applied topically to } \\
\text { treat ringworm } \\
\text { infections }\end{array}$ & $\begin{array}{l}\text { Asong et al., } \\
2019\end{array}$ \\
\hline $\begin{array}{l}\text { Solanum } \\
\text { linnaeanum Hepper } \\
\text { \& P.-M.L.Jaeger }\end{array}$ & Solonaceae & $\begin{array}{l}\text { Devil's apple, apple of Sodom } \\
\text { (English) }\end{array}$ & Fruit & $\begin{array}{l}\text { Preparation and } \\
\text { application methods } \\
\text { are not specified. }\end{array}$ & $\begin{array}{l}\text { Watt and } \\
\text { Breyer- } \\
\text { Brandwijk, } \\
1962\end{array}$ \\
\hline Solanum nigrum L. & Solonaceae & Black nightshade (English) & Whole plant & $\begin{array}{l}\text { A decoction is } \\
\text { applied topically to } \\
\text { treat ringworm } \\
\text { infections }\end{array}$ & $\begin{array}{l}\text { Watt and } \\
\text { Breyer- } \\
\text { Brandwijk, } \\
\text { 1962;; Von } \\
\text { Koenen, 2001; } \\
\text { Mabona and } \\
\text { Van Vuuren, } \\
\text { 2013VanVon }\end{array}$ \\
\hline $\begin{array}{l}\text { Solanum } \\
\text { panduraeforme } \\
\text { Drége ex Dun. }\end{array}$ & Solonaceae & $\begin{array}{l}\text { Bitter apple, apple of Sodom } \\
\text { (English), bitterappel, geelappel } \\
\text { (Afrikaans), intuma-omncane, } \\
\text { intumemncane (Zulu), moralane } \\
\text { (Northern Sotho) }\end{array}$ & Fruit & $\begin{array}{l}\text { Preparation and } \\
\text { application methods } \\
\text { are not specified. }\end{array}$ & $\begin{array}{l}\text { Watt and } \\
\text { Breyer- } \\
\text { Brandwijk, } \\
\text { 1962; } \\
\text { Hutchings, } \\
1996\end{array}$ \\
\hline $\begin{array}{l}\text { Solanum } \\
\text { tomentosum L. }\end{array}$ & Solonaceae & $\begin{array}{l}\text { Slangappel, slangappelbos } \\
\text { (Afrikaans) }\end{array}$ & Not specified & $\begin{array}{l}\text { Applied topically for } \\
\text { the treatment of } \\
\text { ringworm. }\end{array}$ & $\begin{array}{l}\text { Hulley and } \\
\text { Van Wyk, } \\
2017\end{array}$ \\
\hline
\end{tabular}




\begin{tabular}{|c|c|c|c|c|c|}
\hline $\begin{array}{l}\text { Strychnos } \\
\text { madigascariensis } \\
\text { Poir }\end{array}$ & Strychnaceae & $\begin{array}{l}\text { Black monkey orange (English), } \\
\text { swartklapper, botterklapper } \\
\text { (Afrikaans), nkwaka (Tsonga), } \\
\text { mukwakwa(Venda), } \\
\text { umGluguza, umKwakwa (Zulu) }\end{array}$ & $\begin{array}{l}\text { Bark and } \\
\text { leaves }\end{array}$ & $\begin{array}{l}\text { A decoction is } \\
\text { applied topically to } \\
\text { treat ringworm } \\
\text { infections }\end{array}$ & $\begin{array}{l}\text { De Wet et al., } \\
\text { 2013; Dlova } \\
\text { and Ollengo, } \\
2018 \text { et al. }\end{array}$ \\
\hline Salvia disermas L. & Lamiaceae & $\begin{array}{l}\text { Wild giant sage, Transvaal sage } \\
\text { (English), grootsalie, teesalie } \\
\text { (Afrikaans), mogasane (Tswana) }\end{array}$ & Leaf & $\begin{array}{l}\text { A decoction is } \\
\text { applied topically to } \\
\text { treat ringworm } \\
\text { infections }\end{array}$ & $\begin{array}{l}\text { De Beer and } \\
\text { Van Wyk, } \\
2011\end{array}$ \\
\hline $\begin{array}{l}\text { Tabernaemontana } \\
\text { elgans Stapf. }\end{array}$ & Apocynaceae & $\begin{array}{l}\text { Toad tree (English),laeveldse } \\
\text { paddaboom (Afrikaans), } \\
\text { umKhahlwana, umKhadu (Zulu) }\end{array}$ & $\begin{array}{l}\text { Fruit and } \\
\text { laeves }\end{array}$ & $\begin{array}{l}\text { A decoction is } \\
\text { applied topically to } \\
\text { treat ringworm } \\
\text { infections }\end{array}$ & $\begin{array}{l}\text { De Wet et al., } \\
\text { 2013; Dlova } \\
\text { and Ollengo, } \\
\text { 2018et al. }\end{array}$ \\
\hline Urtica urens L. & Urticaceae & $\begin{array}{l}\text { Annual nettle, burning nettle, } \\
\text { sting nettle bush, dwarf stinging } \\
\text { nettle (English), brandnekel } \\
\text { (Afrikaans) }\end{array}$ & Bark & $\begin{array}{l}\text { Bark infusions are } \\
\text { applied topically to } \\
\text { treat ringworm. }\end{array}$ & $\begin{array}{l}\text { Hulley and } \\
\text { Van Wyk, } \\
2017\end{array}$ \\
\hline $\begin{array}{l}\text { Withania somnifera } \\
\text { (L.) Dunal }\end{array}$ & Solonaceae & $\begin{array}{l}\text { Indian ginseng, poison } \\
\text { gooseberry, winter cherry } \\
\text { (English), bitterappelliefie, } \\
\text { koorshout (Afrikaans), ubuvuma } \\
\text { (Xhosa), ubuvimbha (Zulu) }\end{array}$ & Berries & $\begin{array}{l}\text { The green berries are } \\
\text { crushed and applied } \\
\text { topically to treat } \\
\text { ringworm. }\end{array}$ & $\begin{array}{l}\text { Smith, 1888; } \\
\text { Watt and } \\
\text { Breyer- } \\
\text { Brandwijk, } \\
\text { 1962; Von } \\
\text { Koenen, 2001; }\end{array}$ \\
\hline
\end{tabular}


Watt and

Ximenia caffra

Sond.

Olacaceae

Large sourplum (English), groot

suurpruim (Afrikaans),

unThunduluka-obmvu (Zulu)
Pulversised bark and roots are applied

directly to ringworm infections.
Breyer-

Brandwijk,

1962

Hutchings,

1996

Pulversised bark and

roots are applied

Watt and

Breyer-

Brandwijk,

directly to ringworm

infections.
1962; Von

Koenen, 2001; 
The plant species (Table 1) come from a wide range of families including Asioaceae, Asparagaceae, Asphodelaceae, Asteraceae, Euphorbiaceae, Fabaceae, Lamiaceae, Malvaceae, Primulaceae and Solonaceae (Figure 1). Some of these species have already had their antidermatophytic activity validated through in vitro testing (Table 2). In contrast, others species have only had their medicinal uses documented in various ethnobotanical studies and studies are required to validate their traditional use to treat fungal skin infections (de Beer and Van Wyk, 2011; Van Wyk, 2011; Hulley and Van Wyk, 2017). The Asteraceae, Solonaceae and Asphodelaceae families were particularly well represented for the treatment of fungal skin infections, with 12, 11 and 9 species identified from each of these families respectively (Figure 1). Whilst the high representation of plants of these families may indicate that they have better efficacies against fungal skin pathogens, it may also be because of the greater amount of attention that they have received in the ethnopharmacological and laboratory based research in comparison to many of the other plant families (Jaiswal, 2012; Achika et al., 2014; Bessada et al., 2015; Cock, 2015;). Furthermore, these are large families, with species widely spread globally. Asteraceae is a particularly large family with nearly 33,000 species and a wide global distribution (Bremer et al.., 1992). Four members of both Fabaceae and Asparagaceae were also identified, as well as three members each of Asioaceae, Euphorbaceae, Lamiaceae, Malvaceae and Primulaceae.

The most frequently used plant part to treat fungal skin infections in traditional southern African healing systems was the leaves (Figure 2). Interestingly, many other studies have also reported leaves as being the most frequently used plant part to treat a variety of pathogenic conditions (Afolayan et al., 2014; Asong et al., 2019; Cock et al., 2018; Cock et al., 2019; de Beer and Van Wyk, 2011; Hulley and Van Wyk, 2017; Nortje and Van Wyk, 2011; Philander, 2011). The roots/bulbs/corms, bark, fruit/berries/juice and the whole plant are also commonly 
used to treat dermatophytosis. However, bark should only be used sparingly as its removal by wild harvest practices can damage and possibly even kill the plant if careless or incorrect harvesting practices are employed. Decoctions and infusions were most frequently used traditionally for the treatment of fungal skin diseases (for 51 plant species). The plant material was applied directly to the affected area for 18 species, whereas juice/sap/latex was applied for 11 species. The preparation and usage was not specified for the remaining plant species. It is also noteworthy from Table 1 that many of the plant species used to treat fungal skin infections are herbaceous. These species generally grow rapidly and therefore the usage of these species are likely to be more sustainable than the use of bark or roots harvested from trees. As many medicinal plants are endangered, the use of species and the harvesting of plant parts that does not cause extensive damage the plant is preferred. For some of the plants species mentioned, the specific plant part was not specified and further comparative research is required to investigate whether the efficacy between different plant parts varies.

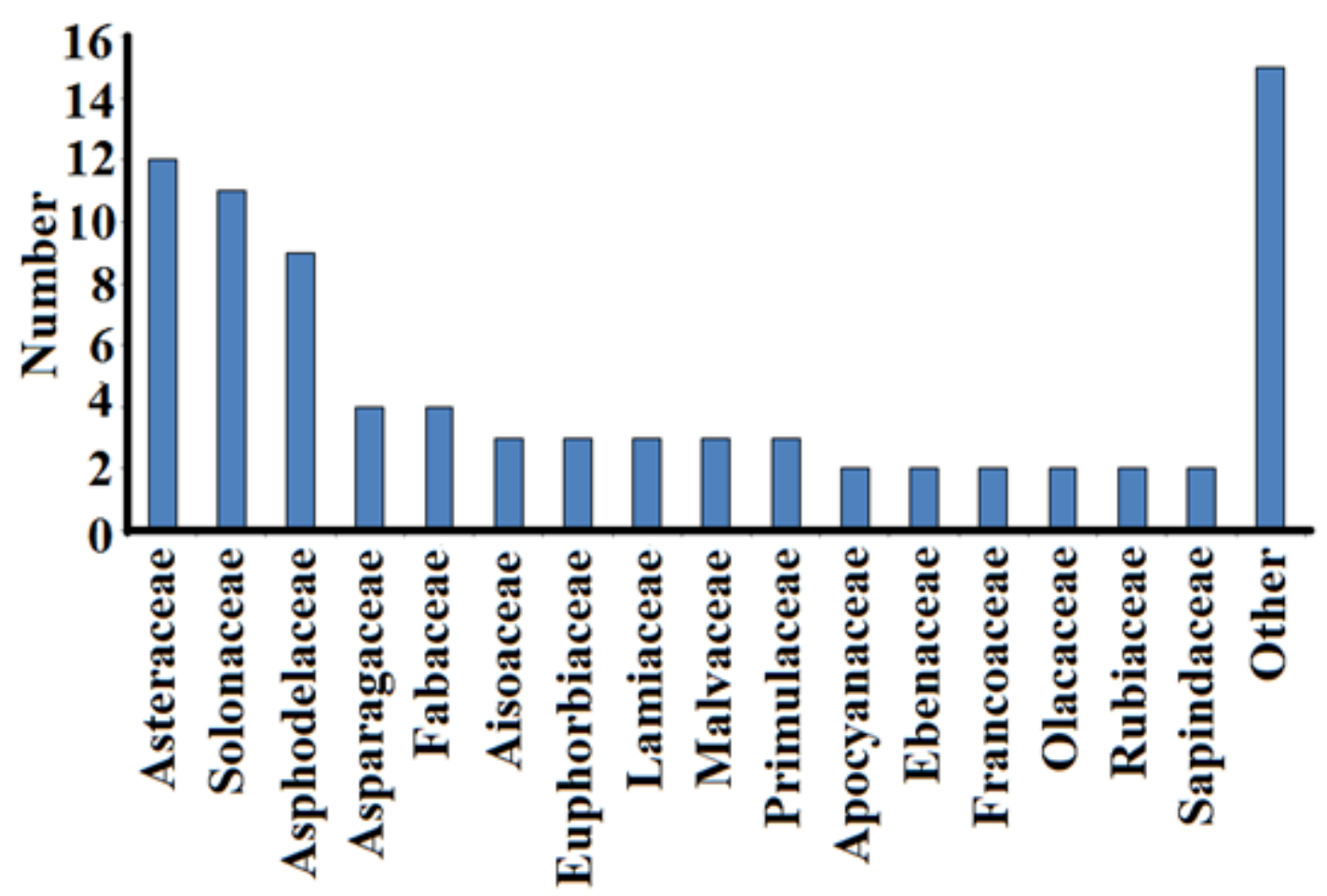

Family 
Figure 1: The number of plant species per families related to medicinal plants for the treatment of fungal infections.

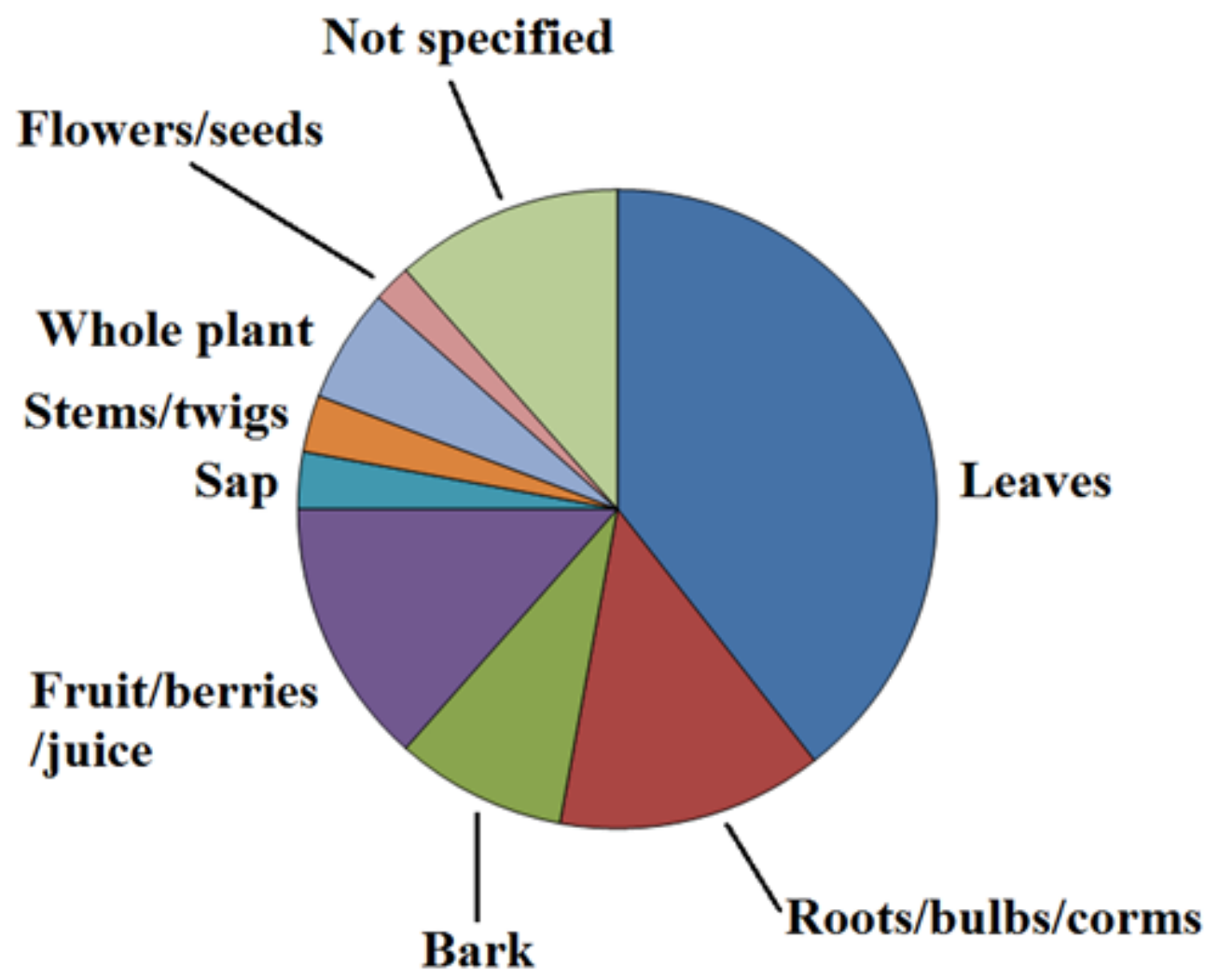

Figure 2: Plant parts and frequency mentioned to dermatological infections.

6. Scientific studies into the growth inhibitory activity of fungal skin pathogens by South African plants

Previous studies have screened southern African plants for the ability to inhibit the growth of fungal skin infections (Table 2). Overwhelmingly, these investigations have screened using in vitro methods and very few studies have examined the efficacy in vivo.

\subsection{Antifungal activity of plant monotherapies}


Of the 89 plant species that have been identified as being used to treat fungal skin infections, 19 of these (Acacia burkei, Aloe ferox, Bulbine frutescens, Canthium inerme, Carpobrotus edulis, Citrus limon, Cissampelos capensis, Dicoma anomala, Diospyros mespiliformis, Hypoxis hemerocallidea, Kigellia africana, Melianthus comosus, Melianthus major, Solanun incanum, Solanum panduraeforme, Strychnos madigascariensis, Tabernaemontana elgans, Withania somnifera, Ximenia caffra) were tested against dermatophytes. Nearly all of these plants strongly inhibited the growth of several dermatophytes, with several species displaying potent activity. The exception was $C$. edulis, for which only low activity was noted. $T$. mentagrophytes was the most susceptible dermatophyte to the plant extracts. Indeed, D. anomala (MIC $30 \mu \mathrm{g} / \mathrm{mL}$ ), D. mespiliformis (MIC $100 \mu \mathrm{g} / \mathrm{mL}$ ), K. africana (MIC $60 \mu \mathrm{g} / \mathrm{mL}$ ), M. comosus (MIC $50 \mu \mathrm{g} / \mathrm{mL}$ ) and M. major (MIC $50 \mu \mathrm{g} / \mathrm{mL}$ ) were particularly good inhibitors of that dermatophyte. Also worth mentioning were $A$. burkei, A. ferox, C. inerme, H. harmerocallidea, $S$. panduriforme, S. madigascariensis, T. elegans, $W$. somnifera and X. caffra which were also strong inhibitors of T. mentagrophytes growth, each with MIC values $\leq 500 \mu \mathrm{g} / \mathrm{mL}$. Both, M. comosus (MIC $50 \mu \mathrm{g} / \mathrm{mL}$ ) and M. major (MIC $50 \mu \mathrm{g} / \mathrm{mL}$ ) were also strong inhibitors of M. canis. Several other of the traditionally used plant extracts were also good inhibitors of M. canis, albeit with MIC values substantially higher than those recorded against $T$. mentagrophytes. In contrast, $C$. albicans was more resistant to these plant extracts, with MIC values $>1000 \mu \mathrm{g} / \mathrm{mL}$. One exception was $C$. limon, with an MIC value of $10 \mu \mathrm{g} / \mathrm{mL}$ reported against $C$. albicans. Studies are still required to test the other seventy species traditionally used to treat fungal skin infections. 
Table 2: Scientific evaluations of the inhibitory activity of South African plants against fungal skin pathogens.

\begin{tabular}{|c|c|c|c|c|c|c|}
\hline Plant Species & Common Name & Family & $\begin{array}{c}\text { Plant } \\
\text { Part Used }\end{array}$ & Formulation & Results & Reference \\
\hline $\begin{array}{l}\text { Acacia erioloba } \\
\text { E.mey. }\end{array}$ & $\begin{array}{l}\text { Camel thorn, giraffe thorn } \\
\text { (English), kameeldoring } \\
\text { (Afrikaans) }\end{array}$ & Fabaceae & $\begin{array}{c}\text { Bark and } \\
\text { leaves }\end{array}$ & $\begin{array}{l}\text { Extracted with } \\
\text { multiple solvents } \\
\text { of varying } \\
\text { polarity }\end{array}$ & $\begin{array}{l}\text { MICs of } 1000 \\
\mu \mathrm{g} / \mathrm{mL} \text { against } T . \\
\text { mentagrophytes, } \\
\text { M. canis } \text { and } \\
\text { C. albicans }\end{array}$ & $\begin{array}{l}\text { Mabona et al., } \\
2013\end{array}$ \\
\hline $\begin{array}{l}\text { Acokanthera } \\
\text { oppositifolia } \\
\text { (Laim.) Codd. }\end{array}$ & $\begin{array}{l}\text { Bushman's poison } \\
\text { (English), boesmansgif } \\
\text { (Afrikaans), } \\
\text { inHlungunyembe (Zulu), } \\
\text { intlungunyembe (Xhosa) }\end{array}$ & Apocynaceae & Leaf & $\begin{array}{l}\text { Extracted with } \\
\text { multiple solvents } \\
\text { of varying } \\
\text { polarity }\end{array}$ & $\begin{array}{l}\text { MICs of } 2000 \mu \mathrm{gmL} \\
\text { against } \\
\text { T. mentagrophytes, } \\
\text { M. canis and } \\
\text { C. albicans }\end{array}$ & $\begin{array}{l}\text { Mabona et al., } \\
2013\end{array}$ \\
\hline
\end{tabular}


Poison-podalbizia, large-

leaved falsethorn

(English),

Albizia vesicolor

Welw. ex Oliv

grootblaarvalsdoring

(Afrikaans), umvangazi,

umphizo, umbhangazi

(Zulu)

Allium sativum L. Garlic (English)

Amaryllidaceae

Krantz aloe (English),

Aloe arborescens

Mill.

kransaalwyn (Afrikaans),

ikalene (Xhosa), inkalane,

umhlabana (Zulu)

Asphodelaceae
Faceaceae

Bark

Aqueous and

methanolic

extracts were

tested

Extracted with

multiple solvents

of varying

polarity
MICs of 250, 2000,

$750 \mu \mathrm{g} / \mathrm{mL}$ against

T. mentagrophytes,

M. canis and

Nciki et al.,

C. albicans

respectively

MICs as low as 560

$\mu \mathrm{g} / \mathrm{mL}$ against

C. albicans

Motsei et al. 2003

Conflicting reports

of efficacy. Mabona

et al., 2013 report an

MIC of $250 \mu \mathrm{g} / \mathrm{mL}$

against

T. mentagrophytes,

but ineffective

Extracted with against $M$. canis and

Leaf multiple solvents

of varying

C. albicans. In

contrast, Ghuman et

al. 2016 report

Mabona et al.,

polarity
2013; Ghuman

et al., 2016. stronger activity

against most fungi

(MICs of $630 \mu \mathrm{g} / \mathrm{mL}$

against

T. mentagrophytes,

T. rubrum and

C. albicans).

\begin{tabular}{|c|c|c|c|c|c|c|}
\hline $\begin{array}{l}\text { Aloe excelsa } \\
\text { Berger }\end{array}$ & Zimbabwe aloe (English) & Asphodelaceae & Leaf & $\begin{array}{l}\text { Aqueous and } \\
\text { ethanolic extracts }\end{array}$ & $\begin{array}{l}\text { MICs of } 200 \mu \mathrm{g} / \mathrm{mL} \\
\text { against }\end{array}$ & $\begin{array}{l}\text { Naidoo and } \\
\text { Coopoosamy, } \\
2011\end{array}$ \\
\hline
\end{tabular}


T. mentagrophytes,

T. rubrum and $C$.

albicans .

\begin{tabular}{|c|c|c|c|c|c|c|}
\hline Aloe ferox Miller & $\begin{array}{l}\text { Cape aloe (English), } \\
\text { Bitteraalwyn, } \\
\text { Winkelaalwyn (Afrikaans), } \\
\text { iKhala (Xhosa), iNhlaba } \\
\text { (Zulu) }\end{array}$ & Asphodelaceae & Leaf & $\begin{array}{l}\text { Aqueous and } \\
\text { ethanolic extracts }\end{array}$ & $\begin{array}{l}\text { MICs of } 310-630 \\
\mu \mathrm{g} / \mathrm{mL} \text { against } \\
\text { T. mentagrophytes, } \\
\text { T. rubrum and } \\
\text { C. albicans. } \\
\end{array}$ & $\begin{array}{l}\text { Ghuman et al., } \\
2016\end{array}$ \\
\hline $\begin{array}{l}\text { Aloidendron } \\
\text { barbarae (Dyer) } \\
\text { Klopper \& } \\
\text { Gideon F.Sm. }\end{array}$ & Tree aloe (English) & Asphodelaceae & $\begin{array}{l}\text { Leaf and } \\
\text { root }\end{array}$ & $\begin{array}{l}\text { Sequential } \\
\text { extraction in } \\
\text { solvents of } \\
\text { different polarity }\end{array}$ & $\begin{array}{l}\text { MICs as low as } 800 \\
\mu \mathrm{g} / \mathrm{mL} \text { against } \\
\text { C. albicans }\end{array}$ & $\begin{array}{l}\text { Ndhlala et al., } \\
2009\end{array}$ \\
\hline $\begin{array}{l}\text { Annona } \\
\text { senegalensis } \\
\text { Oers. }\end{array}$ & $\begin{array}{l}\text { African custard apple, wild } \\
\text { custard apple, wild soup } \\
\text { (English), } \\
\text { wildesuikerappel } \\
\text { (Afrikaans), muembe } \\
\text { (Venda), umhlalajuba, } \\
\text { umphofu (Zulu) }\end{array}$ & Annonaceae & Roots & $\begin{array}{l}\text { Aqueous and } \\
\text { methanolic } \\
\text { extracts were } \\
\text { tested. }\end{array}$ & $\begin{array}{l}\text { MICs of } 130,60, \\
500 \mu \mathrm{g} / \mathrm{mL} \text { against } \\
\text { T. mentagrophytes, } \\
\text { M. canis and } \\
\text { C. albicans } \\
\text { respectively }\end{array}$ & $\begin{array}{l}\text { Nciki et al., } \\
2016\end{array}$ \\
\hline $\begin{array}{l}\text { Athrixia } \\
\text { phylicoides DC }\end{array}$ & $\begin{array}{l}\text { Bushman's tea (English), } \\
\text { ishayelo, iphephetha } \\
\text { (Zulu), icholocholo } \\
\text { (Xhosa), sephomolo } \\
\text { (Sotho) }\end{array}$ & Asteraceae & Leaf & $\begin{array}{l}\text { Extracted with } \\
\text { multiple solvents } \\
\text { of varying } \\
\text { polarity }\end{array}$ & $\begin{array}{l}\text { MICs of } 1000,1000 \\
\text { and } 2000 \mu \mathrm{g} / \mathrm{mL} \\
\text { against } \\
\text { T. mentagrophytes, } \\
\text { M. canis and } \\
\text { C. albicans } \\
\text { respectively }\end{array}$ & $\begin{array}{l}\text { Mabona et al., } \\
2013\end{array}$ \\
\hline $\begin{array}{l}\text { Aristea ecklonni } \\
\text { Baker }\end{array}$ & $\begin{array}{l}\text { Blue stars (English), } \\
\text { blousterre (Afrikaans), } \\
\text { umhushuza (Zulu) }\end{array}$ & Iridaceae & $\begin{array}{l}\text { Root and } \\
\text { leaves }\end{array}$ & $\begin{array}{l}\text { Extracted with } \\
\text { multiple solvents } \\
\text { of varying } \\
\text { polarity }\end{array}$ & $\begin{array}{l}\text { MICs of } 50,30 \text { and } \\
50 \mu \mathrm{g} / \mathrm{mL} \text { against } \\
\text { T. mentagrophytes, } \\
\text { M. canis and }\end{array}$ & $\begin{array}{l}\text { Mabona et al., } \\
2013\end{array}$ \\
\hline
\end{tabular}


C. albicans

respectively

MICs of 1000, 2000

Bauhinia

macranthera

Benth. ex Hemsl.

Chihuahuan orchid tree

(English)

Fabaceae

Extracted with

multiple solvents

of varying

polarity

and $1000 \mu \mathrm{g} / \mathrm{mL}$

against

T. mentagrophytes

M. canis and

C. albicans

respectively

\begin{tabular}{|c|c|c|c|c|c|c|}
\hline Bidens pilosa $\mathrm{L}$. & $\begin{array}{l}\text { Black jack, beggars' ticks, } \\
\text { cobblers pegs, sticky beaks } \\
\text { (English) }\end{array}$ & Asteraceae & Leaf & $\begin{array}{l}\text { Extracted with } \\
\text { multiple solvents } \\
\text { of varying } \\
\text { polarity }\end{array}$ & $\begin{array}{l}\text { Low activity. MIC } \\
>10000 \mu \mathrm{g} / \mathrm{mL} \text { for } \\
\text { all extracts }\end{array}$ & $\begin{array}{l}\text { Motsei et al., } \\
2003\end{array}$ \\
\hline $\begin{array}{l}\text { Boophane } \\
\text { distichya L.f. }\end{array}$ & $\begin{array}{l}\text { Bushman's poison bulb } \\
\text { (English), gifbol } \\
\text { (Afrikaans), leshoma } \\
\text { (Sotho, Tswana), incwadi } \\
\text { (Xhosa), incotha (Zulu) }\end{array}$ & Amaryllidaceae & Leaf & $\begin{array}{l}\text { Extracted with } \\
\text { multiple solvents } \\
\text { of varying } \\
\text { polarity }\end{array}$ & $\begin{array}{l}\text { MICs of } 1000,2000 \\
\text { and } 500 \mu \mathrm{g} / \mathrm{mL} \\
\text { against } \\
\text { T. mentagrophytes, } \\
\text { M. canis and } \\
\text { C. albicans } \\
\text { respectively }\end{array}$ & $\begin{array}{l}\text { Mabona et al., } \\
2013\end{array}$ \\
\hline $\begin{array}{l}\text { Brachylaena } \\
\text { discolor DC. }\end{array}$ & $\begin{array}{l}\text { Coastal silver oak } \\
\text { (English), kusvaalbos } \\
\text { (Afrikaans), phahla (Zulu), } \\
\text { umphahla (Xhosa) }\end{array}$ & Asteraceae & Roots & $\begin{array}{l}\text { Aqueous and } \\
\text { methanolic } \\
\text { extracts were } \\
\text { tested. }\end{array}$ & $\begin{array}{l}\text { MICs of } 250,2000, \\
750 \mu \mathrm{g} / \mathrm{mL} \text { against } \\
\text { T. mentagrophytes, } \\
\text { M. canis and } \\
\text { C. albicans } \\
\text { respectively }\end{array}$ & $\begin{array}{l}\text { Nciki et al., } \\
2016\end{array}$ \\
\hline $\begin{array}{l}\text { Brachylaena } \\
\text { hullensis } \\
\text { O.Hoffm. }\end{array}$ & Silver oak (English) & Asteraceae & Leaves & $\begin{array}{l}\text { Extracted with } \\
\text { multiple solvents } \\
\text { of varying } \\
\text { polarity }\end{array}$ & $\begin{array}{l}\text { Low activity. MIC } \\
>10000 \mu \mathrm{g} / \mathrm{mL} \text { for } \\
\text { all extracts }\end{array}$ & $\begin{array}{l}\text { Motsei et al., } \\
2003\end{array}$ \\
\hline
\end{tabular}

Mabona et al., 2013

Motsei et al.,

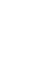

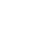




\begin{tabular}{|c|c|c|c|c|c|c|}
\hline $\begin{array}{l}\text { Bridelia } \\
\text { micrantha } \\
\text { (Hochst.) Baill. }\end{array}$ & $\begin{array}{l}\text { Mitseeri, bruin stinkhout } \\
\text { (Afrikaans), motsere } \\
\text { (Sotho), ndzerhe (Tswana) }\end{array}$ & Phyllanthaceae & Leaves & $\begin{array}{l}\text { Extracted with } \\
\text { multiple solvents } \\
\text { of varying } \\
\text { polarity }\end{array}$ & $\begin{array}{l}\text { MICs of } 1000,1000 \\
\text { and } 2000 \mu \mathrm{g} / \mathrm{mL} \\
\text { against } \\
\text { T. mentagrophytes, } \\
\text { M. canis and } \\
\text { C. albicans } \\
\text { respectively }\end{array}$ & $\begin{array}{l}\text { Mabona et al., } \\
2013\end{array}$ \\
\hline $\begin{array}{l}\text { Bulbine } \\
\text { frutescens (L.) } \\
\text { Willd }\end{array}$ & $\begin{array}{l}\text { Burn jelly plant, cat's tail, } \\
\text { snake flower (English), } \\
\text { balsem kopieva, } \\
\text { geelkatstert (Afrikaans) }\end{array}$ & Asphodelaceae & Leaves & $\begin{array}{l}\text { Extracted with } \\
\text { multiple solvents } \\
\text { of varying } \\
\text { polarity }\end{array}$ & $\begin{array}{l}\text { Conflicting reports } \\
\text { of efficacy. Inactive } \\
\text { (MIC }>10000 \\
\mu \mathrm{g} / \mathrm{mL} \text { for all } \\
\text { extracts) reported by } \\
\text { Motsei et al. } 2003 \text {. } \\
\text { MICs against } \\
\text { T. mentagrophytes, } \\
\text { T. rubrum and } \\
\text { C. albicans of } 630- \\
1250 \mu \mathrm{g} / \mathrm{mL} \\
\text { reported by Ghuman } \\
\text { et al., } 2016 \text {. }\end{array}$ & $\begin{array}{l}\text { Motsei et al., } \\
\text { 2003; Ghuman } \\
\text { et al., } 2016 .\end{array}$ \\
\hline $\begin{array}{l}\text { Bulbine } \\
\text { natalensis Baker }\end{array}$ & $\begin{array}{l}\text { Rooiwortel (Afrikaans), } \\
\text { ibhucu (Zulu) }\end{array}$ & Asphodelaceae & Leaves & $\begin{array}{l}\text { Extracted with } \\
\text { multiple solvents } \\
\text { of varying } \\
\text { polarity }\end{array}$ & $\begin{array}{l}\text { MICs against } T \text {. } \\
\text { mentagrophytes, } T \text {. } \\
\text { rubrum and } \\
\text { C. albicans of } 630- \\
2500 \mu \mathrm{g} / \mathrm{mL}\end{array}$ & $\begin{array}{l}\text { Ghuman et al., } \\
2016\end{array}$ \\
\hline
\end{tabular}


Turkey berry, Cape date

(English), gewone

bokdrol, doringels

Canthium inerme

(L.f.) Kuntze

(Afrikaans),

umvuthwamini (Xhosa,

Zulu), umnyushulube

(Xhosa), isitobe

(Zulu)muvhibvela-shadani

(Venda)

Sour fig, Cape fig,

Hottentot's fig (English),

vyerank,

Carpobrotus ghaukum,ghoenavy,

edulis (L.) L.

Bolus

hotnotsvye, Kaapvy,

perdevy, rankvy

(Afrikaans), ikhambi-

lamabulawo, umgongozi

(Zulu)

\begin{tabular}{|c|c|c|c|c|c|c|}
\hline $\begin{array}{l}\text { Chenopodium } \\
\text { ambrosiodes Bert. } \\
\text { ex Steud. }\end{array}$ & $\begin{array}{l}\text { Wormseed, } \\
\text { (English) }\end{array}$ & Amaranthaceae & Leaf & $\begin{array}{l}\text { Extracted with } \\
\text { multiple solvents } \\
\text { of varying } \\
\text { polarity }\end{array}$ & $\begin{array}{l}\text { MICs of } 250,2000 \\
\text { and } 2000 \mu \mathrm{g} / \mathrm{mL} \\
\text { against } \\
\text { T. mentagrophytes, } \\
\text { M. canis and } \\
\text { C. albicans } \\
\text { respectively }\end{array}$ & $\begin{array}{l}\text { Mabona et al., } \\
2013\end{array}$ \\
\hline $\begin{array}{l}\text { Cissampeios } \\
\text { capensis Thumb. }\end{array}$ & $\begin{array}{l}\text { Dawidjies, dawidjiewortel } \\
\text { (Afrikaans) }\end{array}$ & Menispermaceae & Leaf & $\begin{array}{l}\text { Extracted with } \\
\text { multiple solvents } \\
\text { of varying } \\
\text { polarity }\end{array}$ & $\begin{array}{l}\text { MICs of } 500,1000 \\
\text { and } 2000 \mu \mathrm{g} / \mathrm{mL} \\
\text { against } \\
\text { T. mentagrophytes, } \\
\text { M. canis and } \\
\text { C. albicans } \\
\text { respectively }\end{array}$ & $\begin{array}{l}\text { Mabona et al., } \\
2013\end{array}$ \\
\hline
\end{tabular}




\begin{tabular}{|c|c|c|c|c|c|c|}
\hline Citrus limon $\mathrm{L}$. & Lemon (English) & Rutaceae & Fruit peel & $\begin{array}{l}\text { Extracted with } \\
\text { acetone and } \\
\text { ethanol }\end{array}$ & $\begin{array}{l}\mathrm{MIC}<10 \mu \mathrm{g} / \mathrm{ml} \\
\text { against Candida spp. }\end{array}$ & $\begin{array}{l}\text { Otang and } \\
\text { Afolayan, } \\
2016\end{array}$ \\
\hline $\begin{array}{l}\text { Combretum } \\
\text { acuminatum } \\
\text { Roxb. }\end{array}$ & $\begin{array}{l}\text { Rooiboswilg (Afrikaans), } \\
\text { umbondwe (Zulu), } \\
\text { mohwidiri (Tswana), } \\
\text { imbondvo (Swazi) }\end{array}$ & Combretaceae & Leaf & $\begin{array}{l}\text { Extracted with } \\
\text { multiple solvents } \\
\text { of varying } \\
\text { polarity }\end{array}$ & $\begin{array}{l}\text { MICs as low as } 20 \\
\text { and } 20 \mu \mathrm{g} / \mathrm{mL} \\
\text { against } M . \text { canis and } \\
\text { C. albicans } \\
\text { respectively }\end{array}$ & $\begin{array}{l}\text { Masoko et al., } \\
2007\end{array}$ \\
\hline $\begin{array}{l}\text { Combretum } \\
\text { apiculatum Sond. }\end{array}$ & $\begin{array}{l}\text { Redbushwillow (English), } \\
\text { rooiboswilg (Afrikaans), } \\
\text { umbondwe (Zulu), } \\
\text { mohwidiri (Tswana), } \\
\text { mohwelere (Pedi),ndhuva } \\
\text { (Tsonga) }\end{array}$ & Combretaceae & Leaf & $\begin{array}{l}\text { Extracted with } \\
\text { multiple solvents } \\
\text { of varying } \\
\text { polarity }\end{array}$ & $\begin{array}{l}\text { MICs as low as } 20 \\
\text { and } 320 \mu \mathrm{g} / \mathrm{mL} \\
\text { against } M \text {. canis and } \\
\text { C. albicans } \\
\text { respectively }\end{array}$ & $\begin{array}{l}\text { Masoko et al., } \\
2007\end{array}$ \\
\hline $\begin{array}{l}\text { Combretum } \\
\text { caffrum (Eck1. \& } \\
\text { Zeyh) Kuntze }\end{array}$ & $\begin{array}{l}\text { Cape } \\
\text { bushwillow(English), } \\
\text { rooiblaar, rooiblad, } \\
\text { vaderlandwilgerbool } \\
\text { (Afrikaans), umdubu } \\
\text { (Zulu), }\end{array}$ & Combretaceae & Leaf & $\begin{array}{l}\text { Extracted with } \\
\text { multiple solvents } \\
\text { of varying } \\
\text { polarity }\end{array}$ & $\begin{array}{l}\text { MICs as low as } 20 \\
\text { and } 160 \mu \mathrm{g} / \mathrm{mL} \\
\text { against } M . \text { canis and } \\
\text { C. albicans } \\
\text { respectively }\end{array}$ & $\begin{array}{l}\text { Masoko et al., } \\
2007\end{array}$ \\
\hline
\end{tabular}




\begin{tabular}{|c|c|c|c|c|c|c|}
\hline $\begin{array}{l}\text { Combretum } \\
\text { celestroides } \\
\text { Welw. ex Laws } \\
\text { subsp. } \\
\text { celestroides }\end{array}$ & $\begin{array}{l}\text { Cape } \\
\text { bushwillow(English), } \\
\text { rooiblaar, rooiblad, } \\
\text { vaderlandwilgerbool } \\
\text { (Afrikaans), umdubu } \\
\text { (Zulu), }\end{array}$ & Combretaceae & Leaf & $\begin{array}{l}\text { Extracted with } \\
\text { multiple solvents } \\
\text { of varying } \\
\text { polarity }\end{array}$ & $\begin{array}{l}\text { MICs as low as } 20 \\
\text { and } 160 \mu \mathrm{g} / \mathrm{mL} \\
\text { against } M . \text { canis and } \\
\text { C. albicans } \\
\text { respectively }\end{array}$ & $\begin{array}{l}\text { Masoko et al., } \\
2007\end{array}$ \\
\hline $\begin{array}{l}\text { Combretum } \\
\text { celestroides } \\
\text { Welw. ex Laws } \\
\text { subsp. orientale }\end{array}$ & $\begin{array}{l}\text { Jesse bush bushwillow, } \\
\text { trailing bushwillow } \\
\text { (English), umlalanyathi } \\
\text { (Ndebele) }\end{array}$ & Combretaceae & Leaf & $\begin{array}{l}\text { Extracted with } \\
\text { multiple solvents } \\
\text { of varying } \\
\text { polarity }\end{array}$ & $\begin{array}{l}\text { MICs as low as } 20 \\
\text { and } 160 \mu \mathrm{g} / \mathrm{mL} \\
\text { against } M \text {. canis and } \\
\text { C. albicans } \\
\text { respectively }\end{array}$ & $\begin{array}{l}\text { Masoko et al., } \\
2007\end{array}$ \\
\hline $\begin{array}{l}\text { Combretum } \\
\text { collinum Fresen } \\
\text { subsp. suluense }\end{array}$ & $\begin{array}{l}\text { Weeping bushwillow, } \\
\text { biscoloured bushwillow, } \\
\text { variable bushwillow } \\
\text { (English), vaiërende } \\
\text { boswilg (Afrikaans) }\end{array}$ & Combretaceae & Leaf & $\begin{array}{l}\text { Extracted with } \\
\text { multiple solvents } \\
\text { of varying } \\
\text { polarity }\end{array}$ & $\begin{array}{l}\text { MICs as low as } 20 \\
\text { and } 80 \mu \mathrm{g} / \mathrm{mL} \\
\text { against } M . \text { canis and } \\
\text { C. albicans } \\
\text { respectively }\end{array}$ & $\begin{array}{l}\text { Masoko et al., } \\
2007\end{array}$ \\
\hline $\begin{array}{l}\text { Combretum } \\
\text { collinum Fresen } \\
\text { subsp. taborense }\end{array}$ & $\begin{array}{l}\text { Weeping bushwillow, } \\
\text { biscoloured bushwillow, } \\
\text { variable bushwillow } \\
\text { (English), vaiërende } \\
\text { boswilg (Afrikaans) }\end{array}$ & Combretaceae & Leaf & $\begin{array}{l}\text { Extracted with } \\
\text { multiple solvents } \\
\text { of varying } \\
\text { polarity }\end{array}$ & $\begin{array}{l}\text { MICs as low as } 20 \\
\text { and } 640 \mu \mathrm{g} / \mathrm{mL} \\
\text { against } M . \text { canis and } \\
\text { C. albicans } \\
\text { respectively }\end{array}$ & $\begin{array}{l}\text { Masoko et al., } \\
2007\end{array}$ \\
\hline $\begin{array}{l}\text { Combretum } \\
\text { edwardsii Excell. }\end{array}$ & $\begin{array}{l}\text { Natal combretum, forest } \\
\text { climbing bushwillow } \\
\text { (English) }\end{array}$ & Combretaceae & Leaf & $\begin{array}{l}\text { Extracted with } \\
\text { multiple solvents } \\
\text { of varying } \\
\text { polarity }\end{array}$ & $\begin{array}{l}\text { MICs as low as } 20 \\
\text { and } 40 \mu \mathrm{g} / \mathrm{mL} \\
\text { against } M . \text { canis and } \\
\text { C. albicans } \\
\text { respectively }\end{array}$ & $\begin{array}{l}\text { Masoko et al., } \\
2007\end{array}$ \\
\hline
\end{tabular}


River bushwillow

(English),

riviervaderlandswilg,

Combretum erythophyllum (Burch.) Sond. rooiblaar, rooiblad

(Afrikaans), umbondwe, umdubu-wehlandze, umhlalavane (Zulu), miavana, modubo (Sotho),

mugavhi, muvuvhu (Venda)

\begin{tabular}{|c|c|c|c|c|c|c|}
\hline $\begin{array}{l}\text { Combretum } \\
\text { hereroense } \\
\text { Schinz }\end{array}$ & $\begin{array}{l}\text { Russet bushwillow, } \\
\text { mouse-eared combretum } \\
\text { (English), kierieklapper } \\
\text { (Afrikaans), umhlalavane } \\
\text { (Zulu), mokabi (Northern } \\
\text { Sotho), mugavhi (Venda) }\end{array}$ & Combretaceae & Leaf & $\begin{array}{l}\text { Extracted with } \\
\text { multiple solvents } \\
\text { of varying } \\
\text { polarity }\end{array}$ & $\begin{array}{l}\text { Inactive against } \\
\text { M. canis and } \\
\text { C. albicans }\end{array}$ & $\begin{array}{l}\text { Masoko et al., } \\
2007\end{array}$ \\
\hline $\begin{array}{l}\text { Combretum } \\
\text { imberbe Wawra }\end{array}$ & $\begin{array}{l}\text { Leadwood (English), } \\
\text { hardekool (Afrikaans), } \\
\text { motswiri (Pedi), ummono } \\
\text { (Sotho), mondzo (Tsonga), } \\
\text { motswere (Tswana), } \\
\text { umbondwe omnyama } \\
\text { (Zulu), muhiri (Venda) }\end{array}$ & Combretaceae & Leaf & $\begin{array}{l}\text { Extracted with } \\
\text { multiple solvents } \\
\text { of varying } \\
\text { polarity }\end{array}$ & $\begin{array}{l}\text { MICs as low as } 40 \\
\text { and } 160 \mu \mathrm{g} / \mathrm{mL} \\
\text { against } M \text {. canis and } \\
\text { C. albicans } \\
\text { respectively }\end{array}$ & $\begin{array}{l}\text { Masoko et al., } \\
2007\end{array}$ \\
\hline $\begin{array}{l}\text { Combretum } \\
\text { kraussii Hochst }\end{array}$ & $\begin{array}{l}\text { Forest bushwillow } \\
\text { (English), } \\
\text { bosvaderlandswilg } \\
\text { (Afrikaans), uhwabhu, } \\
\text { umdubuwehlathi (Zulu), } \\
\text { ulandile (Xhosa), modlubu } \\
\text { (Northern Sotho), } \\
\text { muvuvhu (Venda) }\end{array}$ & Combretaceae & Leaf & $\begin{array}{l}\text { Extracted with } \\
\text { multiple solvents } \\
\text { of varying } \\
\text { polarity }\end{array}$ & $\begin{array}{l}\text { MICs as low as } 20 \\
\text { and } 80 \mu \mathrm{g} / \mathrm{mL} \\
\text { against } M \text {. canis and } \\
\text { C. albicans } \\
\text { respectively }\end{array}$ & $\begin{array}{l}\text { Masoko et al., } \\
2007\end{array}$ \\
\hline
\end{tabular}

Extracted with $\quad$ MICs as low as 20 multiple solvents and $640 \mu \mathrm{g} / \mathrm{mL}$ of varying polarity against $M$. canis and C. albicans

Masoko et al., 2007 respectively 


\begin{tabular}{|c|c|c|c|c|c|c|}
\hline $\begin{array}{l}\text { Combretum } \\
\text { microphyllum } \\
\text { Klotzsch }\end{array}$ & Flame creeper (English) & Combretaceae & Leaf & $\begin{array}{l}\text { Extracted with } \\
\text { multiple solvents } \\
\text { of varying } \\
\text { polarity }\end{array}$ & $\begin{array}{l}\text { Inactive against } M . \\
\text { canis and } C . \\
\text { albicans }\end{array}$ & $\begin{array}{l}\text { Masoko et al., } \\
2007\end{array}$ \\
\hline $\begin{array}{l}\text { Combretum } \\
\text { miossambicense } \\
\text { (Klotzsch) }\end{array}$ & $\begin{array}{l}\text { Knobbly creeper } \\
\text { (English), knoppiesklimop } \\
\text { (Afrikaans) }\end{array}$ & Combretaceae & Leaf & $\begin{array}{l}\text { Extracted with } \\
\text { multiple solvents } \\
\text { of varying } \\
\text { polarity }\end{array}$ & $\begin{array}{l}\text { MICs as low as } 20 \\
\text { and } 40 \mu \mathrm{g} / \mathrm{mL} \\
\text { against } M . \text { canis and } \\
\text { C. albicans } \\
\text { respectively }\end{array}$ & $\begin{array}{l}\text { Masoko et al., } \\
2007\end{array}$ \\
\hline $\begin{array}{l}\text { Combretum } \\
\text { moggii Excell. }\end{array}$ & Unknown & Combretaceae & Leaf & $\begin{array}{l}\text { Extracted with } \\
\text { multiple solvents } \\
\text { of varying } \\
\text { polarity }\end{array}$ & $\begin{array}{l}\text { MICs as low as } 20 \\
\text { and } 20 \mu \mathrm{g} / \mathrm{mL} \\
\text { against } M . \text { canis and } \\
\text { C. albicans } \\
\text { respectively }\end{array}$ & $\begin{array}{l}\text { Masoko et al., } \\
2007\end{array}$ \\
\hline $\begin{array}{l}\text { Combretum molle } \\
\mathrm{R} . \mathrm{Br} .\end{array}$ & $\begin{array}{l}\text { Velvet bushwillow, velvet } \\
\text { leaf willow (English), } \\
\text { fluweelboswilg, } \\
\text { basterrooibos (Afrikaans), } \\
\text { umBondwe-omhlope } \\
\text { (Zulu), mokgwethe } \\
\text { (Northern Sotho), mugwiti } \\
\text { (Venda) }\end{array}$ & Combretaceae & Leaf & $\begin{array}{l}\text { Extracted with } \\
\text { multiple solvents } \\
\text { of varying } \\
\text { polarity }\end{array}$ & $\begin{array}{l}\text { Inactive against } \\
\text { M. canis and } \\
\text { C. albicans }\end{array}$ & $\begin{array}{l}\text { Masoko et al., } \\
2007\end{array}$ \\
\hline $\begin{array}{l}\text { Combretum } \\
\text { nelsonii } \\
\text { Duemmer }\end{array}$ & $\begin{array}{l}\text { Waterberg bushwillow } \\
\text { (English) }\end{array}$ & Combretaceae & Leaf & $\begin{array}{l}\text { Extracted with } \\
\text { multiple solvents } \\
\text { of varying } \\
\text { polarity }\end{array}$ & $\begin{array}{l}\text { MICs as low as } 20 \\
\text { and } 40 \mu \mathrm{g} / \mathrm{mL} \\
\text { against } M . \text { canis and } \\
\text { C. albicans } \\
\text { respectively }\end{array}$ & $\begin{array}{l}\text { Masoko et al., } \\
2007\end{array}$ \\
\hline $\begin{array}{l}\text { Combretum } \\
\text { padoides Eng. \& } \\
\text { Diels }\end{array}$ & $\begin{array}{l}\text { Thicket bushwillow } \\
\text { (English) }\end{array}$ & Combretaceae & Leaf & $\begin{array}{l}\text { Extracted with } \\
\text { multiple solvents } \\
\text { of varying } \\
\text { polarity }\end{array}$ & $\begin{array}{l}\text { MICs as low as } 80 \\
\text { and } 320 \mu \mathrm{g} / \mathrm{mL} \\
\text { against } M . \text { canis and } \\
\text { C. albicans } \\
\text { respectively }\end{array}$ & $\begin{array}{l}\text { Masoko et al., } \\
2007\end{array}$ \\
\hline
\end{tabular}




\begin{tabular}{|c|c|c|c|c|c|c|}
\hline $\begin{array}{l}\text { Combretum } \\
\text { paniculatum } \\
\text { Vent. }\end{array}$ & $\begin{array}{l}\text { Forest flame creeper, } \\
\text { burning bush (English) }\end{array}$ & Combretaceae & Leaf & $\begin{array}{l}\text { Extracted with } \\
\text { multiple solvents } \\
\text { of varying } \\
\text { polarity }\end{array}$ & $\begin{array}{l}\text { Inactive against } \\
\text { M. canis and } \\
\text { C. albicans }\end{array}$ & $\begin{array}{l}\text { Masoko et al., } \\
2007\end{array}$ \\
\hline $\begin{array}{l}\text { Combretum } \\
\text { petrophilum } \\
\text { Retief }\end{array}$ & Unknown & Combretaceae & Leaf & $\begin{array}{l}\text { Extracted with } \\
\text { multiple solvents } \\
\text { of varying } \\
\text { polarity }\end{array}$ & $\begin{array}{l}\text { Inactive against } \\
\text { M. canis and } \\
\text { C. albicans }\end{array}$ & $\begin{array}{l}\text { Masoko et al., } \\
2007\end{array}$ \\
\hline $\begin{array}{l}\text { Combretum } \\
\text { woodii Duemmer }\end{array}$ & $\begin{array}{l}\text { large leaved forest } \\
\text { bushwillow (English), } \\
\text { grootblaarvaderlandwilg } \\
\text { (Afrikaans), iWaphu } \\
\text { (Zulu), mbondvo sehlatsi } \\
\text { (Swazi) }\end{array}$ & Combretaceae & Leaf & $\begin{array}{l}\text { Extracted with } \\
\text { multiple solvents } \\
\text { of varying } \\
\text { polarity }\end{array}$ & $\begin{array}{l}\text { MICs as low as } 20 \\
\text { and } 80 \mu \mathrm{g} / \mathrm{mL} \\
\text { against } M . \text { canis and } \\
\text { C. albicans } \\
\text { respectively }\end{array}$ & $\begin{array}{l}\text { Masoko et al., } \\
2007\end{array}$ \\
\hline $\begin{array}{l}\text { Combretum } \\
\text { zeyheri Sond. }\end{array}$ & $\begin{array}{l}\text { Large-fruited bushwillow, } \\
\text { Zeyhers bushwillow } \\
\text { (English), raasblaar, } \\
\text { fluisterboom (Afrikaans), } \\
\text { moduba-tshipi (Pedi), } \\
\text { umbondwe wasembudwini } \\
\text { (Zulu)mufhatelathundu } \\
\text { (Venda) }\end{array}$ & Combretaceae & Leaf & $\begin{array}{l}\text { Extracted with } \\
\text { multiple solvents } \\
\text { of varying } \\
\text { polarity }\end{array}$ & $\begin{array}{l}\text { MICs as low as } 20 \\
\text { and } 80 \mu \mathrm{g} / \mathrm{mL} \\
\text { against } M . \text { canis and } \\
\text { C. albicans } \\
\text { respectively }\end{array}$ & $\begin{array}{l}\text { Masoko et al., } \\
2007\end{array}$ \\
\hline $\begin{array}{l}\text { Cotelydon } \\
\text { orbiculata } \\
\text { Forssk. }\end{array}$ & $\begin{array}{l}\text { Pig's ear (English), } \\
\text { plakkie, kouterie } \\
\text { (Afrikaans), imphewula } \\
\text { (Xhosa), seredile (Sotho, } \\
\text { Tswana) }\end{array}$ & Crassulaceae & Leaf & $\begin{array}{l}\text { Extracted with } \\
\text { multiple solvents } \\
\text { of varying } \\
\text { polarity }\end{array}$ & $\begin{array}{l}\text { MICs of } 500,1000 \\
\text { and } 2000 \mu \mathrm{g} / \mathrm{mL} \\
\text { against } \\
\text { T. mentagrophytes, } \\
\text { M. canis and } \\
\text { C. albicans } \\
\text { respectively }\end{array}$ & $\begin{array}{l}\text { Mabona et al., } \\
2013\end{array}$ \\
\hline
\end{tabular}




\begin{tabular}{|c|c|c|c|c|c|c|}
\hline $\begin{array}{l}\text { Curtisa dentata } \\
\text { (Burm.f) C.A. } \\
\text { Sm. }\end{array}$ & $\begin{array}{l}\text { Cape lancewood, assegai } \\
\text { tree (English), assegaai } \\
\text { (Afrikaans), umgxina } \\
\text { (Xhosa), umagunda (Zulu) }\end{array}$ & Comaceae & Leaf & $\begin{array}{l}\text { Extracted with } \\
\text { multiple solvents } \\
\text { of varying } \\
\text { polarity }\end{array}$ & $\begin{array}{l}\text { MICs as low as } 470 \\
\text { and } 360 \mu \mathrm{gmL} \\
\text { against } M \text {. canis and } \\
\text { C. albicans } \\
\text { respectively }\end{array}$ & $\begin{array}{l}\text { Shai et } \\
\text { al.,2008 }\end{array}$ \\
\hline $\begin{array}{l}\text { Cussonia } \\
\text { zuluensis Strey }\end{array}$ & $\begin{array}{l}\text { Zulu cabbage tree } \\
\text { (English), bergkiepersol } \\
\text { (Afrikaans), umsenge } \\
\text { (Xhosa), umsengembuzi } \\
\text { (Zulu) }\end{array}$ & Araliaceae & Leaf & $\begin{array}{l}\text { Extracted with } \\
\text { multiple solvents } \\
\text { of varying } \\
\text { polarity }\end{array}$ & $\begin{array}{l}\text { MIC of } 880 \mu \mathrm{g} / \mathrm{mL} \\
\text { against } C \text {. albicans. } \\
\text { Inactive against } \\
\text { M. canis }\end{array}$ & $\begin{array}{l}\text { Shai et } \\
\text { al.,2008 }\end{array}$ \\
\hline $\begin{array}{l}\text { Dicoma anomala } \\
\text { Sond. }\end{array}$ & $\begin{array}{l}\text { Fever bush, stomach bush } \\
\text { (English), } \\
\text { maagbitterwortel, } \\
\text { kalwerbossie, koorsbossie, } \\
\text { gryshout, maagbossie } \\
\text { (Afrikaans), inyongana } \\
\text { (Xhosa), } \\
\text { isihlabamakhondlwane, } \\
\text { umuna (Zulu) }\end{array}$ & Asteraceae & Tuber & $\begin{array}{l}\text { Extracted with } \\
\text { multiple solvents } \\
\text { of varying } \\
\text { polarity }\end{array}$ & $\begin{array}{l}\text { MICs of } 30,4000 \\
\text { and } 2000 \mu \mathrm{g} / \mathrm{mL} \\
\text { against } \\
\text { T. mentagrophytes, } \\
\text { M. canis and } \\
\text { C. albicans } \\
\text { respectively }\end{array}$ & $\begin{array}{l}\text { Mabona et al., } \\
2013\end{array}$ \\
\hline $\begin{array}{l}\text { Dioscorea } \\
\text { dregeana } \mathrm{T} . \\
\text { Durand \& Schinz. }\end{array}$ & $\begin{array}{l}\text { Wild yam (English), } \\
\text { wildejam (Afrikaans), } \\
\text { isidakwa, udakwa (Zulu) }\end{array}$ & Dioscoreaceae & Tuber & $\begin{array}{l}\text { Extracted with } \\
\text { multiple solvents } \\
\text { of varying } \\
\text { polarity }\end{array}$ & $\begin{array}{l}\text { MICs of } 2000,4000 \\
\text { and } 2000 \mu \mathrm{g} / \mathrm{mL} \\
\text { against } \\
\text { T. mentagrophytes, } \\
\text { M. canis and } \\
\text { C. albicans } \\
\text { respectively }\end{array}$ & $\begin{array}{l}\text { Mabona et al., } \\
2013\end{array}$ \\
\hline
\end{tabular}




\begin{tabular}{|c|c|c|c|c|c|c|}
\hline $\begin{array}{l}\text { Diospyros } \\
\text { mespiliformis } \\
\text { Hochst. Ex } \\
\text { A.D.C. }\end{array}$ & $\begin{array}{l}\text { African ebony, jackal } \\
\text { berry (English), } \\
\text { jakkalbessie (Afrikaans), } \\
\text { mgula (Tsonga) }\end{array}$ & Ebenaceae & Leaf & $\begin{array}{l}\text { Extracted with } \\
\text { multiple solvents } \\
\text { of varying } \\
\text { polarity }\end{array}$ & $\begin{array}{l}\text { MICs of } 100,500 \\
\text { and } 1000 \mu \mathrm{g} / \mathrm{mL} \\
\text { against } \\
\text { T. mentagrophytes, } \\
\text { M. canis and } \\
\text { C. albicans } \\
\text { respectively }\end{array}$ & $\begin{array}{l}\text { Mabona et al., } \\
2013\end{array}$ \\
\hline $\begin{array}{l}\text { Dichrostachys } \\
\text { cinerea (L.) } \\
\text { Wight \& Arn. }\end{array}$ & $\begin{array}{l}\text { Sickle bush (English), } \\
\text { sekelbos (Afrikaans), } \\
\text { ugagane (Zulu) }\end{array}$ & Fabaceae & Twigs & $\begin{array}{l}\text { Aqueous and } \\
\text { methanolic } \\
\text { extracts were } \\
\text { tested. }\end{array}$ & $\begin{array}{l}\text { MICs of 500, 250, } \\
2000 \mu \mathrm{g} / \mathrm{mL} \text { against } \\
\text { T. mentagrophytes, } \\
\text { M. canis and } \\
\text { C. albicans } \\
\text { respectively }\end{array}$ & $\begin{array}{l}\text { Nciki et al., } \\
2016\end{array}$ \\
\hline $\begin{array}{l}\text { Dodonaea } \\
\text { augustifolia } \text { L.f. }\end{array}$ & $\begin{array}{l}\text { Sand olive (English), } \\
\text { sandolien, ysterbos } \\
\text { (Afrikaans), mutata-vhana } \\
\text { (Venda) }\end{array}$ & Sapindaceae & Leaves & $\begin{array}{l}\text { Extracted with } \\
\text { multiple solvents } \\
\text { of varying } \\
\text { polarity }\end{array}$ & $\begin{array}{l}\text { Low activity. MIC } \\
>10,000 \mu \mathrm{g} / \mathrm{mL} \text { for } \\
\text { all extracts }\end{array}$ & $\begin{array}{l}\text { Motsei et al., } \\
2003\end{array}$ \\
\hline $\begin{array}{l}\text { Ekebergia } \\
\text { capenses Sparm. }\end{array}$ & $\begin{array}{l}\text { Cape ash (English), } \\
\text { essenhout (Afrikaans), } \\
\text { mmidibidibi (Northern } \\
\text { Sotho), umnyamathi } \\
\text { (Zulu) }\end{array}$ & Meliaceae & Bark & $\begin{array}{l}\text { Extracted with } \\
\text { multiple solvents } \\
\text { of varying } \\
\text { polarity }\end{array}$ & $\begin{array}{l}\text { MICs of } 1000,1000 \\
\text { and } 1000 \mu \mathrm{g} / \mathrm{mL} \\
\text { against } \\
\text { T. mentagrophytes, } \\
\text { M. canis and } \\
\text { C. albicans } \\
\text { respectively }\end{array}$ & $\begin{array}{l}\text { Mabona et al., } \\
2013\end{array}$ \\
\hline
\end{tabular}


Elandsbean (English), elandsboontjie

Elephantorrhiza elephantina

(Afrikaans), mositsane

(Sotho, Tswana),

intolwane (Xhosa, Zulu)

MICs of 250, 500

and $1000 \mu \mathrm{g} / \mathrm{mL}$ for leaf extracts against T. mentagrophytes,

M. canis and

C. albicans

respectively.

Rhizome extracts are

stronger

MICs of 4000, 2000

Embelia ruminata

$\begin{array}{ll}\text { Embelia ruminata } & \\ \text { (E. Mey ex } & \text { Ibhinini (Zulu) }\end{array}$

A.DC) $\mathrm{Mez}$

Myrsinaceae

Extracted with

multiple solvents

of varying

polarity

and $200 \mu \mathrm{g} / \mathrm{mL}$

against

T. mentagrophytes,

M. canis and

Mabona et al.,

C. albicans

respectively

Common coral tree, lucky

Erythina

lysistemon Hutch.

Eucalyptus

camaldulensis

Dehnh. bean tree (English),

gewone, koraalboom,

kanniedood (Afrikaans),

umsintsi (Xhosa), muvhale

(Venda), mophete

(Tswana), umsinsi (Zulu)

Red rivergum (English)

Myrtaceae

Fabaceae

Bark

Extracted with
multiple solvents

of varying

polarity

Low activity. MIC

$>10000 \mu \mathrm{g} / \mathrm{mL}$ for

all extracts

Motsei et al., 2003; Mabona et al., 2013 et

al.

\section{MICs of 1000, 2000}

and $500 \mu \mathrm{g} / \mathrm{mL}$

against

T. mentagrophytes

M. canis and

C. albicans

respectively multiple solvents

of varying

polarity
Mabona et al., 2013
Mabona et al., 2013; Nciki et al., 2016. 


\begin{tabular}{|c|c|c|c|c|c|c|}
\hline $\begin{array}{l}\text { Euphorbia } \\
\text { tirucalli L. }\end{array}$ & $\begin{array}{l}\text { Pencil plant, rubber hedge } \\
\text { euphorbia (English), } \\
\text { kraalmelkbos (Afrikaans) }\end{array}$ & Euphorbiaceae & Stems & $\begin{array}{l}\text { Aqueous and } \\
\text { methanolic } \\
\text { extracts were } \\
\text { tested. }\end{array}$ & $\begin{array}{l}\text { MICs of } 500,4000, \\
1500 \mu \mathrm{g} / \mathrm{mL} \text { against } \\
\text { T. mentagrophytes, } \\
\text { M. canis and } \\
\text { C. albicans } \\
\text { respectively }\end{array}$ & $\begin{array}{l}\text { Nciki et al., } \\
2016\end{array}$ \\
\hline $\begin{array}{l}\text { Eucomis } \\
\text { autumnalis } \\
\text { (Mill.) Chitt. }\end{array}$ & $\begin{array}{l}\text { Autumn pineapple lily, } \\
\text { pineapple flower } \\
\text { (English), wildepynappel, } \\
\text { krulkoppie (Afrikaans), } \\
\text { ubuhlungu becanti, } \\
\text { isithithibala esimathunzi } \\
\text { (Xhosa), umathunga, } \\
\text { ukhokho, } \\
\text { umakhandakantsele (Zulu) }\end{array}$ & Asparagaceae & Bulb & $\begin{array}{l}\text { Extracted with } \\
\text { multiple solvents } \\
\text { of varying } \\
\text { polarity }\end{array}$ & $\begin{array}{l}\text { Conflicting reports } \\
\text { of efficacy. MICs } \\
\text { against } \\
\text { T. mentagrophytes, } \\
\text { T. rubrum and } \\
\text { C. albicans of } 1250 \\
\mu \mathrm{g} / \mathrm{mL} \text { reported by } \\
\text { Ghuman et al., } 2016 \text {. } \\
\text { Inactive (MIC } \\
>10,000 \mu \mathrm{g} / \mathrm{mL} \text { for } \\
\text { all extracts) reported } \\
\text { by Motsei et al., } \\
2003 \text {. }\end{array}$ & $\begin{array}{l}\text { Ghuman et al., } \\
\text { 2016; Motsei } \\
\text { et al., } 2003\end{array}$ \\
\hline $\begin{array}{l}\text { Ficus natalensis } \\
\text { Forssk. }\end{array}$ & $\begin{array}{l}\text { Natal fig (English), } \\
\text { mutuba (Zulu) }\end{array}$ & Moraceae & Bark & $\begin{array}{l}\text { Extracted with } \\
\text { multiple solvents } \\
\text { of varying } \\
\text { polarity }\end{array}$ & $\begin{array}{l}\text { MICs of } 1000,1000 \\
\text { and } 500 \mu \mathrm{g} / \mathrm{mL} \\
\text { against } \\
\text { T. mentagrophytes, } \\
\text { M. canis and } \\
\text { C. albicans } \\
\text { respectively }\end{array}$ & $\begin{array}{l}\text { Mabona et al., } \\
2013\end{array}$ \\
\hline $\begin{array}{l}\text { Garcinia } \\
\text { livingstonei } \mathrm{T} . \\
\text { Anderson }\end{array}$ & $\begin{array}{l}\text { African mangosteen } \\
\text { (English), Afrika- } \\
\text { geelmelkhout (Afrikaans), } \\
\text { uGobandlovu (Zulu), } \\
\text { mmimbi (Tsonga), } \\
\text { mokongono (Pedi) }\end{array}$ & Clusiaceae & Bark & $\begin{array}{l}\text { Aqueous and } \\
\text { methanolic } \\
\text { extracts were } \\
\text { tested. }\end{array}$ & $\begin{array}{l}\text { MICs of } 130,130, \\
250 \mu \mathrm{g} / \mathrm{mL} \text { against } \\
\text { T. mentagrophytes, } \\
\text { M. canis and } \\
\text { C. albicans } \\
\text { respectively }\end{array}$ & $\begin{array}{l}\text { Nciki et al., } \\
2016\end{array}$ \\
\hline
\end{tabular}




\begin{tabular}{|c|c|c|c|c|c|c|}
\hline $\begin{array}{l}\text { Glycyrryhiza } \\
\text { glabra L. }\end{array}$ & $\begin{array}{l}\text { Liquorice, licorice } \\
\text { (English) }\end{array}$ & Fabaceae & Rhizome & $\begin{array}{l}\text { Extracted with } \\
\text { multiple solvents } \\
\text { of varying } \\
\text { polarity }\end{array}$ & $\begin{array}{l}\text { Moderate activity. } \\
\text { MIC } 1560 \mu \mathrm{g} / \mathrm{mL}\end{array}$ & $\begin{array}{l}\text { Motsei et al., } \\
2003\end{array}$ \\
\hline $\begin{array}{l}\text { Haemanthus } \\
\text { albiflos Jacq. }\end{array}$ & $\begin{array}{l}\text { Paintbrush (English), } \\
\text { poeierkwas (Afrikaans) }\end{array}$ & Amaryllidaceae & $\begin{array}{l}\text { Leaves } \\
\text { and bulbs }\end{array}$ & $\begin{array}{l}\text { Extracted with } \\
\text { multiple solvents } \\
\text { of varying } \\
\text { polarity }\end{array}$ & $\begin{array}{l}\text { Low activity. MIC } \\
>10000 \mu \mathrm{g} / \mathrm{mL} \text { for } \\
\text { all extracts }\end{array}$ & $\begin{array}{l}\text { Motsei et al., } \\
2003\end{array}$ \\
\hline Hallaria lucida L. & $\begin{array}{l}\text { Tree fuchsia, white olive } \\
\text { (English), notsung, } \\
\text { witolienhout, witolyfhout } \\
\text { (Afrikaans), umbinza, } \\
\text { (Xhosa), indomela, } \\
\text { umbinza (Zulu) }\end{array}$ & Stilbaceae & Leaf & $\begin{array}{l}\text { Extracted with } \\
\text { multiple solvents } \\
\text { of varying } \\
\text { polarity }\end{array}$ & $\begin{array}{l}\text { MICs of } 2000,2000 \\
\text { and } 2000 \mu \mathrm{g} / \mathrm{mL} \\
\text { against } \\
\text { T. mentagrophytes, } \\
\text { M. canis and } \\
\text { C. albicans } \\
\text { respectively }\end{array}$ & $\begin{array}{l}\text { Mabona et al., } \\
2013\end{array}$ \\
\hline $\begin{array}{l}\text { Harpephyllum } \\
\text { caffrum Bernh. ex } \\
\text { Krauss }\end{array}$ & $\begin{array}{l}\text { Wildplum (English), } \\
\text { wildepruim (Afrikaans), } \\
\text { mothekele (Northern } \\
\text { Sotho), umgwenya } \\
\text { (Xhosa, Zulu) }\end{array}$ & Anacardiaceae & Bark & $\begin{array}{l}\text { Extracted with } \\
\text { multiple solvents } \\
\text { of varying } \\
\text { polarity }\end{array}$ & $\begin{array}{l}\text { MICs of } 500,1000 \\
\text { and } 250 \mu \mathrm{g} / \mathrm{mL} \\
\text { against } \\
\text { T. mentagrophytes, } \\
\text { M. canis and } \\
\text { C. albicans } \\
\text { respectively }\end{array}$ & $\begin{array}{l}\text { Mabona et al., } \\
2013\end{array}$ \\
\hline
\end{tabular}




\begin{tabular}{|c|c|c|c|c|c|c|}
\hline $\begin{array}{l}\text { Haworthiopis } \\
\text { limifolia } \\
\text { (Marloth.) } \\
\text { G.D.Rowley }\end{array}$ & Fairy washboard (English) & Asphodelaceae & Leaf & $\begin{array}{l}\text { Aqueous and } \\
\text { ethanolic extracts }\end{array}$ & $\begin{array}{l}\text { MICs of } 200-2500 \\
\mu \mathrm{g} / \mathrm{mL} \text { against } \\
\text { T. mentagrophytes, } \\
\text { T. rubrum and } \\
\text { C. albicans }\end{array}$ & $\begin{array}{l}\text { Naidoo and } \\
\text { Coopoosamy, } \\
\text { 2011;Ghuman } \\
\text { et al., } 2016\end{array}$ \\
\hline $\begin{array}{l}\text { Hewittia } \\
\text { malabarica L. } \\
\text { (Suresh.) }\end{array}$ & Ihlanzandulo (Zulu) & Convulvulaceae & Leaf & $\begin{array}{l}\text { Aqueous and } \\
\text { methanolic } \\
\text { extracts were } \\
\text { tested. }\end{array}$ & $\begin{array}{l}\text { MICs of 500, } 750, \\
500 \mu \mathrm{g} / \mathrm{mL} \text { against } \\
\text { T. mentagrophytes, } \\
\text { M. canis and } \\
\text { C. albicans } \\
\text { respectively }\end{array}$ & $\begin{array}{l}\text { Nciki et al., } \\
2016\end{array}$ \\
\hline $\begin{array}{l}\text { Hibiscus } \\
\text { surattensis L. }\end{array}$ & Wild sour shrub (English) & Malvaceae & Leaf & $\begin{array}{l}\text { Aqueous and } \\
\text { methanolic } \\
\text { extracts were } \\
\text { tested. }\end{array}$ & $\begin{array}{l}\text { MICs of 500, } 750, \\
500 \mu \mathrm{g} / \mathrm{mL} \text { against } \\
\text { T. mentagrophytes, } \\
\text { M. canis and } \\
\text { C. albicans } \\
\text { respectively }\end{array}$ & $\begin{array}{l}\text { Nciki et al., } \\
2016\end{array}$ \\
\hline $\begin{array}{l}\text { Hypericum } \\
\text { aethiopicum } \\
\text { Thunb. }\end{array}$ & Unknown & Asphodelaceae & Leaf & Cloroform extract & $\begin{array}{l}\text { MICs of } 630 \mu \mathrm{g} / \mathrm{mL} \\
\text { against } \\
\text { T. mentagrophytes, } \\
\text { T. rubrum and } \\
\text { C. albicans }\end{array}$ & $\begin{array}{l}\text { Ghuman et al., } \\
2016\end{array}$ \\
\hline $\begin{array}{l}\text { Hypericum } \\
\text { perforatum } \mathrm{L} \text {. }\end{array}$ & $\begin{array}{l}\text { Saint John's wort } \\
\text { (English), Johanneskruid } \\
\text { (Afrikaans) }\end{array}$ & Hypericaceae & Leaf & $\begin{array}{l}\text { Extracted with } \\
\text { multiple solvents } \\
\text { of varying } \\
\text { polarity }\end{array}$ & $\begin{array}{l}\text { MICs of } 1000,1000 \\
\text { and } 1000 \mu \mathrm{g} / \mathrm{mL} \\
\text { against } \\
\text { T. mentagrophytes, } \\
\text { M. canis and } \\
\text { C. albicans } \\
\text { respectively }\end{array}$ & $\begin{array}{l}\text { Mabona et al., } \\
2013\end{array}$ \\
\hline
\end{tabular}


Yellow star, star lily, star

flower (English), sterblom, geelsterretjie, gifbol Hypoxis (Afrikaans), moli kharatsa,

MICs of 130,1000

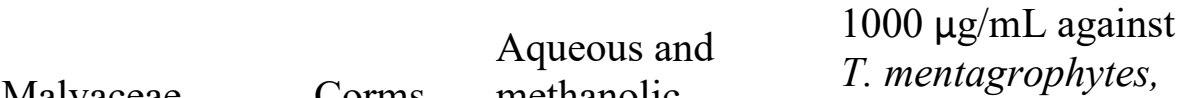

Malvaceae Corms methanolic

extracts hemerocallidea lotsane (southern Sotho); Fisch. C.A. Mey inkomfe, inkomfe enkulu \& Ave

(Zulu) inongwe, ilabatheka, ixhalanxa, ikhubalo lezithunzela
M. canis and

C. albicans

respectively
Nciki et al., 2016

MICs of 2000, 1000 and $4000 \mu \mathrm{g} / \mathrm{mL}$ against

T. mentagrophytes, M. canis and

Mabona et al.,

Extracted with

Aquifoliaceae Bark multiple solvents of varying polarity

C. albicans respectively

(Sotho), mutanzwakhameol (Venda)

Jatropha curcas

L.

Physicnut, poison nut, bubble nut, purging nut (English)

Euphorbiaceae

Extracted with

multiple solvents

of varying

polarity

Low activity. MIC

$>10000 \mu \mathrm{g} / \mathrm{mL}$ for all extracts

Motsei et al., 2003

Shai et al.,

Sausage tree (English),

Kigelia africana worsboom (Afrikaans) (Lam) Benth umVunguta, umFongothi (Zulu), muvevha (Venda)
Bignoniaceae Leaf

Extracted with multiple solvents of varying polarity 2008; Mabona
MICs as low as 60

$\mu \mathrm{g} / \mathrm{mL}$ against et al., 2013; $\begin{array}{ll}\text { T. mentagrophytes, } & \text { Arkhipov et } \\ \text { T. rubrum, M. canis } & \text { al., 2014; }\end{array}$ $\begin{array}{ll}\text { T. rubrum, M. canis } & \text { al., 2014, } \\ \text { and } C \text { albicans } & \text { Nciki et al. }\end{array}$ respectively
2016; et al.et al.et al. 


\begin{tabular}{|c|c|c|c|c|c|c|}
\hline $\begin{array}{l}\text { Lannea discolor } \\
\text { Engl. }\end{array}$ & $\begin{array}{l}\text { Live-long, tree grape } \\
\text { (English), morulamopsane, } \\
\text { mokgokgothwane (Pedi), } \\
\text { muvhumbu (Venda) }\end{array}$ & Anacardiaceae & Leaf & $\begin{array}{l}\text { Extracted with } \\
\text { multiple solvents } \\
\text { of varying } \\
\text { polarity }\end{array}$ & $\begin{array}{l}\text { MICs of } 4000,2000 \\
\text { and } 200 \mu \mathrm{g} / \mathrm{mL} \\
\text { against } \\
\text { T. mentagrophytes, } \\
\text { M. canis and } \\
\text { C. albicans } \\
\text { respectively }\end{array}$ & $\begin{array}{l}\text { Mabona et al., } \\
2013\end{array}$ \\
\hline $\begin{array}{l}\text { Lantana rugosa } \\
\text { Thunb. }\end{array}$ & $\begin{array}{l}\text { Bird's beer, bird's brandy } \\
\text { (English), voelbrandewyn, } \\
\text { wildesalie (Afrikaans), } \\
\text { utyani-bentaka (Xhosa), } \\
\text { impema, ubukhwebezane, } \\
\text { uguguvama (Zulu) }\end{array}$ & Verbenaceae & Leaf & $\begin{array}{l}\text { Extracted with } \\
\text { multiple solvents } \\
\text { of varying } \\
\text { polarity }\end{array}$ & $\begin{array}{l}\text { MICs of } 50,2000 \\
\text { and } 3000 \mu \mathrm{g} / \mathrm{mL} \\
\text { against } \\
\text { T. mentagrophytes, } \\
\text { M. canis and } \\
\text { C. albicans } \\
\text { respectively }\end{array}$ & $\begin{array}{l}\text { Mabona et al., } \\
2013\end{array}$ \\
\hline $\begin{array}{l}\text { Leonitis leonoris } \\
\text { (L.) R.Br. }\end{array}$ & $\begin{array}{l}\text { Wild dagga (English), } \\
\text { wildedagga, duiwelstabak } \\
\text { (Afrikaans), mvovo } \\
\text { (Xhosa), uyshwala- } \\
\text { bezinyoni (Zulu) }\end{array}$ & Lamiaceae & Leaf & $\begin{array}{l}\text { Extracted with } \\
\text { multiple solvents } \\
\text { of varying } \\
\text { polarity }\end{array}$ & $\begin{array}{l}\text { Low activity. MIC } \\
>10000 \mu \mathrm{g} / \mathrm{mL} \text { for } \\
\text { all extracts }\end{array}$ & $\begin{array}{l}\text { Motsei et al., } \\
2003\end{array}$ \\
\hline $\begin{array}{l}\text { Malva parviflora } \\
\text { L. }\end{array}$ & $\begin{array}{l}\text { Small mallow, bread-and- } \\
\text { butter, cheeseweed mallow } \\
\text { (English),brood-en-botter, } \\
\text { kiesieblaar (Afrikaans) }\end{array}$ & Malvaceae & Leaf & $\begin{array}{l}\text { Extracted with } \\
\text { multiple solvents } \\
\text { of varying } \\
\text { polarity }\end{array}$ & $\begin{array}{l}\text { MICs of } 50 \mu \mathrm{g} / \mathrm{mL} \\
\text { against } \\
\text { T. mentagrophytes. } \\
\text { Inactive against } \\
\text { M. canis and } \\
\text { C. albicans }\end{array}$ & $\begin{array}{l}\text { Mabona et al., } \\
2013\end{array}$ \\
\hline
\end{tabular}




\begin{tabular}{|c|c|c|c|c|c|c|}
\hline $\begin{array}{l}\text { Melianthus } \\
\text { comosus Vahl. }\end{array}$ & $\begin{array}{l}\text { Honey flower (Eng); } \\
\text { kruidjie-roer-my-nie (Afr.) }\end{array}$ & Francoaceae & Leaf & $\begin{array}{l}\text { Extracted with } \\
\text { multiple solvents } \\
\text { of varying } \\
\text { polarity }\end{array}$ & $\begin{array}{l}\text { MICs of } 50,50 \text { and } \\
250 \mu \mathrm{g} / \mathrm{mL} \text { against } \\
\text { T. mentagrophytes, } \\
\text { M. canis and } C \text {. } \\
\text { albicans respectively }\end{array}$ & $\begin{array}{l}\text { Mabona et al., } \\
2013\end{array}$ \\
\hline $\begin{array}{l}\text { Melianthus major } \\
\text { L. }\end{array}$ & $\begin{array}{l}\text { Giant honey flower, } \\
\text { kruidjie-roer-my-nie } \\
\text { (Afrikaans) }\end{array}$ & Francoaceae & Leaf & $\begin{array}{l}\text { Extracted with } \\
\text { multiple solvents } \\
\text { of varying } \\
\text { polarity }\end{array}$ & $\begin{array}{l}\text { MICs of } 50,50 \text { and } \\
25 \mu \mathrm{g} / \mathrm{mL} \text { against } \\
\text { T. mentagrophytes, } \\
\text { M. canis and } \\
\text { C. albicans } \\
\text { respectively }\end{array}$ & $\begin{array}{l}\text { Mabona et al., } \\
2013\end{array}$ \\
\hline $\begin{array}{l}\text { Mentha longifolia } \\
\text { Huds. }\end{array}$ & $\begin{array}{l}\text { Wild mint (English), } \\
\text { kruisement, balderjan } \\
\text { (Afrikaans), koena-ya- } \\
\text { thabo (Sotho), inixina, } \\
\text { inzinziniba (Xhosa), } \\
\text { ufuthana, lomhlanga } \\
\text { (Zulu) }\end{array}$ & Lamiaceae & Leaf & $\begin{array}{l}\text { Extracted with } \\
\text { multiple solvents } \\
\text { of varying } \\
\text { polarity }\end{array}$ & $\begin{array}{l}\text { MICs of } 800,1000 \\
\text { and } 200 \mu \mathrm{g} / \mathrm{mL} \\
\text { against } \\
\text { T. mentagrophytes, } \\
\text { M. canis and C. } \\
\text { albicans respectively }\end{array}$ & $\begin{array}{l}\text { Mabona et al., } \\
2013\end{array}$ \\
\hline $\begin{array}{l}\text { Momordica } \\
\text { balsamina L. }\end{array}$ & $\begin{array}{l}\text { Balsam pear (English), } \\
\text { laloentjie (Afrikaans), } \\
\text { mohodo (Sotho), } \\
\text { intshungu (Zulu) }\end{array}$ & Curcubitaceae & Leaves & $\begin{array}{l}\text { Aqueous and } \\
\text { methanolic } \\
\text { extracts }\end{array}$ & $\begin{array}{l}\text { MICs of } 190,500 \text {, } \\
1000 \mu \mathrm{g} / \mathrm{mL} \text { against } \\
\text { T. mentagrophytes, } \\
\text { M. canis and } \\
\text { C. albicans } \\
\text { respectively }\end{array}$ & $\begin{array}{l}\text { Nciki et al., } \\
2016\end{array}$ \\
\hline
\end{tabular}




\begin{tabular}{|c|c|c|c|c|c|c|}
\hline $\begin{array}{l}\text { Opuntia ficus- } \\
\text { indica Mill. }\end{array}$ & $\begin{array}{l}\text { Sweet prickly pear } \\
\text { (English) }\end{array}$ & Cactaceae & Leaf & $\begin{array}{l}\text { Extracted with } \\
\text { multiple solvents } \\
\text { of varying } \\
\text { polarity }\end{array}$ & $\begin{array}{l}\text { MIC of } 2000 \mu \mathrm{g} / \mathrm{mL} \\
\text { against } T \text {. } \\
\text { mentagrophytes }\end{array}$ & $\begin{array}{l}\text { Mabona et al., } \\
2013\end{array}$ \\
\hline $\begin{array}{l}\text { Ozoroa engleri } \\
\text { R.Fern \& A.Fern }\end{array}$ & Unknown & Anacardiaceae & $\begin{array}{l}\text { Bark and } \\
\text { leaves }\end{array}$ & $\begin{array}{l}\text { Aqueous and } \\
\text { methanolic } \\
\text { extracts }\end{array}$ & $\begin{array}{l}\text { MICs of } 890,190, \\
500 \mu \mathrm{g} / \mathrm{mL} \text { for the } \\
\text { bark extracts against } \\
\text { T. mentagrophytes, } \\
\text { M. canis and } \\
\text { C. albicans } \\
\text { respectively }\end{array}$ & $\begin{array}{l}\text { Nciki et al., } \\
2016\end{array}$ \\
\hline $\begin{array}{l}\text { Parinari capensis } \\
\text { Harv. subsp. } \\
\text { capensis }\end{array}$ & $\begin{array}{l}\text { Sand apple, dwarf mobola } \\
\text { plum (English), bosappel, } \\
\text { gruisappeltjie (Arikaans) }\end{array}$ & Chrysobalanaceae & Roots & $\begin{array}{l}\text { Aqueous and } \\
\text { methanolic } \\
\text { extracts }\end{array}$ & $\begin{array}{l}\text { MICs of } 660,60, \\
380 \mu \mathrm{g} / \mathrm{mL} \text { for the } \\
\text { bark extracts against } \\
\text { T. mentagrophytes, } \\
\text { M. canis and } \\
\text { C. albicans } \\
\text { respectively }\end{array}$ & $\begin{array}{l}\text { Nciki et al., } \\
2016\end{array}$ \\
\hline $\begin{array}{l}\text { Pellaea } \\
\text { calomelanos } \\
\text { Link. }\end{array}$ & $\begin{array}{l}\text { Hard fern (English), } \\
\text { lehorometso (Sotho), } \\
\text { inkomankoma (Zulu) }\end{array}$ & Adiantaceae & Leaf & $\begin{array}{l}\text { Extracted with } \\
\text { multiple solvents } \\
\text { of varying } \\
\text { polarity }\end{array}$ & $\begin{array}{l}\text { MICs of } 1000,2000 \\
\text { and } 500 \mu \mathrm{g} / \mathrm{mL} \\
\text { against } \\
\text { T. mentagrophytes, } \\
\text { M. canis and } \\
\text { C. albicans } \\
\text { respectively }\end{array}$ & $\begin{array}{l}\text { Mabona et al., } \\
2013\end{array}$ \\
\hline $\begin{array}{l}\text { Pentanasia } \\
\text { pruinelloides } \\
\text { Walp. }\end{array}$ & $\begin{array}{l}\text { Wild verbena (English), } \\
\text { sooibrandbossie } \\
\text { (Afrikaans), setimamollo } \\
\text { (Sotho), icimamlilo (Zulu) }\end{array}$ & Rubiaceae & $\begin{array}{l}\text { Rhizomes, } \\
\text { root bark }\end{array}$ & $\begin{array}{l}\text { Extracted with } \\
\text { multiple solvents } \\
\text { of varying } \\
\text { polarity }\end{array}$ & $\begin{array}{l}\text { MICs of } 2000 \\
\mu \mathrm{g} / \mathrm{mL} \text { against both } \\
T . \text { mentagrophytes } \\
\text { and } M . \text { canis }\end{array}$ & $\begin{array}{l}\text { Mabona et al., } \\
2013\end{array}$ \\
\hline
\end{tabular}




\begin{tabular}{|c|c|c|c|c|c|c|}
\hline $\begin{array}{l}\text { Pittosporum } \\
\text { viridiflorum } \mathrm{Sm} .\end{array}$ & $\begin{array}{l}\text { Cheesewood (English), } \\
\text { kasuur (Afrikaans), } \\
\text { kgalagangwe (Northern } \\
\text { Sotho), umkhwenkhwe } \\
\text { (Zhosa, Zulu), umfusamvu } \\
\text { (Zulu) }\end{array}$ & Pittosporaceae & Leaf & $\begin{array}{l}\text { Extracted with } \\
\text { multiple solvents } \\
\text { of varying } \\
\text { polarity }\end{array}$ & $\begin{array}{l}\text { MICs of } 500,1000 \\
\text { and } 2000 \mu \mathrm{g} / \mathrm{mL} \\
\text { against } \\
\text { T. mentagrophytes, } \\
\text { M. canis and } \\
\text { C. albicans } \\
\text { respectively }\end{array}$ & $\begin{array}{l}\text { Mabona et al., } \\
2013\end{array}$ \\
\hline $\begin{array}{l}\text { Polygala } \\
\text { myrtifolia L. }\end{array}$ & $\begin{array}{l}\text { September bush (English), } \\
\text { septemberbossie, } \\
\text { blouertjie, langelede } \\
\text { (Afrikaans), ulopesi, } \\
\text { umabalabala (Xhosa), } \\
\text { uchwasha (Zulu) }\end{array}$ & Polygalaceae & Leaf & $\begin{array}{l}\text { Extracted with } \\
\text { multiple solvents } \\
\text { of varying } \\
\text { polarity }\end{array}$ & $\begin{array}{l}\text { Moderate activity } \\
\text { MIC } 1560 \mu \mathrm{g} / \mathrm{mL}\end{array}$ & $\begin{array}{l}\text { Motsei et al., } \\
2003\end{array}$ \\
\hline $\begin{array}{l}\text { Portulacaria afra } \\
\text { Jacq. }\end{array}$ & $\begin{array}{l}\text { Elephant bush, dwarf jade } \\
\text { planr, porkbush (English), } \\
\text { spekboom (Afrikaans), } \\
\text { isicococo (Zulu), } \\
\text { iGqwanitsha (Xhosa) }\end{array}$ & Portulacaceae & Leaf & $\begin{array}{l}\text { Aqueous and } \\
\text { methanolic } \\
\text { extracts }\end{array}$ & $\begin{array}{l}\text { MICs of } 1940,250, \\
190 \mu \mathrm{g} / \mathrm{mL} \text { for the } \\
\text { bark extracts against } \\
\text { T. mentagrophytes, } \\
\text { M. canis and C. } \\
\text { albicans respectively }\end{array}$ & $\begin{array}{l}\text { Nciki et al., } \\
2016\end{array}$ \\
\hline $\begin{array}{l}\text { Plumbago } \\
\text { auriculata Lam. }\end{array}$ & $\begin{array}{l}\text { Cape leadwort, plumbago } \\
\text { (English), blousysebos } \\
\text { (Afrikaans), umabophe } \\
\text { (Xhosa, Zulu), } \\
\text { umasheleshele (Zulu) }\end{array}$ & Plumbaginaceae & Leaf & $\begin{array}{l}\text { Extracted with } \\
\text { multiple solvents } \\
\text { of varying } \\
\text { polarity }\end{array}$ & $\begin{array}{l}\text { Low activity. MIC } \\
>10000 \mu \mathrm{g} / \mathrm{mL} \text { for } \\
\text { all extracts }\end{array}$ & $\begin{array}{l}\text { Motsei et al., } \\
2003\end{array}$ \\
\hline $\begin{array}{l}\text { Ranunculus } \\
\text { multifidus Forssk. }\end{array}$ & $\begin{array}{l}\text { Common buttercup } \\
\text { (English), botterblom } \\
\text { (Afrikaans), hlapi (Sotho), } \\
\text { isijojkazane, uxhaphozi } \\
\text { (Zulu) }\end{array}$ & Ranunculaceae & $\begin{array}{l}\text { Whole } \\
\text { plant }\end{array}$ & $\begin{array}{l}\text { Aqueous and } \\
\text { methanolic } \\
\text { extracts }\end{array}$ & $\begin{array}{l}\text { MICs of } 1710,130, \\
250 \mu \mathrm{g} / \mathrm{mL} \text { for the } \\
\text { bark extracts against } \\
\text { T. mentagrophytes, } \\
\text { M. canis and } \\
\text { C. albicans } \\
\text { respectively. }\end{array}$ & $\begin{array}{l}\text { Nciki et al., } \\
2016\end{array}$ \\
\hline
\end{tabular}




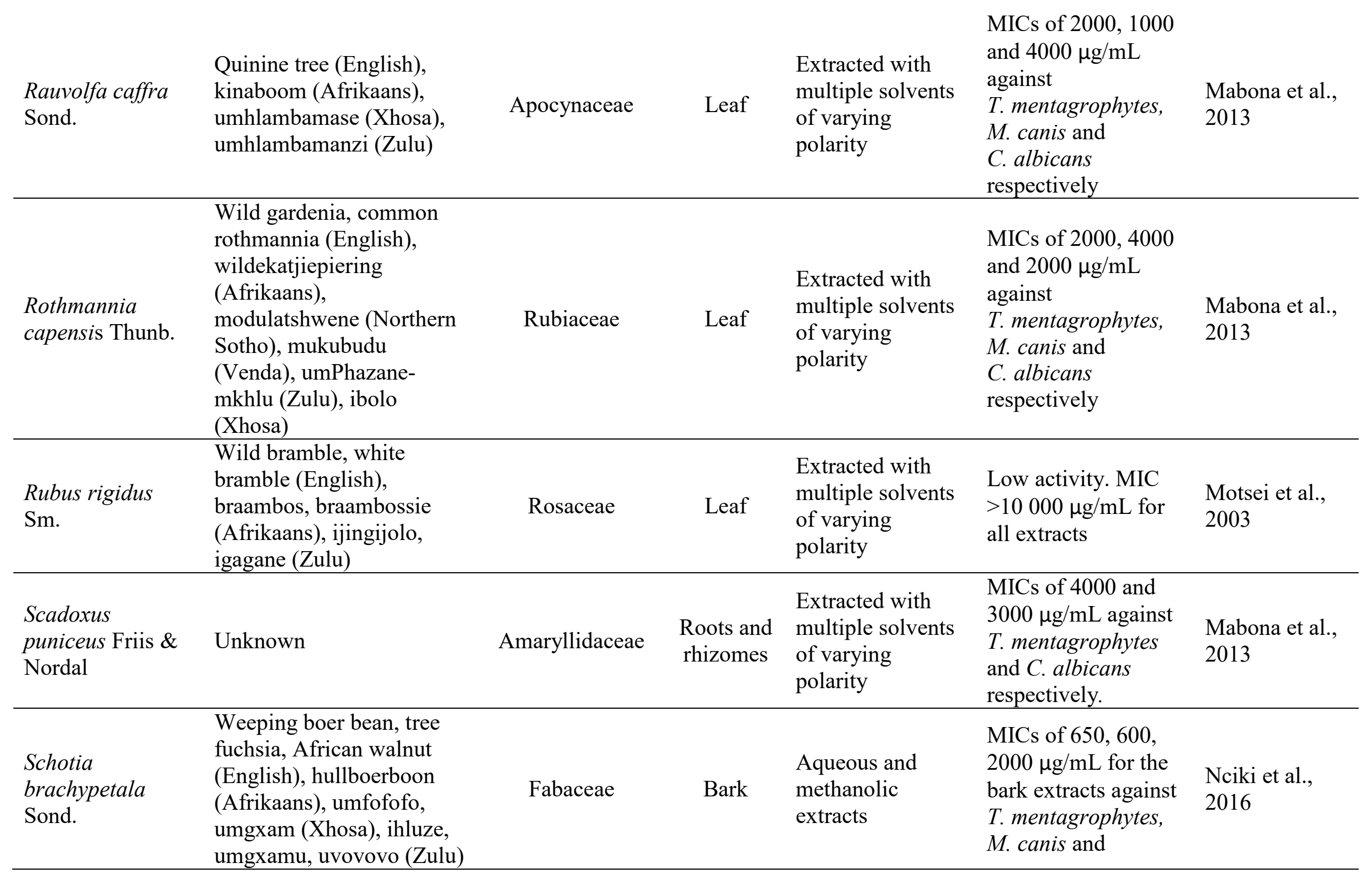




\section{C. albicans}

respectively

\begin{tabular}{|c|c|c|c|c|c|c|}
\hline $\begin{array}{l}\text { Sclerocarya } \\
\text { birrea (A. Rich.) } \\
\text { Hotsch. }\end{array}$ & $\begin{array}{l}\text { Marula (English), morula } \\
\text { (Northern Sotho) }\end{array}$ & Anacardiaceae & Bark & $\begin{array}{l}\text { Aqueous and } \\
\text { methanolic } \\
\text { extracts }\end{array}$ & $\begin{array}{l}\text { MICs of } 370,380, \\
190 \mu \mathrm{g} / \mathrm{mL} \text { for the } \\
\text { bark extracts against } \\
\text { T. mentagrophytes, } \\
\text { M. canis and } \\
\text { C. albicans } \\
\text { respectively }\end{array}$ & $\begin{array}{l}\text { Nciki et al., } \\
2016\end{array}$ \\
\hline $\begin{array}{l}\text { Senecio } \\
\text { serratuloides DC. }\end{array}$ & $\begin{array}{l}\text { Two-day cure (English), } \\
\text { ichazampukane, } \\
\text { insukumbili (Zulu) }\end{array}$ & Asteraceae & Leaf & $\begin{array}{l}\text { Extracted with } \\
\text { multiple solvents } \\
\text { of varying } \\
\text { polarity }\end{array}$ & $\begin{array}{l}\text { MICs of } 1280,380 \\
\text { and } 1000 \mu \mathrm{g} / \mathrm{mL} \\
\text { against } \\
\text { T. mentagrophytes, } \\
\text { M. canis and } \\
\text { C. albicans } \\
\text { respectively }\end{array}$ & $\begin{array}{l}\text { Mabona et al., } \\
2013\end{array}$ \\
\hline $\begin{array}{l}\text { Siphonocilus } \\
\text { aethiopicus } \\
\text { (Schweif.) B.L. } \\
\text { Burt }\end{array}$ & $\begin{array}{l}\text { Natal ginger, wild ginger } \\
\text { (English), wildegemmer } \\
\text { (Afrikaans), indungulo, } \\
\text { isiphephetho (Zulu) }\end{array}$ & Zingiberaceae & Bulb & $\begin{array}{l}\text { Extracted with } \\
\text { multiple solvents } \\
\text { of varying } \\
\text { polarity }\end{array}$ & $\begin{array}{l}\text { Low activity. MIC } \\
>10000 \mu \mathrm{g} / \mathrm{mL} \text { for } \\
\text { all extracts }\end{array}$ & $\begin{array}{l}\text { Motsei et al., } \\
2003\end{array}$ \\
\hline $\begin{array}{l}\text { Solanun incanum } \\
\text { L. }\end{array}$ & $\begin{array}{l}\text { Bark weed, bitter apple, } \\
\text { thorn apple (English) }\end{array}$ & Solonaceae & Leaf & $\begin{array}{l}\text { Extracted with } \\
\text { multiple solvents } \\
\text { of varying } \\
\text { polarity }\end{array}$ & $\begin{array}{l}\text { MICs of } 1000,2000 \\
\text { and } 2000 \mu \mathrm{g} / \mathrm{mL} \\
\text { against } \\
\text { T. mentagrophytes, } \\
\text { M. canis and } \\
\text { C. albicans } \\
\text { respectively }\end{array}$ & $\begin{array}{l}\text { Mabona et al., } \\
2013\end{array}$ \\
\hline
\end{tabular}


Appleof Sodom, bitter

Solanum apple, poison apple

panduriforme E. (English), bitterappel, Mey.

geelappel, gifappel

(Afrikaans), intuma,

intumemncane (Zulu)

\begin{tabular}{|c|c|c|c|c|}
\hline $\begin{array}{l}\text { Solanum } \\
\text { rigescens Jacq. }\end{array}$ & Unknown & Solonaceae & Fruit & $\begin{array}{l}\text { Aqueous and } \\
\text { methanolic } \\
\text { extracts }\end{array}$ \\
\hline
\end{tabular}

\begin{tabular}{|c|c|c|c|c|c|c|}
\hline & & & & & respectively & \\
\hline $\begin{array}{l}\text { Strychnos } \\
\text { madagascariensis } \\
\text { Poir }\end{array}$ & $\begin{array}{l}\text { Black monkey orange } \\
\text { (English), swartklapper, } \\
\text { botterklapper (Afrikaans), } \\
\text { nkwaka (Tsonga), } \\
\text { mukwakwa(Venda), } \\
\text { umGluguza, umKwakwa } \\
\text { (Zulu) }\end{array}$ & Strychnaceae & $\begin{array}{c}\text { Bark and } \\
\text { leaves }\end{array}$ & $\begin{array}{l}\text { Aqueous and } \\
\text { methanolic } \\
\text { extracts were } \\
\text { tested. }\end{array}$ & $\begin{array}{l}\text { MICs of } 130,1000, \\
250 \mu \mathrm{g} / \mathrm{mL} \text { for the } \\
\text { bark extracts against } \\
\text { T. mentagrophytes, } \\
\text { M. canis and } \\
\text { C. albicans } \\
\text { respectively }\end{array}$ & $\begin{array}{l}\text { Nciki et al., } \\
2016\end{array}$ \\
\hline $\begin{array}{l}\text { Strychnos spinosa } \\
\text { Lam. }\end{array}$ & Unknown & Strychnaceae & Fruit & $\begin{array}{l}\text { Aqueous and } \\
\text { methanolic } \\
\text { extracts were } \\
\text { tested. }\end{array}$ & $\begin{array}{l}\text { MICs of } 250,500, \\
500 \mu \mathrm{g} / \mathrm{mL} \text { against } \\
\text { T. mentagrophytes, } \\
\text { M. canis and } \\
\text { C. albicans } \\
\text { respectively }\end{array}$ & $\begin{array}{l}\text { Nciki et al., } \\
2016\end{array}$ \\
\hline $\begin{array}{l}\text { Syzygium } \\
\text { cordatum Hochst. } \\
\text { ex C. Krauss }\end{array}$ & $\begin{array}{l}\text { Waterberry (English), } \\
\text { waterbessie, waterboom, } \\
\text { waterhout (Afrikaans), } \\
\text { umdoni (Zulu), umswi, } \\
\text { umjomi (Xhosa), mawthoo } \\
\text { (Sotho), mutu (Venda) }\end{array}$ & Myrtaceae & Bark & $\begin{array}{l}\text { Aqueous and } \\
\text { methanolic } \\
\text { extracts }\end{array}$ & $\begin{array}{l}\text { MICs of } 370,380, \\
190 \mu \mathrm{g} / \mathrm{mL} \text { for the } \\
\text { bark extracts against } \\
\text { T. mentagrophytes, } \\
\text { M. canis and } \\
\text { C. albicans } \\
\text { respectively }\end{array}$ & $\begin{array}{l}\text { Nciki et al., } \\
2016\end{array}$ \\
\hline
\end{tabular}

MICs of 500 and $1000 \mu \mathrm{g} / \mathrm{mL}$ against

T. mentagrophytes

Nciki et al., and C. albicans

respectively

MICs of 130, 190,

$130 \mu \mathrm{g} / \mathrm{mL}$ against

T. mentagrophytes,

M. canis and

Nciki et al.,

2016

C. canis and

C. albicans

Black monkey orange

English), swartklapper,

nkwaka (Tsonga)

,

methanolic

2016

extracts

ciki et al.,

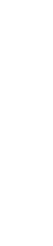

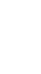


Toad tree

(English),laeveldse

Tabernaemontana elgans Stapf. paddaboom (Afrikaans), umKhahlwana, umKhadu (Zulu)

$\begin{array}{ccl}\text { Apocynaceae } & \begin{array}{c}\text { Fruit and } \\ \text { leaves }\end{array} & \begin{array}{l}\text { Aqueous and } \\ \text { methanolic } \\ \text { extracts }\end{array}\end{array}$

Wildmarigold, stinking roger, tall khaki weed,

Wildmarigold, stinking
roger, tall khaki weed,

Tagetes minuta L. khaki bush (English), kakiebos, Lang kakiebos, stinkbos (Afrikaans)

\begin{tabular}{|c|c|c|c|c|c|c|}
\hline $\begin{array}{l}\text { Terminalia } \\
\text { brachystema } \\
\text { Exell. }\end{array}$ & Unknown & Combretaceae & Leaf & $\begin{array}{l}\text { Extracted with } \\
\text { multiple solvents } \\
\text { of varying } \\
\text { polarity }\end{array}$ & $\begin{array}{l}\text { MICs as low as } 20 \\
\text { and } 160 \mu \mathrm{g} / \mathrm{mL} \\
\text { against } M \text {. canis and } \\
\text { C. albicans } \\
\text { respectively }\end{array}$ & $\begin{array}{l}\text { Mosoko et al., } \\
2005\end{array}$ \\
\hline $\begin{array}{l}\text { Terminalia } \\
\text { gazensis Baker f. }\end{array}$ & $\begin{array}{l}\text { Fringe-leaved cluster leaf, } \\
\text { fringe-leaved terminalia } \\
\text { (English) }\end{array}$ & Combretaceae & Leaf & $\begin{array}{l}\text { Extracted with } \\
\text { multiple solvents } \\
\text { of varying } \\
\text { polarity }\end{array}$ & $\begin{array}{l}\text { MICs as low as } 20 \\
\text { and } 160 \mu \mathrm{g} / \mathrm{mL} \\
\text { against } M \text {. canis and } \\
\text { C. albicans } \\
\text { respectively }\end{array}$ & $\begin{array}{l}\text { Mosoko et al., } \\
2005\end{array}$ \\
\hline $\begin{array}{l}\text { Terminalia mollis } \\
\text { M.A. Lawson }\end{array}$ & $\begin{array}{l}\text { Large-leaved terminalia } \\
\text { (English) }\end{array}$ & Combretaceae & Leaf & $\begin{array}{l}\text { Extracted with } \\
\text { multiple solvents } \\
\text { of varying } \\
\text { polarity }\end{array}$ & $\begin{array}{l}\text { MICs as low as } 20 \\
\text { and } 160 \mu \mathrm{g} / \mathrm{mL} \\
\text { against } M \text {. canis and } \\
\text { C. albicans } \\
\text { respectively }\end{array}$ & $\begin{array}{l}\text { Mosoko et al., } \\
2005\end{array}$ \\
\hline $\begin{array}{l}\text { Terminalia } \\
\text { phanerophlebia } \\
\text { Engl. \& Diels }\end{array}$ & $\begin{array}{l}\text { Lebombo cluster-leaf } \\
\text { (English), } \\
\text { lebombotrosblaar } \\
\text { (Afrikaans), amaNgwe- }\end{array}$ & Combretaceae & Leaf & $\begin{array}{l}\text { Extracted with } \\
\text { multiple solvents } \\
\text { of varying } \\
\text { polarity }\end{array}$ & $\begin{array}{l}\text { MICs as low as } 880 \\
\text { and } 490 \mu \mathrm{g} / \mathrm{mL} \\
\text { against } M \text {. canis and } \\
\text { C. albicans } \\
\text { respectively }\end{array}$ & $\begin{array}{l}\text { Shai et } \\
\text { al.,2008 }\end{array}$ \\
\hline
\end{tabular}
$750 \mu \mathrm{g} / \mathrm{mL}$ for the leaf extracts against T. mentagrophytes, M. canis and

Nciki et al., 2016

C. albicans respectively

\section{Extracted with} multiple solvents of varying polarity

Low activity. MIC $>10000 \mu \mathrm{g} / \mathrm{mL}$ for all

Motsei et al. 2003

MICs of 130, 130, 
amnyama, amaNgwe-

omphofu (Zulu)

\begin{tabular}{|c|c|c|c|c|c|c|}
\hline $\begin{array}{l}\text { Terminalia } \\
\text { pruinoides } \\
\text { M.A.Lawson }\end{array}$ & $\begin{array}{l}\text { Purple pod terminalia } \\
\text { (English) }\end{array}$ & Combretaceae & Leaf & $\begin{array}{l}\text { Extracted with } \\
\text { multiple solvents } \\
\text { of varying } \\
\text { polarity }\end{array}$ & $\begin{array}{l}\text { MICs as low as } 20 \\
\text { and } 160 \mu \mathrm{g} / \mathrm{mL} \\
\text { against } M . \text { canis and } \\
\text { C. albicans } \\
\text { respectively }\end{array}$ & $\begin{array}{l}\text { Mosoko et al., } \\
2005\end{array}$ \\
\hline $\begin{array}{l}\text { Terminalia } \\
\text { sambesiaca Engl. } \\
\text { \& Diels }\end{array}$ & $\begin{array}{l}\text { River cluster-leaf, river } \\
\text { terminalia (English) }\end{array}$ & Combretaceae & Leaf & $\begin{array}{l}\text { Extracted with } \\
\text { multiple solvents } \\
\text { of varying } \\
\text { polarity }\end{array}$ & $\begin{array}{l}\text { Inactive against both } \\
\text { fungal species }\end{array}$ & $\begin{array}{l}\text { Masoko et al., } \\
\text { 2005; Shai et } \\
\text { al.,2008. }\end{array}$ \\
\hline $\begin{array}{l}\text { Terminalia } \\
\text { sericea } \text { Burch. ex } \\
\text { DC }\end{array}$ & $\begin{array}{l}\text { Silver terminalia, silver } \\
\text { cluster-leaf, (English), } \\
\text { vaalboom (Afrikaans), } \\
\text { mususu (Venda), } \\
\text { mogonono (Tswana), } \\
\text { amangwe (Zulu) }\end{array}$ & Combretaceae & Leaf & $\begin{array}{l}\text { Extracted with } \\
\text { multiple solvents } \\
\text { of varying } \\
\text { polarity }\end{array}$ & $\begin{array}{l}\text { MICs as low as } 40, \\
130,130 \text { and } 160 \\
\mu \mathrm{g} / \mathrm{mL} \text { against } \\
\text { M. canis, } \\
T . \text { mentagrophytes, } \\
\text { T. rubrum and } \\
\text { C. albicans } \\
\text { respectively }\end{array}$ & $\begin{array}{l}\text { Nciki et al., } \\
\text { 2016; Mabona } \\
\text { et al., 2013; } \\
\text { Mosoko et al., } \\
2005\end{array}$ \\
\hline $\begin{array}{l}\text { Tetradenia } \\
\text { riparia (Hochst.) } \\
\text { Codd. }\end{array}$ & $\begin{array}{l}\text { Misty plume bush, ginger } \\
\text { bush (English), } \\
\text { gemmerbos, watersalie } \\
\text { (Afrikaans), iboza, ibozane } \\
\text { (Zulu) }\end{array}$ & Lamiaceae & $\begin{array}{l}\text { Stems, } \\
\text { leaves }\end{array}$ & $\begin{array}{l}\text { Extracted with } \\
\text { multiple solvents } \\
\text { of varying } \\
\text { polarity }\end{array}$ & $\begin{array}{l}\text { MICs } 310-2500 \\
\mu \mathrm{g} / \mathrm{mL} \text { against } \\
\text { T. mentagrophytes, } \\
\text { M. canis and } \\
\text { C. albicans }\end{array}$ & $\begin{array}{l}\text { Ghuman et al., } \\
2016\end{array}$ \\
\hline $\begin{array}{l}\text { Trichilia emetica } \\
\text { Vahl }\end{array}$ & $\begin{array}{l}\text { Natal mahogony (English), } \\
\text { rooissenhout (Afrikaans), } \\
\text { mamba (Northern Sotho), } \\
\text { umkhuhlu (Xhosa), }\end{array}$ & Meliaceae & Leaf & $\begin{array}{l}\text { Extracted with } \\
\text { multiple solvents } \\
\text { of varying } \\
\text { polarity }\end{array}$ & $\begin{array}{l}\text { MIC of } 880 \mu \mathrm{g} / \mathrm{mL} \\
\text { against } C . \text { albicans. } \\
\text { Inactive against } \\
\text { M. cani. }\end{array}$ & $\begin{array}{l}\text { Mabona et al., } \\
\text { 2013; Shai et } \\
\text { al.,2008 }\end{array}$ \\
\hline
\end{tabular}


umathunzini (Zulu),

mutuhu (Venda)

\begin{tabular}{|c|c|c|c|c|c|c|}
\hline $\begin{array}{l}\text { Tulbaghia } \\
\text { violaceae Harv. }\end{array}$ & $\begin{array}{l}\text { Wild garlic, society garlic } \\
\text { (English), wildeknoffel, } \\
\text { wildeknoflok (Afrikaans), } \\
\text { utswelane (Xhosa), } \\
\text { isihaqa, incisini (Zulu) }\end{array}$ & Alliaceae & Leaf & $\begin{array}{l}\text { Extracted with } \\
\text { multiple solvents } \\
\text { of varying } \\
\text { polarity }\end{array}$ & $\begin{array}{l}\text { Moderate to poor } \\
\text { activity. MIC } 3250 \\
\mu \text { gmL }\end{array}$ & $\begin{array}{l}\text { Motsei et al., } \\
2003\end{array}$ \\
\hline $\begin{array}{l}\text { Vepris reflexa I. } \\
\text { Verd }\end{array}$ & Unknown & Rutaceae & Leaf & $\begin{array}{l}\text { Extracted with } \\
\text { multiple solvents } \\
\text { of varying } \\
\text { polarity }\end{array}$ & $\begin{array}{l}\text { MIC of } 880 \mu \mathrm{g} / \mathrm{mL} \\
\text { against } C \text {. albicans. } \\
\text { Inactive against } \\
\text { M. canis }\end{array}$ & $\begin{array}{l}\text { Shai et } \\
\text { al.,2008 }\end{array}$ \\
\hline $\begin{array}{l}\text { Vernonia } \\
\text { natalensis Sch. } \\
\text { Bip. ex Walp. }\end{array}$ & $\begin{array}{l}\text { Silver vernonia (English), } \\
\text { ihlambihloshana, ileleva } \\
\text { (Zulu) }\end{array}$ & Asteraceae & Leaf & $\begin{array}{l}\text { Extracted with } \\
\text { multiple solvents } \\
\text { of varying } \\
\text { polarity }\end{array}$ & $\begin{array}{l}\text { MICs of } 1000,4000 \\
\text { and } 4000 \mu \mathrm{g} / \mathrm{mL} \\
\text { against } \\
\text { T. mentagrophytes, } \\
\text { M. canis and } \\
\text { C. albicans } \\
\text { respectively }\end{array}$ & $\begin{array}{l}\text { Mabona et al., } \\
2013\end{array}$ \\
\hline $\begin{array}{l}\text { Vertiveria } \\
\text { zizaniodes (Linn) } \\
\text { Nash }\end{array}$ & Vertiver grass (English) & Poaceae & Leaf & $\begin{array}{l}\text { Extracted with } \\
\text { multiple solvents } \\
\text { of varying } \\
\text { polarity }\end{array}$ & $\begin{array}{l}\text { Moderate activity. } \\
\text { MIC } 3250 \mu \mathrm{g} / \mathrm{mL}\end{array}$ & $\begin{array}{l}\text { Motsei et al., } \\
2003\end{array}$ \\
\hline $\begin{array}{l}\text { Viscum capense } \\
\text { L.f. }\end{array}$ & $\begin{array}{l}\text { Cape mistletoe (English), } \\
\text { lidliestee, voelent } \\
\text { (Afrikaans) }\end{array}$ & Santalaceae & $\begin{array}{c}\text { Roots and } \\
\text { leaves }\end{array}$ & $\begin{array}{l}\text { Extracted with } \\
\text { multiple solvents } \\
\text { of varying } \\
\text { polarity }\end{array}$ & $\begin{array}{l}\text { MICs of } 1000,1000 \\
\text { and } 4000 \mu \mathrm{g} / \mathrm{mL} \\
\text { against } \\
\text { T. mentagrophytes, } \\
\text { M. canis and }\end{array}$ & $\begin{array}{l}\text { Mabona et al., } \\
2013\end{array}$ \\
\hline
\end{tabular}


C. albicans

respectively

\begin{tabular}{|c|c|c|c|c|c|c|}
\hline $\begin{array}{l}\text { Waltheria indica } \\
\text { L. }\end{array}$ & $\begin{array}{l}\text { Meidebossie (Afrikaans), } \\
\text { mokhuteseia (Pedi) }\end{array}$ & Malvaceae & Roots & $\begin{array}{l}\text { Aqueous and } \\
\text { methanolic } \\
\text { extracts }\end{array}$ & $\begin{array}{l}\text { MICs of } 250 \mu \mathrm{g} / \mathrm{mL} \\
\text { against } \\
\text { T. mentagrophyte. }\end{array}$ & $\begin{array}{l}\text { Nciki et al., } \\
2016\end{array}$ \\
\hline $\begin{array}{l}\text { Warbargia } \\
\text { salutaris (Bertol.) } \\
\text { Chlov }\end{array}$ & $\begin{array}{l}\text { Pepper-bark tree (English), } \\
\text { peperbasboom } \\
\text { (Afrikaans), isibhaha } \\
\text { (Zulu), manaka (Venda), } \\
\text { shibaha (Tsonga) }\end{array}$ & Canellaceae & $\begin{array}{l}\text { Bark and } \\
\text { leaves }\end{array}$ & $\begin{array}{l}\text { Extracted with } \\
\text { multiple solvents } \\
\text { of varying } \\
\text { polarity }\end{array}$ & $\begin{array}{l}\text { Low activity. MIC } \\
6250 \mu \mathrm{g} / \mathrm{mL} \text { for the } \\
\text { bark extracts, }>10 \\
000 \mu \mathrm{g} / \mathrm{mL} \text { for the } \\
\text { leaf extracts }\end{array}$ & $\begin{array}{l}\text { Mabona et al., } \\
\text { 2013; Motsei } \\
\text { et al., } 2003\end{array}$ \\
\hline $\begin{array}{l}\text { Withania } \\
\text { somnifera (L.) } \\
\text { Dunal }\end{array}$ & $\begin{array}{l}\text { Indian ginseng, poison } \\
\text { gooseberry, winter cherry } \\
\text { (English), bitterappelliefie, } \\
\text { koorshout (Afrikaans), } \\
\text { ubuvuma (Xhosa), } \\
\text { ubuvimbha (Zulu) }\end{array}$ & Solonaceae & Roots & $\begin{array}{l}\text { Aqueous and } \\
\text { methanolic } \\
\text { extracts }\end{array}$ & $\begin{array}{l}\text { MICs of } 250,500, \\
2000 \mu \mathrm{g} / \mathrm{mL} \text { against } \\
\text { T. mentagrophytes, } \\
\text { M. canis and } \\
\text { C. albicans } \\
\text { respectively }\end{array}$ & $\begin{array}{l}\text { Nciki et al., } \\
2016\end{array}$ \\
\hline $\begin{array}{l}\text { Ximenia caffra } \\
\text { Sond. }\end{array}$ & $\begin{array}{l}\text { Large sourplum (English), } \\
\text { groot suurpruim } \\
\text { (Afrikaans), } \\
\text { unThunduluka-obmvu } \\
\text { (Zulu) }\end{array}$ & Olacaceae & Twigs & $\begin{array}{l}\text { Aqueous and } \\
\text { methanolic } \\
\text { extracts }\end{array}$ & $\begin{array}{l}\text { MICs of 130, 750, } \\
500 \mu \mathrm{g} / \mathrm{mL} \text { against } T \text {. } \\
\text { mentagrophytes, } M . \\
\text { canis and } \\
\text { C. albicans } \\
\text { respectively }\end{array}$ & $\begin{array}{l}\text { Nciki et al., } \\
2016\end{array}$ \\
\hline
\end{tabular}




\begin{tabular}{|c|c|c|c|c|}
\hline $\begin{array}{l}\text { Zantedeschia } \\
\text { aethiopica (L.) } \\
\text { Spreng. }\end{array}$ & $\begin{array}{l}\text { Whitecommon arum lily } \\
\text { (English), wit varkoor } \\
\text { (Afrikaans), intebe } \\
\text { (Xhosa), ihlukwe (Zulu) }\end{array}$ & Araceae & Leaf & $\begin{array}{l}\text { Extracted with } \\
\text { multiple solvents } \\
\text { of varying } \\
\text { polarity }\end{array}$ \\
\hline
\end{tabular}

Conflicting reports

of efficacy. MICs

against

T. mentagrophytes,

T. rubrum and

C. albicans of 630-

$1250 \mu \mathrm{g} / \mathrm{mL}$

reported by Ghuman

et al., 2016. Low

activity reported in

the Mabona et al.,

2013 and Motsei et

al., 2003 studies

(MIC > 10000

$\mu \mathrm{g} / \mathrm{mL}$ for all

extracts)

Conflicting reports

of efficacy. MICs

against

Small knob-wood, lemon

thorn, wild cardamon

(English), kleinperdepram,

Zanthyxylum parapis, prambos,

knopdoring (Afrikaans),

Rutaceae

Extracted with

capense (Thunb.)

amaBelentombi,

multiple solvents

Harv.

umNungumabele (Zulu),

arying

polarity

T. mentagrophytes,

T. rubrum and

C. albicans of 130-

$500 \mu \mathrm{g} / \mathrm{mL}$ reported

by Nciki etal, 2016 .

Low activity

reported in the

Mabona et al., 2013

and Motsei et al.,

2003 studies (MIC

$>10000 \mu \mathrm{g} / \mathrm{mL}$ for

all extracts)

Ghuman et al., 2016; Mabona

et al., 2013;

Motsei et al.,

2003

umLungumabele(Xhosa) 
Buffalo-thorn (English), blinkblaar-wag-n-bietjie

\section{Ziziphus}

murconata Willd. (Northern Sotho, Tswana),

umphafa (Xhosa, Zulu),

umlahlankosi (Zulu)
Conflicting reports

of efficacy. MICs

against

T. mentagrophytes,

T. rubrum and

C. albicans of $130-$

Extracted with

multiple solvents

of varying

polarity
$500 \mu \mathrm{g} / \mathrm{mL}$ reported

by Nciki et al., 2016 .

MIC's of 2000,2

000 and 4000

$\mu \mathrm{g} / \mathrm{mL}$ against

T. mentagrophytes,

M. canis and

C. albicans

respectively 
There are no records of therapeutic use to treat dermatophytosis for the other 121 plant species that have been screened for anti-dermaphytic activity. Plant species were additionally screened based on alternative criteria other than ethnobotanical, including their genus/family. For example, twenty-four Combretum species (Masoko et al., 2007) and seven Terminalia species (Masoko et al., 2005) were screened in two separate studies by the same group. The selection of these species coincides with that group's interest in plants of the family Combretaceae, rather than on their traditional use to treat fungal skin diseases. However, Combretum (de Morais Lima et al., 1012) and Terminalia (Cock, 2015b) species from other global regions have good antifungal activity and therefore these species are good candidates for further testing. Regardless of the reason for selecting those species, their inclusion in those studies was fortuitous as most of the species were potent inhibitors of M. canis and C. albicans. Indeed, MIC values of 20-80 $\mu \mathrm{g} / \mathrm{mL}$ were achieved by various Combretum and Terminalia spp. against $M$. canis. Extracts prepared from the same species were also good inhibitors of $C$. albicans growth, albeit generally with MIC values an order of magnitude higher than noted against M. canis (Masoko et al., 2005). With the exception of T. sericea (MIC $130 \mu \mathrm{g} / \mathrm{mL}$ ), these plants were not tested against T. mentagrophytes and further testing is required to test the efficacy of these extracts against this pathogen.

Four Aloe species (A. ferox, A. maculata, A. microstigma, A. vera) are used traditionally to treat fungal skin infections. A. ferox has been screened for inhibitory activity against $T$. mentagrophytes, T. rubrum and C. albicans (MIC 310-630 $\mu \mathrm{g} / \mathrm{mL}$ against all fungi) (Ghuman et al., 2016). Aloe vera, has only had some international recognition with respect to antifungal activity. A recent study has been undertaken on C. albicans biofilms (Nazar and Meidyawati, 2019) but until recently more attention has been given to other fungal pathogens not related to human skin dematophytes (Rosca-Casian et al., 2007). Aloe maculata has been neglected 
completely. Further studies are required to test the other three traditionally used Aloe species against these fungi. Interestingly, three other Aloe species (A. arborescens, A. excels, $A$. barbare) have been screened against the dermatophytes and have displayed good inhibition (MICs 200-800 g/mL) (Ndhlala et al., 2009; Ghuman et al., 2016; Mabona et al., 2013; Naidoo and Coopoosamy, 2011). Presumably these species were also selected for screening on the basis of their taxonomic relationship to the traditionally used Aloe species. Whilst it is unclear why the other plant species were selected for screening against the dermatophytes, it is likely that many were randomly selected. Table 2 summarises studies that have screened on southern African plant species against fungal skin pathogens.

The following introduced plant species were good inhibitors of dermatophyte growth: Allium sativum (MIC value $560 \mu \mathrm{g} / \mathrm{mL}$ against C. albicans), Citrus limon (MIC value $<10$ $\mu \mathrm{g} / \mathrm{mL}$ against $C$. albicans) and Withania somnifera (MIC values of 250, 500 and $2000 \mu \mathrm{g} / \mathrm{mL}$ against $T$. mentagrophytes, M. canis and C. albicans respectively). Eucalyptus camaldulensis (MIC values of 1000, 2000 and $500 \mu \mathrm{g} / \mathrm{mL}$ against $T$. mentagrophytes, M. canis and C. albicans respectively) and Glycyrryhiza glabra (MIC values of $1560 \mu \mathrm{g} / \mathrm{mL}$ ) also had moderate inhibitory activity against those dermatophytes.

\subsection{Synergistic antifungal activity of plant combinations}

Traditional plant-based healing systems frequently use combinations of plants to provide effective therapies. This is particularly evident for traditional Asian therapeutic systems, including Indian Ayuverda and traditional Chinese medicine (TCM). Whilst plant monotherapies are more frequently used in most southern African traditional medicine systems, combinations of plants may be used for some disorders to increase the efficacy of the therapy. As well as containing therapeutic compounds, plants may also contain compounds that 
potentiate the effects of the therapy (Cheesman et al., 2017). For example, studies comparing the efficacy of the antimalarial drug artemisinin with Artemesia annua extracts (from which artemisinin is derived) highlights this point. Substantially lower doses of Artemesia annua extracts are required to inhibit Plasmodium falciparum growth compared to an equivalent amount of pure artemesinin (as reviewed by Cock, 2018). Indeed, A. annua extracts contain approximately $20 \%$ of the artemisinin required to produce the same effects, indicating that other extract components may potentiate the activity of artemisinin in the extract. Notably, several A. annua flavonoids have been reported to potentiate the activity of artemisinin, despite being inactive alone (Deharo and Ginsburg 2011). It is surprising that studies examining the effects of combinations of plant extracts, or combinations of extracts and conventional drugs remain under-represented in antifungal drug discovery research and far more combinational studies are required.

Few studies (Mabona et al., 2013; Naidoo et al., 2013) have examined the effects of combinations of southern African medicinal plants against fungal skin pathogens. Those studies screened nearly 65 different plant species traditionally used to treat skin disorders for the ability to inhibit the growth of dermatophytes and $C$. albicans. The majority of the plant species displayed moderate to promising antifungal activity. Three species (D. anolala, E. elephantina, P. pruinelloides) were selected for further combinational studies based on their strong antimicrobial activity and reports of their traditional use as combinations to treat fungal skin infections (Watt and Breyer-Brandwijk, 1962; Hutchings, 1996; Von Koenen, 2001; Van Wyk, 2009). Whilst the majority of the combinations produced no notable benefit over plant monotherapy alone, the combination of $D$. anolala and $P$. pruinelloides extracts was substantially more potent than either therapy alone against $C$. albicans. Unfortunately, the effects of combinations of the extracts were not tested against T. mentagrophytes or M. canis in that study so it is uncertain whether this (or other combinations) have similar synergistic 
effects against these dermatophytes. Further studies are required to evaluate combinations of these plants (and the other plants screened in that study) against these, and other dermatophytes. Furthermore, the toxicity of the extracts (and the combinations) was not examined in that study, so it is not possible to calculate selectivity indices (SI) and further research is required to evaluate the potential of these plant extracts and their combinations therapeutically. However, whilst combinational therapy studies against skin fungi are still in their infancy, the Mabona et al. (2013), study highlights the potential of combinational therapies. Far more studies are needed to test extract/extract combinations, as well as combinations of conventional antifungal drugs with plant extracts. A study on a selection of medicinal plants with commercial potential, in combination with nystatin and amphotericin $\mathrm{B}$, has shown various effective interactions against $C$. albicans (Hübsch et al., 2014). Synergy was observed for the combination of Lippia javanica with nystatin. Synergy was also noted for the combination of Salvia frutescens with amphotericin B. What should also be considered is antagonism, and many more combinations in that study demonstrated antagonistic interations. It is possible that not only may new antifungal combination therapies be discovered, but strategies to counteract fungal antibiotic resistance mechanisms may also be developed, thereby extending the effective life of current antibiotics, and even repurposing some drugs that are no longer effective alone. The author Jin, 2019 has made a significant contribution in the review of natural antifungal flavonoids and their derivatives with special emphasis on synergistic interactions. Works such as that pave the way for future studies to develop.

\section{Discussion and conclusions}

Fungal skin infections are one of the most widespread classes of infectious diseases globally, yet development of new therapies to treat these infections remains relatively 
neglected. Whilst dermatophyte infections cause discomfort, they rarely cause mortality or serious morbidity except in immune-compromised individuals. It is likely that the relative lack of severity of these infections may contribute to the low number of studies into the effects of southern African plants on dermatophytes. Indeed, a large portion of these studies have occurred in the most recent 15-year period. Interestingly, the increase in research in this field coincides with increases in the incidence in these infections, not only in southern Africa, but globally. The global increase in dermatophytosis further correlates with the development of dermatophyte resistance to the commonly used antifungal drugs. Prior to 2000, antibioticresistant dermatophyte strains were rare. However, more recently, resistance to many humaninfective dermatophytes are evident (Khurana et al., 2019) and new antifungal agents are urgently needed.

Whilst this review focused on dermatatophytes such as the Epidermophyton, Microsporum and Trichophyton spp., it must be noted that emerging fungal skin infections caused by other species such as Histoplasma capsulatum, Blastomyces dermatitidis, Cladosporium carrionii, Fonsecaea pedrosoi, Fonsecaea compacta, Phialophora verrucosa and Coccidioides spp. are becoming more prevelant (Zambelli and Griffiths, 2015; Lockhart and Guarner, 2019) and attention should be given to these species as well.

Several studies have already screened some southern African plants for dermatophyte inhibitory activity. Indeed, Table 2 summarises studies screening 140 plant species. Surprisingly, of those 140 species, only 19 species were selected for study on the basis of their traditional usage, despite 89 species being recorded as being used traditionally to treat dermatophytosis. Looking at the low correlation (13\%) between recorded traditional knowledge (Table 1) and what reseach has been done (Table 2), there are many good candidates that are used as therapies for dermatophytosis and are yet to be screened against these pathogens. It seems that much of the existing antifungal data is based on plant availability 
rather than enthnobotanical leads. This is particularly evident when looking at the Combretacaeae family as there is no traditional link with use for infectious dermatitis. Another aspect that requires attention is the correlation to the plant part tested. In some cases the plant part tested correlates with traditional use. However, in some instances for example with $K$. africana, the leaf material was tested, yet traditionally the bark and fruit is used. While it is understandable to forego testing on bark and roots for sustainability reasons, the fruit is readily available and should have been tested. Another example in this respect is $C$. inerme where twigs were tested yet traditionally the leaves are used. Also, with D. anomala, the tuber was tested, yet the stems and leaves are used traditionally. Researchers need to take cognisence that the chemistry between different plant parts is variable and thus might yield completely different biological activity.

It is likely that substantially more species are also used to treat dermatophytosis, although many of the older records are not definitive and often refer to the usage of the plants in generic terms. For example, several books and reviews refer to the use of some plant species to treat skin disorders. Whilst this may indicate that they were used for skin infections, or for some other type of skin condition. Skin infections may encompass dermatophytosis, although it could also refer to bacterial or viral infections. Futhermore, ethnobotanical surveys may reveal more specific roles for some of these plant species and may thereby provide further plant targets for anti-dermatophyte screening in the future.

Even those studies that have screened southern African plants against skin-infective fungi generally did not screen against the most relevant model organisms for a southern African context. Tinea capitis is substantially more prevalent in southern Africa than all other forms of dermatophytosis combined (Coulibaly et al., 2018). Whilst tinea capitis is caused by M. canis, T. rubrum, T. mentagrophytes and Trichophyton tonsurans in most regions of the world (Ameen, 2010), T. violaceum and $M$. audouinii are the main causative dermatophytes in 
southern Africa (Neil et al., 1987; Morar et al., 2004). Despite this, we were unable to find any studies that screened southern African plants against these dermatophytes. Instead, all of the previous studies have screened against dermatophytes which are more relevant to northern hemisphere regions. Screening the plants against M. canis, T. rubrum, T. mentagrophytes is still relevant as these species contribute to the dermatophytosis load in southern Africa. However, susceptibility of these fungi to southern African plant extracts does not necessarily indicate that the plants will also be effective against the dominant southern African dermatophyte species, as different dermatophytes may have substantially different susceptibilities. Future studies are needed to confirm efficacy against $T$. violaceum and $M$. audouinii. Additionally, all of the previous studies have screened against dermatophytes that are susceptible to conventional therapies. Screening against resistant strains has been neglected. As there have been substantial increases in reports of dermatophyte strains that are resistant to conventional therapies in recent years, it is important that southern African plants are also screened against resistant dermatophyte strains.

Almost without exception, the plants species screened for anti-dermatophyte activity were also not tested for toxicity. Perhaps this is because these plants have been used for hundreds of years and are assumed to be safe. However, often the plant is prepared by different methods for bioactivity screening than was employed by traditional medicine practitioners. Different preparation methods will alter the phytochemical profile of the preparations and could thereby also alter their toxicity profiles. Indeed, some studies have reported toxic, carcinogenic and mutagenic effects for extracts prepared from multiple plants traditionally used as medicines (Fennell et al., 2004). Several other studies have also investigated the toxicity of several of the plant species highlighted herein. However, the focus of those studies was solely on evaluation of toxicity of the extracts, or on investigating the safety of the extracts in conjunction with other bioactivities (Fennell et al., 2004; Mapunya et al., 2006; Steenkamp and 
Gouws 2006; Versaeve and Van Staden, 2008). Toxicity evaluations should be run concurrently with anti-dermatophyte studies to allow the safety/selectivity indices to be calculated. This is imperative as the chemotherapeutic value of a plant preparation will be limited if it has substantial toxicity. Of the studies we identified of southern African plants for anti-dermatophyte activity, only a single study (Ghuman et al., 2016) also screened the extracts for toxicity in parallel with the bioactivity screening, and toxicity evaluations of all other plant species are required. Ideally, toxicity screening should incorporate more than one assay to allow for comparisons between studies.

Ethnobotanical records have already identified a number of promising plant species used traditionally for the treatment of dermatophytosis and several of those species (as well as multiple species for which a traditional use against dermatophytes was not recorded) have already been tested against one or more pathogen. Further research is required to screen all identified species (including previously tested species) against $T$. violaceum and M. audouinii (which are particularly relevant in a southern African context), and against resistant dermatophyte strains.

\section{Acknowledgements}

The authors are grateful to the Department of Pharmacy and Pharmacology, University of the Witwatersrand, South Africa and by the Environmental Futures Research Institute, Griffith University, Australia for the support provided to undertake these studies.

\section{References}


Achika, J.I., Arthur, D.E., Gerald, I., Adedayo, A., 2014. A review on the phytoconstituents and related medicinal properties of plants in the Asteraceae family. IOSR-JAC. 7(8), $1-8$

Afolayan, A.J., Grierson, D.S., Mbeng, W.O., 2014. Ethnobotanical survey of medicinal plants used in the management of skin disorders amongst the Xhosa communities of Amathole District, Eastern Cape, South Africa. J. Ethnopharmacol. 153, 220-232.

Ameen, M., 2010. Epidemiology of superficial fungal infections. Clin. Dermatol. 28, 197-201.

Amoo, S.O., Aremu, A.O., Van Staden, J., 2014. Unraveling the medicinal potential of South African Aloe species. J. Ethnopharmacol. 153, 19-41.

Arkhipov, A., Sirdaarta, J., Rayan, P., McDonnell, P.A., Cock, I.E., 2014. An examination of the antibacterial, antifungal, anti-Giardial and anticancer properties of Kigellia africana fruit extracts. Pharmacogn. Commun. 4(3), 62-76.

Asong, J.A., Ndhlovu, P.T., Khosana, N.S., Aremu, A.O., Otang-Mbeng, W., 2019. Medicinal plants used for skin-related among the Batswanas in Ngaka District Municipality, South Africa. S. Afr. J. Bot., DOI: 10.1016/j.sajb.2019.05.002

Berkow, E.L., Lockhart, S.R., 2017. Fluconazole resistance in Candida species: a current perspective. Infect. Drug Resist. 10, 237.

Bessada, S.M., Barreira, J.C., Oliveira, M.B., 2015. Asteraceae species with most prominent bioactivity and their potential applications: A review. Ind. Crop. Prod. 76, 604-615.

Bremer, K., Jansen, R.K., Karis, P.O., Källersjö, M., Keeley, S.C., Kim, K.J., Michaels, H.J., Palmer, J.D., Wallace, R.S., 1992. A review of the phylogeny and classification of the Asteraceae. Nord. J. Bot. 12(2), 141-148. 
Brown, G.D., Denning, D.W., Gow, N.A.R., Levitz, S.M., Netea, M.G., White, T.C., 2012. Med. Mycol. 4(165), 165rv13.

Cheesman, M.J., Ilanko, A., Blonk, B., Cock, I.E., 2017. Developing new antimicrobial therapies: Are synergistic combinations of plant extracts? Compounds with conventional antibiotics the solution? Pharmacog. Rev. 11, 57-72.

Cock, I.E., 2018. Is the pharmaceutical industry's preoccupation with the monotherapy drug model stifling the development of effective new drug therapies? Inflammopharmacol. 26(3), 861-879. DOI: 10.1007/s10787-018-0488-7

Cock, I.E., Selesho, I., VanVuuren, S.F., 2019. A review of the traditional use of South African medicinal plants for the treatment of malaria. J. Ethnopharmacol., DOI: 10.1016/j.jep.2019.112176

Cock, I.E., Selesho, M.I., Van Vuuren, S.F., 2018. A review of the traditional use of southern African medicinal plants for the treatment of selected parasite infections affecting humans. J. Ethnopharmacol. 220, 250-264.

Cock, I.E., 2015a. The genus Aloe: Phytochemistry and therapeutic uses including treatments for gastrointestinal conditions and chronic inflammation. Prog. Drug Res. 70, 179-236.

Cock, I.E., 2015b. The medicinal properties and phytochemistry of plants of the genus Terminalia (Combretaceae). Inflammopharmacol. 23(5), 203-229.

Coulibaly, O., L'Ollivier, C., Piarroux, R., Ranque, S., 2018. Epidemiology of human dermatophytoses in Africa. Med. Mycol. 56, 145-161.

Crowley, P.D., Gallagher, H.C., 2014. Clotrimazole as a pharmaceutical: past, present and future. J. Appl. Microbiol. 117(3), 611-617. 
De Beer, J.J.J., Van Wyk, B.-E., 2011. An ethnobotanical survey of the Agter-Hantam, Northern Cape Province, South Africa. S. Afr. J. Bot. 77, 741-754.

de Morais Lima, G.R., De Sales, I.R., Caldas Filho, M.R., De Jesus, N.Z., de Sousa Falcão, H., Barbosa-Filho, J.M., Cabral, A.G., Souto, A.L., Tavares, J.F., Batista, L.M., 2012. Bioactivities of the genus Combretum (Combretaceae): a review. Molecules. 17(8), 9142-2906.

De Wet, H., Sibongile, N., Van Vuuren, S.F., 2013. Medicinal plants used for the treatment of various skin disorders by a rural community in northern Maputaland, South Africa. J. Ethnobiol. Ethnomed. 9, 51.

De Wet, H., Van Wyk, B.-E., 2008. An ethnobotanical survey of southern African Menispermaceae. S. Afr. J. Bot. 74, 2-9.

Dlova, N.C., Ollengo, M.A., 2018. Traditional and ethnobotanical dermatology practices in Africa. Clin. Dermat. 36(3), 353-362.

Efuntoye, M.O., Fashanu, S.O., 2002. Occurrence of keratinophilic fungi and dermatophytes on domestic birds in Nigeria. Mycopathologia. 153, 87-89.

Fennell, C.W., Lindsey, K.L., McGaw, L.J., Sparg, S.G., Stafford, G.I., Elgorashi, E.E., Grace, O.M., Van Staden, J., 2004. Assessing African medicinal plants for efficacy and safety: pharmacological screening and toxicology. J. Ethnopharmacol. 94, 205-217.

George, A., Bhatia, A., Kanish, B., Williams, A., 2015. Terbinafine induced pityriasis rosealike eruption. Ind. J. Pharmacol. 47(6), 680.

Ghannoum, M., 2016. Azole resistance in dermatophytes: prevalence and mechanism of action. J. Am. Podiatr. Med. Assoc. 106(1), 79-86. 
Ghuman, S., Ncube, B., Finnie, J.F., McGaw, L.J., Coopoosamy, R.M., Van Staden, J. 2016. Antimicrobial activity, phenolic content, and cytotoxicity of medicinal plant extracts used for treating dermatological diseases and wound healing in KwaZulu-Natal, South Africa. Fronteirs Pharmacol. 7, 320.

Ginsburg, H., Deharo, E., 2011. A call for using natural compounds in the development of new antimalarial treatments-an introduction. Malar. J. 10(1), S1.

Havlickova, B., Czaika, V.A., Friedrich, M., 2008. Epidemiological trends in skin mycoses worldwide. Mycoses 51(S4), 2-15.

Hsiao, Y.H., Chen, C., Han, H.S., Kano, R., 2018. The first report of terbinafine resistance Microsporum canis from a cat. J. Vet. Med. Sci., 17-0680.

Hu, Y., Hu, Y., Lu, Y., Huang, S., Liu, K., Han, X., Mao, Z., Wu, Z., Zhou. X., 2017. A case report of penile infection caused by fluconazole-and terbinafine-resistant Candida albicans. Mycopathologia. 182(3-4), 397-402.

Hübsch, Z., van Zyl, R.L., Cock, I., van Vuuren, S.F., 2014. Interactive antimicrobial and toxicity profiles of conventional antimicrobials with southern African medicinal plants. The South African Journal of Botany 93, 185-197.

Hulley, I.M., Van Wyk, B.-E. Quantitative medicinal ethnobotany of Kannaland (western Little Karoo, South Africa): Non-homogeneity amongst villages. S. Afr. J. Bot. 122, 225265.

Hutchings, A., Scott, A.H., Lewis, G., Cunningham, B., 1996. Zulu Medicinal Plants: an inventory, $1^{\text {st }}$ ed. University of Natal Press, Pietermaritzburg.

Jaiswal, B.S., 2012. Solanum torvum: a review of its traditional uses, phytochemistry and pharmacology. Int. J. Pharma Bio Sci. 3(4), 104. 
Jin,Y-S., 2019. Recent advances in natural antifungal flavonoids and their derivatives. Bioorg Med Chem Lett., 29, 126589.

Khurana, A., Sardana, K., Chowdhary, A., 2019. Antifungal resistance in dermatophytes: Recent trends and therapeutic implications. Fungal Genet Biol 132, 103255.Köhler, J.R., Casadevall, A., Perfect, J., 2015. The spectrum of fungi that infects humans. Cold Spring Harb Perspect Med 5(1), a019273.

Krishnasamy, L., Krishnakumar, S., Kumaramanickavel, G., Saikumar, C.. Molecular mechanisms of antifungal drug resistance in Candida species. J. Clin. Diagn. Res., 12(9).

Lockhart, S.R, Guarner, J., 2019. Emerging and reemerging fungal infections. Semin Diagn Pathol 36, 177-181.

Mabona, U., 2013. Antimicrobial activity of southern African medicinal plants with dermatological releVance. Masters thesis, University of the Witwatersrand.

Mabona, U., Van Vuuren, S.F., 2013. Southern African medicinal plants used to treat skin diseases. S. Afr. J. Bot. 87, 175-193.

Mabona, U., Viljoen, A., Shikanga, E., Marston, A., Van Vuuren, S.F., 2013. Antimicrobial activity of southern African medicinal plants with dermatological releVance: From an ethnobotanical screening approach, to combination studies and the isolation of a bioactive compound. J. Ethnopharmacol. 148, 45-55.

Mapunya, M.B., Nikolova, R.V., Lall, N., 2012. Melanogenesis and antityrosinase activity of selected South African plants. eCAM, 374017.

Maroyi, A., 2017. Acacia karoo Hayne: Ethnomedical uses, phytochemistry and pharmacology of an important medicinal plant in southern Africa. Asian Pac. J. Trop. Med. 10(4), $351-360$. 
Masoko, P., Picard, J., Eloff, J.N., 2007. The antifungal activity of twenty-four southern African Combretum species (Combretaceae). S. Afr. J. Bot. 73, 173-183.

Masoko, P., Picard, J., Eloff, J.N., 2005. Antifungal activities of six South African Terminalia species (Combretaceae). J. Ethnopharmacol. 99, 301-308.

Mishra, N., Prasad, T., Sharma, N., Payasi, A., Prasad, R., Gupta, D., Singh, R., 2007. Pathogenicity and drug resistance in Candida albicans and other yeast species. Acta Microbiol. Immunol. Hung. 54, 201- 235.

Moffett, R., 2010. Sesotho Plant and Animal Names and Plants Used by the Basotho. Sun Press, Free State, South Africa.

Morar, N., Dlova, N.C., Gupta, A.K., Aboobaker, J., 2004. Tinea capitis in Kwa-Zulu Natal, South Africa. Pediatr Dermatol. 21, 444-447.

Motsei, M.L., Lindsay, K.L., Van Staden, J., Jäger, A.K., 2003. Screening of traditionally used South African plants for antifungal activity against Candida albicans. J. Erthnopharmacol. 86: 235-241.

Naidoo, K.K., Coopoosamy, R.M., 2011. A comparitative analysis of two medicinal plants used to treat common skin conditions in South Africa. Afr. J. Pharm. Pharmacol. 5(3), 393-397.

Naidoo, D., van Vuuren, S.F., van Zyl, R.L., de Wet, H., 2013. Plants used traditionally to treat sexually transmitted infections in northern Maputaland: Antimicrobial activity and toxicity. Journal of Ethnopharmacology, 2013, 149, 656-667.

Nazar, A.K., Meidyawati, R., 2019. Antifungal effects of Aloe vera irrigant on

Candida albicans biofilm. Int J App Pharm, DOI

https://doi.org/10.22159/ijap.2019.v11s1.AR151 
Nciki, S., Van Vuuren, S.F., Van Eyk, A., de Wet, H., 2016, Plants used to treat skin diseases in northern Maputaland, South Africa: antimicrobial activity and in vitro permeability studies. Pharm. Biol. 54(11), 2420-2436.

Ndhlala, A.R., Amoo, S.O., Stafford, G.I., Finnie, J.F., Van Staden, J., 2009. Antimicrobial, anti-inflammatory and mutagenuc investigation of South African tree Aloe (Aloe barberae). J. Ethnopharmacol. 124, 404-408.

Neil, G., Dyke, A.V., Hanslo, D., 1987. Ringworm of the scalp in children. South Afr Med J. 1987; 71: 575-576.

Ngwenya, M.A., Koopman, A., Williams, R., 2003. Zulu Botanical Knowledge. National Botanical Institute, Durban, South Africa.

Nortje, J.M., Van Wyk, B.-E., 2015. Medicinal plants of the Kamiesberg, Namaqualand, South Africa. J. Ethnopharmacol. 171, 205-222.

Nweze, E.I., 2011. Dermatophytoses in domesticated animals. Rev. Inst. Med. Trop. São Paolo 43(2), 95-99.

Nweze, E.I., Eke, I.E., 2018. Dermatophytes and dermatophytosis in the eastern and southern parts of Africa. Med. Mycol. 56, 13-28.

Otang, W.M., Afolayan, A.J., 2016. Antimicrobial and antioxidant efficacy of Citrus limon L. peel extracts used for skin by Xhosa tribe of Amathole District, East Cape, South Africa. S. Afr. J. Bot. 102, 46-49.

Philander, L.A., 2011. An ethnobotany of Western Cape Rasta bush medicine. J. Ethnopharmacol. 138, 578-594.

Rosca-Casian, O., Parvu, M., Vlase, L., Tamas M., 2007 Antifungal activity of Aloe vera leaves. Fitoterapia 78 219-222. 
Samie, A., Tambani, T., Harshfield, E., Green, E., Ramalivhana, J.N., Bessong, P.O., 2010. Antifungal activities of selected Venda medicinal plants against Candida albicans, Candida krusei and Cryptococcus neoformans isolated from South African AIDS patients. Afr. J. Biotechnol. 9(20), 2965-2976.

Santos, H.L., Lang, E.A., Segato, F., Rossi, A., Martinez-Rossi, N.M., 2017. Terbinafine resistance conferred by multiple copies of the salicylate 1-monooxygenase gene in Trichophyton rubrum. Med. Mycol. 56(3), 378-381.

Shai, L.J., McGaw, L.J., Masoko, P., Eloff, J.N., 2008. Antifungal and antibacterial activity of seven traditionally use South African plant species active against Candida albicans. S. Afr. J. Bot. 74, 677-684.

Sidat, M.M., Correia, D., Buene, T.B., 2006. Tinea capitis among rural school children of the district of Uagude, in Maputo province, Mozambique. Mycoses 49, 480-483.

Smith, A., 1888. A Contribution to South African Materia Medica. $2^{\text {nd }}$ Edition, Lovedale Institution Press, South Africa.

Sobel, J.D., 2007. Vulvovaginal candidosis. Lancet 369, 1961-1971.

Steenkamp, V., Gouws, M.C., 2006. Cytotoxicity of six South African medicinal plant extracts used in the treatment of cancer. S. Afr. J Bot. 72, 630-633.

Thring, T.S.A., Weitz, F.M., 2006. Medicinal plant use in the Bredasdorp/Elim region of the Southern Overberg in the Western Cape Province of South Africa. J. Ethnopharmacol. 103, 261-275.

Van Wyk, B.-E., Van Oudtshoorn, B., Gericke, N., 2009. Medicinal Plants of South Africa, 2nd ed. Briza Publications, Pretoria, South Africa. 
Van Wyk, B.-E., 2008. A review of Khoi-San and Cape Dutch medicinal ethnobotany. J. Ethnopharmacol. 119, 331-341.

Verschaeve, L., Van Staden, J., 2008. Mutagenic and antimutagenic properties of extracts from South African traditional medicinal plants. J. Ethnopharmacol. 119, 575-587.

Von Koenen, E., 2001. Medicinal, poisonous and edible plants in Namibia. $4^{\text {th }}$ Edition, Klaus Hess Publishers, Windhoek, Namibia.

Watt, J.M., Breyer-Brandwijk, M.G., 1962. The medicinal and poisonous plants of southern and eastern Africa, 2nd ed. Livingstone, Edinburg and London.

Yamada, T., Maeda, M., Alshahni, M.M., Tanaka, R., Yaguchi, T., Bontems, O., Salamin, K., Fratti, M., Monod, M., 2017. Terbinafine resistance of Trichophyton clinical isolates caused by specific point mutations in the squalene epoxidase gene. Antimicrob. Agents Chemother. 61(7), e00115-17.

Zambelli, A.B., Griffiths, C.A., 2015. 2South African report of first case of chromoblastomycosis caused by Cladosporium (syn Cladophialophora) carrionii infection in a cat with feline immunodeficiency virus and lymphosarcoma. Journal of Feline Medicine and Surgery 17(4) 375- 380 